\title{
Terminal, Open-shell Mo Carbide and Carbyne Complexes: Spin Delocalization and Ligand Noninnocence
}

\author{
Gwendolyn A. Bailey, Joshua A. Buss, Paul H. Oyala, and Theodor Agapie
}

Division of Chemistry and Chemical Engineering, California Institute of Technology, 1200 E. California Blvd. MC 127-72, Pasadena CA 91125, USA

Experimental Details

\section{Supporting Information}

General considerations

S5

Chart S1-Structures of open-shell carbide and carbyne complexes discussed.

S5

Scheme S1-Synthesis of labelled carbides and carbynes

S5

S6

Synthesis of open-shell carbide and carbyne complexes

S6

Freeze-trapping of [1][BAAr $\left.{ }_{4}{ }_{4}\right]$

S6

Synthesis of [K][1]

S6

Synthesis of [2] [BAr $\left.{ }^{\mathrm{F}}{ }_{4}\right]$

S7

Synthesis of [3][BAr ${ }^{\mathbf{F}}$ ]

S7

Synthesis of [4][BA $\mathbf{r}^{\mathrm{F}}$ ]

S7

$C-C$ coupling reactivity

S8

$[\mathrm{K}][1]_{2}[5]$

S8

[K][6]

S8

Electron Paramagnetic Resonance (EPR) spectroscopy

S8

CW-EPR spectroscopy

S8

Pulse EPR spectroscopy

S8

Figure S1- a) HYSCORE powder patterns for an $S=1 / 2, I=1 / 2$ spin system with an isotropic hyperfine tensor A. b) HYSCORE powder patterns for an $S=1 / 2, I=1 / 2$ spin system with an axial hyperfine tensor that contains isotropic $\left(a_{i s o}\right)$ and dipolar $(T)$ contributions. $\quad \mathrm{S} 10$

EPR simulations

Estimation of spin density from hyperfine coupling parameters

Table S1-Hyperfine coupling tensors in MHz measured for open-shell carbide complexes [1][BAAr ${ }_{4}$ ] and $[\mathbf{K}][\mathbf{1}]$ along with the corresponding spin populations.

Table S2-Hyperfine coupling tensors in MHz measured for open-shell carbyne complexes [2] [BAAr ${ }_{4}{ }_{4}$, $[3]\left[\mathbf{B A r}^{\mathbf{F}}{ }_{4}\right]$, and $[4]\left[\mathbf{B A r}^{\mathbf{F}}{ }_{4}\right]$ along with the corresponding spin populations.

Figure S2 - X-band CW-EPR spectra (black) of oxidized natural abundance (top) and ${ }^{13} \mathrm{C}$ labeled (bottom) complexes at a temperature of $77 \mathrm{~K}$ with spectral simulations overlaid (red) using parameters in Table 2 .

Figure S3 - X-band CW-EPR spectra zoomed on Mo hyperfine satellite peaks (black) of oxidized natural abundance (top) and ${ }^{13} \mathrm{C}$ labeled (bottom) complexes at a temperature of $77 \mathrm{~K}$ with spectral simulations overlaid (red) using parameters in Table 2.

Figure S4 - X-band CW-EPR spectra of [K][1] (black) with natural abundance (top) and ${ }^{13} \mathrm{C}$ enrichment (bottom) at $77 \mathrm{~K}$ with spectral simulations overlaid (red) using parameters in Table 2. 
Figure S5- X-band CW-EPR spectra zoomed in on Mo hyperfine satellite peaks of [K][1] (black) with natural abundance (top) and ${ }^{13} \mathrm{C}$ enrichment (bottom) at $77 \mathrm{~K}$ with spectral simulations overlaid (red) using parameters in Table 2.

S17

Figure S6 - $77 \mathrm{~K} \mathrm{X}$-band EPR spectra of (top) freshly prepared [2][BArr ${ }^{\mathrm{F}}$ ]; (bottom) an aged sample of [2][BAr $\left.{ }_{4}{ }_{4}\right]$ (stored in the solid state at RT for weeks).

S18

Davies ENDOR and HYSCORE spectra

S19

Figure S7- Field-Dependent X-band Davies ENDOR spectra of natural abundance [1][BAr ${ }^{\mathrm{F}}$ ] (black) with simulations overlaid using parameters in Table 2.

S19

Figure S8 - (Top) X-band HYSCORE of natural abundance [1] [BAAr $\left.{ }_{4}{ }_{4}\right]$ collected at $340.8 \mathrm{mT}(\mathrm{g}=$ 2.044). (Bottom) X-band HYSCORE of $\left[\mathbf{1}^{13} \mathbf{C}_{2}\right]\left[\mathbf{B A A r}{ }^{\mathbf{F}}\right.$ ] collected at $340.8 \mathrm{mT}(\mathrm{g}=2.044) . \quad \mathrm{S} 20$

Figure S9- (Top) X-band HYSCORE of natural abundance [1] [BAAr ${ }_{4}^{\mathbf{F}_{4}}$ collected at $344.2 \mathrm{mT}(\mathrm{g}=$ 2.024). (Bottom) X-band HYSCORE of $\left[\mathbf{1}^{-{ }^{13}} \mathbf{C}_{2}\right]\left[\mathbf{B A} \mathbf{r}^{\mathbf{F}}{ }_{4}\right]$ collected at $344.2 \mathrm{mT}(g=2.024) . \quad$ S21

Figure S10 - (Top) X-band HYSCORE of natural abundance [1] [BAAr $\left.{ }_{4}^{\mathbf{F}}\right]$ collected at $350.0 \mathrm{mT}(\mathrm{g}=$

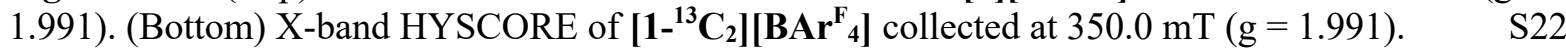

Figure S11-(Top) X-band HYSCORE of $\left[\mathbf{1 -}^{13} \mathbf{C}_{2}\right]\left[\mathbf{B A r}{ }^{\mathbf{F}_{4}}\right]$ collected at $340.8 \mathrm{mT}(\mathrm{g}=2.044)$. (Bottom) Monochromatic representations of the HYSCORE data (grey), with simulations using parameters in Table 2 overlaid in red and blue for ${ }^{13} \mathrm{C}_{\mathrm{A}}$ and ${ }^{13} \mathrm{C}_{\mathrm{B}}$, respectively.

$\mathrm{S} 23$

Figure S12-X-band HYSCORE spectrum of $\left[\mathbf{1 -}^{13} \mathbf{C}_{2}\right]\left[\mathbf{B} \mathbf{A r}{ }^{\mathbf{F}_{4}}\right]$ (top) measured at $344.2 \mathrm{mT}(\mathrm{g}=2.024)$. (Bottom) Monochromatic representations of the HYSCORE data (grey), with simulations using parameters in Table 2 overlaid in red and blue for ${ }^{13} \mathrm{C}_{\mathrm{A}}$ and ${ }^{13} \mathrm{C}_{\mathrm{B}}$, respectively.

S24

Figure S13 - (Top) X-band HYSCORE of $\left[\mathbf{1 -}^{13} \mathbf{C}_{2}\right]\left[\mathbf{B A r}{ }^{\left.\mathbf{F}_{4}\right]}\right.$ collected at $350.0 \mathrm{mT}(\mathrm{g}=1.991)$. (Bottom) Monochromatic representations of the HYSCORE data (grey), with simulations using parameters in Table 2 overlaid in red and blue for ${ }^{13} \mathrm{C}_{\mathrm{A}}$ and ${ }^{13} \mathrm{C}_{\mathrm{B}}$, respectively.

S25

Figure S14-Field-dependent X-band Davies ENDOR of [K][1] (black) with simulations using parameters in Table 2 overlaid.

S26

Figure S15 - (Top) X-band HYSCORE of natural abundance [K][1] collected at $351.6 \mathrm{mT}(\mathrm{g}=1.981)$. (Bottom) X-band HYSCORE of $[\mathbf{K}]\left[1-{ }^{13} \mathbf{C}_{2}\right]$ collected at $351.6 \mathrm{mT}(\mathrm{g}=1.981)$.

S27

Figure S16 - (Top) X-band HYSCORE of [K][1] collected at $347.7 \mathrm{mT}(\mathrm{g}=2.002)$. (Bottom) X-band HYSCORE of [K][ $\mathbf{1 -}^{13} \mathbf{C}_{2}$ ] collected at $347.7 \mathrm{mT}(\mathrm{g}=2.002)$.

S28

Figure S17-(Top) X-band HYSCORE of [K][1] collected at $351.6 \mathrm{mT}(\mathrm{g}=1.981)$. (Bottom) X-band HYSCORE of [K] $\mathbf{1}^{13} \mathbf{C}_{2}$ ] collected at $351.6 \mathrm{mT}(\mathrm{g}=1.981)$.

S29

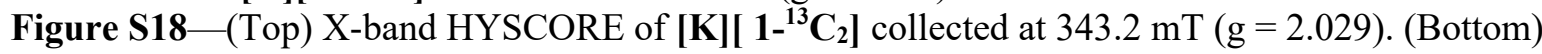
Monochromatic representations of the HYSCORE data (grey), with simulations using parameters in Table 2 overlaid: (red) ${ }^{13} \mathrm{C}_{\mathrm{A}}$, (blue) ${ }^{13} \mathrm{C}_{\mathrm{B}}$, (green) ${ }^{31} \mathrm{P}_{1,2}$.

Figure S19-(Top) X-band HYSCORE of [K][ $\mathbf{1}^{\mathbf{1 3}} \mathbf{C}_{2}$ ] collected at $347.7 \mathrm{mT}(\mathrm{g}=2.002)$. (Bottom) Monochromatic representations of the HYSCORE data (grey), with simulations using parameters in Table 2 overlaid: (red) ${ }^{13} \mathrm{C}_{\mathrm{A}}$, (blue) ${ }^{13} \mathrm{C}_{\mathrm{B}}$, (green) ${ }^{31} \mathrm{P}_{1,2}$.

Figure S20 - (Top) X-band HYSCORE of [K][ $\mathbf{1}^{\mathbf{1 3}} \mathbf{C}_{2}$ ] collected at $351.6 \mathrm{mT}(\mathrm{g}=1.981)$. (Bottom) Monochromatic representations of the HYSCORE data (grey), with simulations using parameters in Table 2 overlaid: (red) ${ }^{13} \mathrm{C}_{\mathrm{A}}$, (blue) ${ }^{13} \mathrm{C}_{\mathrm{B}}$, (green) ${ }^{31} \mathrm{P}_{1,2}$.

Figure S21 - Field-Dependent X-band Davies ENDOR spectra of natural abundance [3][BAAr $\left.{ }_{4}{ }_{4}\right]$ (black) with simulations overlaid using parameters in Table 4.

S33

Figure S22 - Field-Dependent X-band Davies ENDOR spectra of natural abundance [3][BAr ${ }^{\mathrm{F}}$ ] (black) and $\left[3-{ }^{13} \mathbf{C}_{2}\right]\left[\mathbf{B A r}^{\mathrm{F}}{ }_{4}\right]$ (red).

S34

Figure S23-Field-dependent ${ }^{13} \mathrm{C}$-minus-natural abundance $\mathrm{X}$-band Davies ENDOR spectra of [3] [BAr $\left.{ }_{4}{ }_{4}\right]$, with simulations of two inequivalent ${ }^{13} \mathrm{C}$ couplings overlaid (parameters in Table 4). S35 Figure S24-Field-Dependent X-band Davies ENDOR spectra of natural abundance [4][BAr $\left.{ }_{4}{ }_{4}\right]$ (black) with simulations overlaid using parameters in Table 4.

S36

Figure S25- Q-band Pseudomodulated ESE-EPR spectra of [4][BAAr $\left.{ }_{4}{ }_{4}\right]$ with natural abundance (top) and ${ }^{13} \mathrm{C}$ enrichment (bottom) represented in black with simulations using parameters in Table $4 . \quad$ S37 
Figure S26 - Field-Dependent Q-band Davies ENDOR spectra of natural abundance [4][BAr ${ }_{4}^{\mathrm{F}}$ ] (black) with simulations overlaid using parameters in Table 4.

Figure S27-Field-Dependent Q-band Davies ENDOR spectra of natural abundance [4][BAr ${ }_{4}^{\left.\mathbf{F}_{4}\right]}$ (black) and $\left[4-^{13} \mathbf{C}_{1}\right]\left[\mathrm{BAr}^{\mathrm{F}}{ }_{4}\right]$ (red).

Figure S28 - Field-Dependent ${ }^{13} \mathrm{C}$-minus-natural abundance Q-band Davies ENDOR spectra of [4] [BAr $\left.{ }_{4}{ }_{4}\right]$ (black), with simulations of ${ }^{13} \mathrm{C}$ coupling overlaid in red using parameters in Table 4 . S40 Figure S29-(Top) Q-band HYSCORE of [4][BA $\left.\mathbf{B r}^{\mathrm{F}}{ }_{4}\right]$ collected at $1216 \mathrm{mT}(\mathrm{g}=2.003)$. (Bottom) Qband HYSCORE of $\left[\mathbf{4}^{-13} \mathbf{C}\right]\left[\mathbf{B A r} \mathbf{F}_{4}\right]$ collected at $1216 \mathrm{mT}(\mathrm{g}=2.003)$.

Figure S30 - (Top) Q-band HYSCORE of [4] [BAAr $\left.{ }_{4}{ }_{4}\right]$ collected at $1241 \mathrm{mT}(\mathrm{g}=2.963)$. (Bottom) Q-

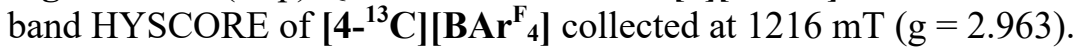

Figure S31 - (Top) Q-band HYSCORE of $\left[4-{ }^{13} \mathbf{C}\right]\left[\mathbf{B A r}^{\mathbf{F}}{ }_{4}\right]$ collected at $1216 \mathrm{mT}(\mathrm{g}=2.003)$. (Bottom) Monochromatic representations of the HYSCORE data (grey), with ${ }^{13} \mathrm{C}$ simulation using parameters in Table 4 overlaid in red.

Figure S32- (Top) Q-band HYSCORE of ${ }^{13} \mathrm{C}$-enriched [4] $\left[\mathbf{B A r}^{\mathrm{F}}{ }_{4}\right]$ collected at $1241 \mathrm{mT}(\mathrm{g}=2.963)$. (Bottom) Monochromatic representations of the HYSCORE data (grey), with ${ }^{13} \mathrm{C}$ simulation using parameters in Table 4 overlaid in red.

Figure S33-ATR-IR spectrum of [2][BAr $\left.{ }^{\mathrm{F}}{ }_{4}\right]$.

S45

Figure S34-ATR-IR spectrum of [3][BAr $\left.{ }_{4}{ }_{4}\right]$.

S45

Figure S35-ATR-IR spectra of freshly-prepared [2][BAAr $\left.{ }_{4}{ }_{4}\right]$ (top) and a sample aged at RT in the solid state for a period of months (bottom) showing loss of CO.

S46

\section{Computational Details}

Figure S36 - DFT-optimized structures for open-shell carbide and carbyne complexes studied (BP86/def2-TZVP).

Figure S37-DFT-calculated spin density plots (BP86/def2-TZVP) for open-shell carbide and carbyne complexes studied.

Figure S38 - Qualitative MO diagram and Mo-C bonding orbitals for [1][BArF 4 ] $(\alpha$ MOs). $\quad$ S49

Figure S39-Qualitative MO diagram and Mo-C bonding orbitals for [1] [BArF 4 ] ( $\beta$ MOs). $\quad$ S50

Figure S40 - Qualitative MO diagram and Mo-C bonding orbitals for [K][1] ( $\alpha$ MOs). $\quad$ S51

Figure S41 - Qualitative MO diagram and Mo-C bonding orbitals for [K][1] ( $\beta$ MOs). $\quad$ S52

Figure S42-Qualitative MO diagram and Mo-C bonding orbitals for [2][BArF 4 ] $(\alpha$ MOs). $\quad$ S53

Figure S43-Qualitative MO diagram and Mo-C bonding orbitals for [2][BArF 4 ] ( $\beta$ MOs). $\quad$ S53

Figure S44-Qualitative MO diagram and Mo-C bonding orbitals for [3][BArF 4 ] $(\alpha$ MOs). $\quad$ S54

Figure S45-Qualitative MO diagram and Mo-C bonding orbitals for [3][BArF 4 ] ( $\beta$ MOs). $\quad$ S55

Figure S46-Qualitative MO diagram and Mo-C bonding orbitals for [4][BArF 4 ] $(\alpha$ MOs). $\quad$ S56

Figure S47-Qualitative MO diagram and Mo-C bonding orbitals for [5] [BArF 4 ] ( $\beta$ MOs). $\quad$ S57

Expectation values of total spin, $<S^{2}>$

S57

Table S3 - Expectation values of total spin for open-shell carbide and carbyne complexes. $\quad$ S57

Cartesian coordinates of DFT-optimized structures 
Details for $[4]\left[\mathrm{BAr}^{\mathrm{F}}{ }_{4}\right]$

Details for [K][6]

Details for $[\mathbf{K}]_{6}[\mathbf{1}]_{2}[\mathbf{5}]$

Table S4-Crystal and refinement data for open-shell carbide and carbyne complexes. $\quad$ S66

Table S5 - Crystal and refinement data for C-C coupled complexes.

S66

Figure S48 - Structural drawing of [K(18-crown-6)][1] with anisotropic displacement ellipsoids shown at the $50 \%$ probability level.

Figure S49-Structural drawing of $[2]\left[\mathbf{B A r}^{\left.\mathbf{F}_{4}\right]}\right.$ with anisotropic displacement ellipsoids shown at the $50 \%$ probability level.

Figure S50 - Structural drawing of [3][BAr $\left.{ }_{4}{ }_{4}\right]$ with anisotropic displacement ellipsoids shown at the $50 \%$ probability level.

S68

Figure S51 - Structural drawing of $[4]\left[\mathbf{B A r}^{\mathbf{F}}{ }_{4}\right]$ with anisotropic displacement ellipsoids shown at the $50 \%$ probability level.

Figure S52 - Structural drawing of $[\mathbf{K}][5][1]_{2}$ as a ball and stick representation.

Figure S53 - Structural drawing of $[\mathbf{K}][\mathbf{6}]$ with anisotropic displacement ellipsoids shown at the $50 \%$ probability level.

$\mathrm{S} 70$

Table S6-Key bond lengths $(\AA)$ and angles $\left(^{\circ}\right)$ for open-shell complexes [2][BAr $\left.{ }^{\mathrm{F}}{ }_{4}\right]-[4]\left[\mathbf{B A r} \mathbf{F}_{4}{ }_{4}\right.$ and [K(18-crown-6)][1], compared with those of previously reported Mo(IV) silylcarbyne and methylidyne complexes 2/2' and 3/3' (Chart S1).

Chart S2 - Structures of relevant comparator complexes 2' and 3'.

Table S7-Key bond lengths $(\AA)$ and angles $\left({ }^{\circ}\right)$ for open-shell complexes $[2]\left[\mathbf{B A r}^{\mathrm{F}}{ }_{4}\right]-[4]\left[\mathbf{B A} \mathbf{r}_{4}{ }_{4}\right]$ and [K(18-crown-6)][1], compared with those of previously reported Mo(IV) silylcarbyne and methylidyne complexes $\mathbf{2} / \mathbf{2}^{\prime}$ and $\mathbf{3} / \mathbf{3}^{\prime}$ (Chart S1). 


\section{EXPERIMENTAL DETAILS}

\section{General Considerations.}

Unless otherwise specified, all operations were carried out in an MBraun glovebox under a $\mathrm{N}_{2}$ atmosphere. Solvents for air- and moisture-sensitive reactions were dried over sodium benzophenone ketyl, or by the method of Grubbs. ${ }^{1}$ Solvents, once dried and degassed, were vacuum-transferred prior to use and stored under an inert atmosphere over $4 \AA$ molecular sieves. Carbides $\mathbf{1}$ and $\mathbf{1 -}{ }^{\mathbf{1 3}} \mathbf{C}_{\mathbf{2}},{ }^{2}$ methylidyne $\mathbf{2}$ and $\mathbf{2 -}^{\mathbf{1 3}} \mathbf{C}_{\mathbf{2}},{ }^{2}$ silylcarbynes 3 and $\mathbf{3}^{13} \mathrm{C}_{2},{ }^{3}$ and $[\mathrm{Fc}]\left[\mathrm{BAr}^{\mathrm{F}}\right]^{4}$ were prepared according to literature procedures. Solutions of potassium naphthalenide $\left([\mathrm{K}]\left[\mathrm{C}_{10} \mathrm{H}_{8}\right]\right)$ were prepared in THF or 2-MeTHF by vigorously stirring solutions of naphthalene (30-50 mM) over a potassium mirror (ca. 1.2 equiv) for $1 \mathrm{~h}$. Pre-reduced, Tefloncoated stir bars were prepared by stirring in naphthalenide solutions for $16 \mathrm{~h}$ followed by rinsing three times with THF. Pre-reduced stir bars were used in reactions involving $[\mathrm{K}]\left[\mathrm{C}_{10} \mathrm{H}_{8}\right]$. Attenuated total reflectance infrared (ATR-IR) spectra were collected on a Bruker Alpha II FTIR spectrometer equipped with an ATR sampling accessory house in an MBraun glovebox. Transmission IR spectra were collected on a Thermo Fischer Nicolet 6700 FTIR spectrometer. Elemental analysis was performed using a PerkinElmer 2400 Series II CHN Elemental Analyzer. ${ }^{1} \mathrm{H},{ }^{13} \mathrm{C}\left\{{ }^{1} \mathrm{H}\right\}$, and ${ }^{31} \mathrm{P}\left\{{ }^{1} \mathrm{H}\right\}$ NMR spectra were recorded on a Varian $400 \mathrm{MHz}$ spectrometer. ${ }^{1} \mathrm{H}$ and ${ }^{13} \mathrm{C}\left\{{ }^{1} \mathrm{H}\right\}$ NMR spectra are referenced to residual solvent peaks. ${ }^{5}$ Multiplicities are abbreviated as follows: $\mathrm{s}=$ singlet, $\mathrm{d}=$ doublet, $\mathrm{t}=$ triplet, $\mathrm{m}=$ multiplet, $\mathrm{br}=$ broad.

\section{Chart S1-Structures of open-shell carbide and carbyne complexes discussed. ${ }^{a}$}

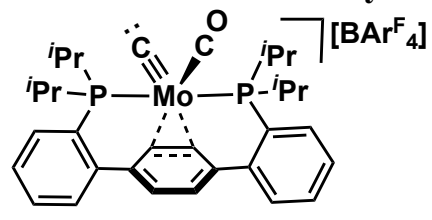

[1][BArF $\left.{ }_{4}\right]$

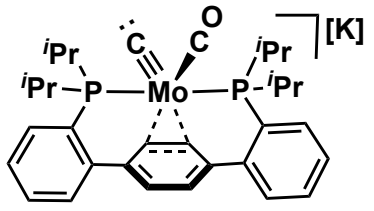

[K][1]

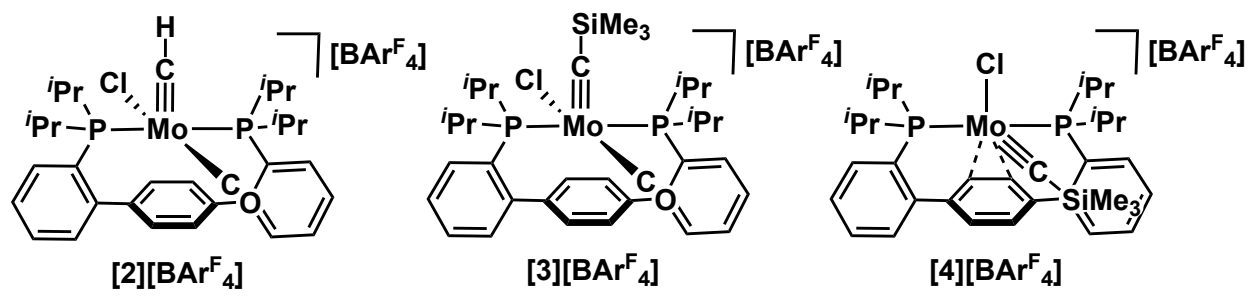

${ }^{a}$ The ${ }^{13} \mathrm{C}$-labelled derivatives bear isotopic labels at the $\mathrm{Mo} \equiv \mathrm{C}$ and $\mathrm{CO}$ positions. 
Scheme S1-Synthesis of labelled $1-{ }^{13} \mathrm{C}_{2}, 2-{ }^{13} \mathrm{C}_{2}$, and $3-{ }^{13} \mathrm{C}_{2}$, precursors to $\left[1-{ }^{13} \mathrm{C}_{2}\right]\left[\mathrm{BAr}{ }_{4}^{\mathrm{F}}\right]-\left[4-{ }^{13} \mathrm{C}_{2}\right]\left[\mathrm{BAr}{ }_{4}^{\mathrm{F}}\right]$ and $[\mathrm{K}]\left[1-{ }^{13} \mathrm{C}_{2}\right]$. Syntheses are reproduced from refs 2 and 3 .

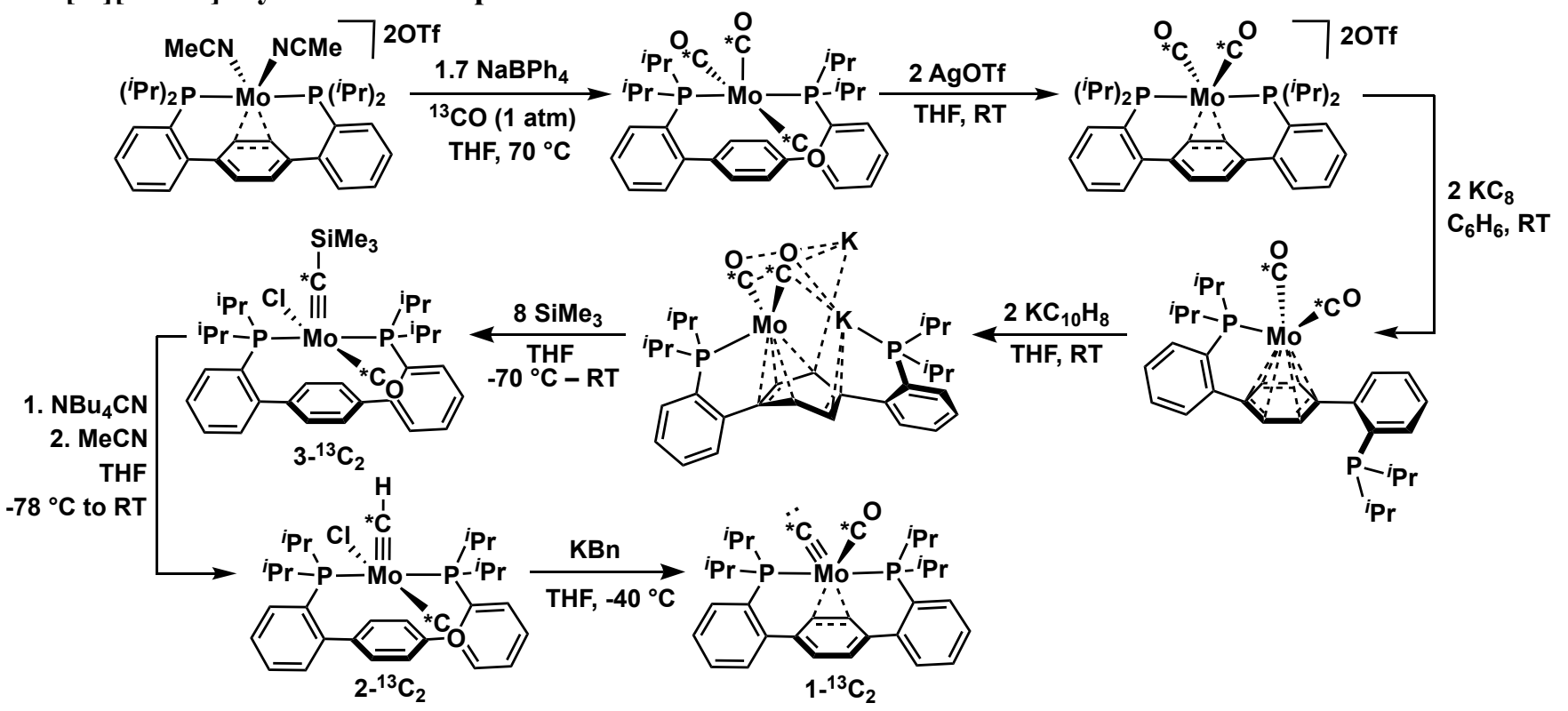

\section{Synthesis of open-shell carbide and carbyne complexes.}

Freeze-trapping of [1] $\left[\mathbf{B A r}^{\mathrm{F}}\right.$ ]. Stock solutions of [Fc][BAr$\left.{ }_{4}\right]$ (49.6 mg, $\left.0.047 \mathrm{mmol}\right)$ in 2-MeTHF $(0.50$ $\mathrm{mL})$ and carbide $1(28.3 \mathrm{mg}, 0.047 \mathrm{mmol})$ in 2-MeTHF $(2.0 \mathrm{~mL})$ were prepared. An aliquot of $1(300 \mu \mathrm{L}$, $0.070 \mathrm{mmol}, 1$ equiv) was transferred to an X-band EPR tube and frozen in the glovebox cold well. Then, $75 \mu \mathrm{L}$ of $[\mathrm{Fc}]\left[\mathrm{BAr}^{\mathrm{F}}\right.$ ] solution $(0.070 \mathrm{mmol}, 1$ equiv) was carefully and slowly dribbled down the inside of the pre-chilled EPR tube, such that the solution froze when or before reaching the bottom. The EPR tube was capped and quickly removed from the glovebox, taking care not to thaw the contents before freeze-trapping in a liquid $\mathrm{N}_{2}$ bath. The contents were then briefly thawed in a $-130{ }^{\circ} \mathrm{C}$ bath (pentane / liquid $\mathrm{N}_{2}$ ), agitated briefly to mix, immersed for a further $30 \mathrm{~s}$, and refrozen. Upon mixing of the two layers, a color change from red to deep brown was apparent. At this point, the X-band CW-EPR spectrum at $77 \mathrm{~K}$ revealed the expected $\mathrm{S}=1 / 2$ signal, which did not increase in intensity on immersing for longer periods at $-130{ }^{\circ} \mathrm{C}$. Solutions of $\left[\mathbf{1 -}^{\mathbf{1 3}} \mathbf{C}_{\mathbf{2}}\right]\left[\mathbf{B} \mathbf{A} \mathbf{r}^{\mathbf{F}}\right.$ ] were prepared analogously starting from $\mathbf{1 -}^{\mathbf{1 3}} \mathbf{C}_{\mathbf{2}}$. The extreme thermal sensitivity of $[\mathbf{1}]\left[\mathbf{B A r}^{\mathbf{F}} \mathbf{4}\right]$ precluded its isolation as a solid.

Synthesis of [K][1]. To a thawing solution of 1 (30 mg, $0.047 \mathrm{mmol})$ in 2-MeTHF (1 mL) was added dropwise a solution of $\mathrm{KC}_{10} \mathrm{H}_{8}(0.50 \mathrm{~mL}$ of a $9.4 \mathrm{mM}$ solution, $0.047 \mathrm{mmol}, 1$ equiv). An immediate color change from red to deep teal was apparent. The solution was quickly transferred to a pre-chilled X-band EPR tube, freeze-trapped, and analyzed. The X-band CW-EPR spectrum confirmed generation of the expected $\mathrm{S}=1 / 2$ signal. ${ }^{1} \mathrm{H}$ NMR $\left(\mathrm{THF}-\mathrm{h}_{8}, 400 \mathrm{MHz},-10{ }^{\circ} \mathrm{C}\right): 7.78\left(\mathrm{~s}, \mathrm{C}_{7} \mathrm{H}_{8}\right), 7.38\left(\mathrm{~s}, \mathrm{C}_{7} \mathrm{H}_{8}\right), 7.34-6.97(\mathrm{~m})$, $2.30(\mathrm{t}), 2.25(\mathrm{~s}), 1.34(\mathrm{~m}), 1.26(\mathrm{~m}), 1.14(\mathrm{~m}), 0.93(\mathrm{~m}), 0.85(\mathrm{~m}) .{ }^{31} \mathrm{P}\left\{{ }^{1} \mathrm{H}\right\}$ NMR (THF-h $, 162 \mathrm{MHz},-$ $\left.10^{\circ} \mathrm{C}\right)$ : silent. For analysis by single crystal XRD, 18 -crown-6 (11.8 mg, $0.047 \mathrm{mmol}, 1$ equiv) was added as a thawing solution in 2-MeTHF $(0.5 \mathrm{~mL})$ following addition of $\mathrm{KC}_{10} \mathrm{H}_{8}$. An aliquot was removed for analysis by $\mathrm{CW}$-EPR, confirming generation of the expected $\mathrm{S}=1 / 2$ signal. The signal appeared identical to that observed in the absence of 18-crown-6. The remaining solution was layered with cold pentane in an NMR tube. Slow mixing of the layers at $-40{ }^{\circ} \mathrm{C}$ yielded brown, single crystalline blocks of [K(18- 
crown-6)][1] amenable to analysis by XRD. $[\mathbf{K}]\left[\mathbf{1 -}{ }^{13} \mathbf{C}_{2}\right]$ was prepared analogously starting from $\mathbf{1 -} \mathbf{C}_{\mathbf{2}}$. The thermal sensitivity of [K][1] precluded its isolation as a pure solid. Addition of thawing pentane to thawing solutions of [K][1] led to precipitation of a mixture of paramagnetic compounds, as judged by CW-EPR. Solutions for EPR analysis were therefore prepared freshly and not isolated.

Synthesis of [2][BAr ${ }^{\mathbf{F}}$ ]. To a thawing suspension of 2 (40 mg, $\left.0.063 \mathrm{mmol}\right)$ in 2-MeTHF $(2 \mathrm{~mL})$ was added dropwise a solution of [Fc] $\left[\mathrm{BAr}^{\mathrm{F}}{ }_{4}\right](66 \mathrm{mg}, 0.063 \mathrm{mmol}, 1$ equiv) in 2-MeTHF (1 mL). The reaction mixture was allowed to warm gradually by stirring at ambient temperature for $2 \mathrm{~min}$. During this time, the orange solids dissolved, and a color change to dark green-brown was observed. The reaction was transferred to the freezer $\left(-40^{\circ} \mathrm{C}\right)$ for $30 \mathrm{~min}$, and then added dropwise in equal portions to rapidly stirring and thawing vials of pentane $(4 \times 20 \mathrm{~mL})$. Decanting the pale orange solution, washing with cold pentane, and drying afforded [2][BArr ${ }^{\left.\mathbf{F}_{4}\right]}$ as a sticky green-brown solid $(73 \mathrm{mg}, 81 \%) .{ }^{1} \mathrm{H}$ NMR $\left(\mathrm{THF}-\mathrm{h}_{8}, 400 \mathrm{MHz}\right.$, $\left.23{ }^{\circ} \mathrm{C}\right): 7.72\left(\mathrm{~s},\left[\mathrm{BAr}_{4}^{\mathrm{F}}\right]^{-}\right), 7.50\left(\mathrm{~s},\left[\mathrm{BAr}_{4}^{\mathrm{F}}\right]^{-}\right), 7.36$ (br s). ${ }^{31} \mathrm{P}\left\{{ }^{1} \mathrm{H}\right\} \mathrm{NMR}\left(\mathrm{THF}-\mathrm{h}_{8}, 162 \mathrm{MHz}, 23{ }^{\circ} \mathrm{C}\right)$ : silent. ${ }^{19} \mathrm{~F}$ NMR (THF-h $\left., 376 \mathrm{MHz}, 23{ }^{\circ} \mathrm{C}\right):-61.5 .{ }^{11} \mathrm{~B}$ NMR (THF-h $\left., 128 \mathrm{MHz}, 23{ }^{\circ} \mathrm{C}\right):-8.46$ (s). IR (ATR, $\left.\mathrm{cm}^{-1}\right)$ : 2070. Elemental analysis results are consistent with retention of 1 equiv 2-MeTHF in the sticky solid. These signals are obscured in the ${ }^{1} \mathrm{H}$ NMR spectra by the solvent peaks. Anal. calcd (\%) for $\mathrm{C}_{64} \mathrm{H}_{53} \mathrm{BClF}_{24} \mathrm{MoOP}_{2} \bullet \mathrm{C}_{5} \mathrm{H}_{10} \mathrm{O}\left(\mathrm{M}_{\mathrm{w}}=1584.38\right)$ : $\mathrm{C}, 52.31 ; \mathrm{H}, 4.01$. Found: $\mathrm{C}, 52.46 ; \mathrm{H}, 3.89$. Solid samples of [2][BAr $\left.{ }^{F_{4}}\right]$ exhibit spontaneous $\mathrm{CO}$ loss at RT, and thus should be stored in the freezer $\left(-40^{\circ} \mathrm{C}\right)$. Single crystalline blocks of $[2]\left[\mathbf{B A r}^{\left.\mathbf{F}_{4}\right]}\right.$ were grown by vapor diffusion of hexanes into THF at $-40{ }^{\circ} \mathrm{C}$. Solid samples of $\left[\mathbf{2 -}^{\mathbf{1 3}} \mathbf{C}_{\mathbf{2}}\right]\left[\mathbf{B} \mathbf{A r} \mathbf{r}_{4}\right]$ were prepared analogously starting from $\mathbf{2 -}^{\mathbf{1 3}} \mathbf{C}_{\mathbf{2}}$.

Synthesis of [3][BAr ${ }^{\mathbf{F}}$ ]. To a thawing solution of $3(50 \mathrm{mg}, 0.071 \mathrm{mmol})$ in 2-MeTHF $(0.5 \mathrm{~mL})$ was added dropwise a solution of [Fc][BAr $\left.{ }_{4}\right](74 \mathrm{mg}, 0.071 \mathrm{mmol}, 1$ equiv) in 2-MeTHF $(0.5 \mathrm{~mL})$. Upon addition of the oxidant, the light red color of $\mathbf{3}$ darkened to brown. The reaction mixture was allowed to warm gradually by stirring at ambient temperature for $2 \mathrm{~min}$. Then, thawing pentane $(20 \mathrm{~mL})$ was added to precipitate a solid. Decanting, rinsing with thawing pentane $(2 \times 10 \mathrm{~mL})$, and filtering afforded [3] $\left[\mathbf{B A r}^{\mathrm{F}_{4}}\right.$ ] as a free-flowing tan solid. Material prepared in this fashion contained little or no [4][BAr ${ }^{\mathbf{F}}$ ], as judged by $\mathrm{CW}$ or pulse EPR. ${ }^{1} \mathrm{H}$ NMR $\left(\mathrm{THF}-\mathrm{h}_{8}, 400 \mathrm{MHz}, 23^{\circ} \mathrm{C}\right): 7.72\left(\mathrm{~s},\left[\mathrm{BAr}^{\mathrm{F}}{ }_{4}\right]^{-}\right), 7.51\left(\mathrm{~s},\left[\mathrm{BAr}^{\mathrm{F}}\right]^{-}\right.$ ) ppm. ${ }^{31} \mathrm{P}\left\{{ }^{1} \mathrm{H}\right\}$ NMR $\left(\mathrm{THF}-\mathrm{h}_{8}, 162 \mathrm{MHz}, 23{ }^{\circ} \mathrm{C}\right)$ : silent. ${ }^{19} \mathrm{~F}$ NMR (THF-h8, $\left.376 \mathrm{MHz}, 23{ }^{\circ} \mathrm{C}\right):-61.5 \mathrm{ppm}$. ${ }^{11} \mathrm{~B}$ NMR $\left(\mathrm{THF}-\mathrm{h}_{8}, 128 \mathrm{MHz}, 23{ }^{\circ} \mathrm{C}\right.$ ): $-8.50 \mathrm{ppm}(\mathrm{s})$. IR (transmission, thin film, $\mathrm{cm}^{-1}$ ): 2049, 1971. IR (transmission, THF solution, $\mathrm{cm}^{-1}$ ): 1967. [3-13 $\left.\mathbf{C}_{2}\right]\left[\mathbf{B A} \mathbf{r}^{\mathbf{F}}\right.$ ] was prepared analogously starting from $\mathbf{3 -}^{\mathbf{1 3}} \mathbf{C}_{\mathbf{2}}$. Anal. calcd (\%) for $\mathrm{C}_{67} \mathrm{H}_{61} \mathrm{BClF}_{24} \mathrm{MoOP}_{2} \mathrm{Si}\left(\mathrm{M}_{\mathrm{w}}=1570.43\right)$ : C, 51.24; H, 3.92. Found: C, 51.36; H, 3.86. Solid-state samples of [3][BA- $\left.\mathbf{B r}_{4}{ }_{4}\right]$ exhibit spontaneous CO loss at RT, and thus should be stored in the freezer $\left(-40^{\circ} \mathrm{C}\right)$. Brown, single-crystalline blades of [3][BA- $\left.\mathbf{B r}_{4}^{\mathbf{F}}\right]$ were grown by vapor diffusion of pentane into $\mathrm{Et}_{2} \mathrm{O}$ at $-40{ }^{\circ} \mathrm{C}$.

Synthesis of [4][BAr ${ }^{\mathbf{F}}$ ]. To a thawing solution of $\mathbf{3}(200 \mathrm{mg}, 0.282 \mathrm{mmol})$ in 2-MeTHF $(8 \mathrm{~mL})$ was added dropwise a thawing solution of [Fc][BAr ${ }_{4}$ ] $(297 \mathrm{mg}, 0.282 \mathrm{mmol}, 1$ equiv) in 2-MeTHF (4 mL). Upon addition of the oxidant, a color change from light red to brown was observed. After warming to RT, volatiles were removed in vacuo, providing a maroon residue. The solids were triturated with $\mathrm{Et}_{2} \mathrm{O}(4 \mathrm{~mL})$ and pentane $(4 \mathrm{~mL})$, washed with hexanes $(3 \times 10 \mathrm{~mL})$, and then dried in vacuo, providing dark red powder (394 mg, 89\%). The CW and pulse EPR data at this point reveal a mixture that contains both [4][BAAr ${ }_{4}$ ] and [3] $\mathbf{B A r}^{\mathbf{F}_{4}}$ ] (see Figure $8 \mathrm{~b}$ in the main text, for example). Red single crystalline blocks of [4][BA $\mathbf{B r}^{\mathbf{F}}$ ] were grown by vapor diffusion of pentane into a saturated $\mathrm{Et}_{2} \mathrm{O}$ solution at $-40{ }^{\circ} \mathrm{C}$. $\mathrm{XRD}$ analysis of the 
blocks reveals co-crystallization of $[4]\left[\mathbf{B A r}^{\mathrm{F}_{4}}\right]$ with $[\mathrm{P} 2 \mathrm{Mo}(\mathrm{CH})(\mathrm{CO})]\left[\mathrm{BAr}^{\mathrm{F}} 4\right](20 \%)$, which was not observed spectroscopically and thus may be a product of disproportionation with [3][BA $\mathbf{r}^{\mathbf{F}}$ ]. Solid-state samples of [4][BAAr $\left.{ }^{\mathbf{F}}\right]$ decompose to a mixture of species at RT (as judged by CW-EPR), and should therefore should be stored in the freezer $\left(-40^{\circ} \mathrm{C}\right)$. A sample of $\left[4-{ }^{13} \mathbf{C}\right]\left[\mathbf{B A r} \mathbf{r}^{\mathbf{F}}\right.$ ], prepared analogously from ${ }^{3-}{ }^{13} \mathbf{C}_{2}$, exhibited complete $\mathrm{CO}$ loss as judged by $\mathrm{CW}$ and pulse EPR spectroscopy. Elemental analysis of [4] $\left[\mathbf{B A r}{ }^{\mathbf{F}}\right.$ ] was not attempted, owing to challenges in reproducibly obtaining samples that exhibit complete CO loss, without competing decomposition.

\section{C-C coupling reactivity.}

$\left.[\mathbf{K}]_{[1}\right]_{2}[\mathbf{5}]$. A freshly prepared, thawing solution of [K][1] in 2-MeTHF $(0.5 \mathrm{~mL})$ was layered with thawing pentane $(1 \mathrm{~mL})$ and stored in the freezer at $-40{ }^{\circ} \mathrm{C}$ for several days, during which time brown blocks crystallized. An X-ray diffraction study of the crystals identified $\left.[\mathbf{K}]_{[1}\right]_{2}[\mathbf{5}]$ as the product; however, the quality of the crystals was insufficient for reliable determination of bond metrics. The high thermal sensitivity of $\left.[\mathbf{K}]_{[1}\right]_{2}[5]$ precluded recrystallization.

[K][6]. To a freshly-prepared, thawing solution of carbide $1(0.048 \mathrm{mmol})$ in THF $(1 \mathrm{~mL})$ was added dropwise a solution of $\mathrm{KC}_{10} \mathrm{H}_{8}(0.048 \mathrm{mmol})$ in THF $(1 \mathrm{~mL})$. The solution was refrozen and set up to crystallize via vapor diffusion of pentane at $-40{ }^{\circ} \mathrm{C}$. An X-ray diffraction study identified the crystals as $\mathrm{C}-\mathrm{C}$ coupled $[\mathbf{K}][\mathbf{6}]$.

\section{Electron Paramagnetic Resonance (EPR) Spectroscopy}

CW-EPR spectroscopy. X-band CW-EPR spectra were obtained on a Bruker EMX spectrometer at a temperature of $77 \mathrm{~K}$ using a quartz liquid nitrogen immersion dewar on solutions prepared as frozen glasses in 2-MeTHF, unless otherwise noted.

Pulse EPR spectroscopy. All pulse EPR and electron nuclear double resonance (ENDOR) experiments were acquired using a Bruker (Billerica, MA) ELEXSYS E580 pulse EPR spectrometer. All X-band data was acquired using a Bruker MD-4 resonator, while Q-band data was acquired using a Bruker D2 resonator. Temperature control was achieved using an ER 4118HV-CF5-L Flexline Cryogen-Free VT cryostat manufactured by ColdEdge (Allentown, PA) equipped with an Oxford Instruments Mercury ITC.

Pulse X- and Q-band ENDOR was acquired using the Davies pulse sequence $\left(\pi-T_{R F}-\pi_{R F}-T_{R F}-\right.$ $\pi / 2-\tau-\pi$-echo), where $T_{R F}$ is the delay between mw pulses and RF pulses, $\pi_{R F}$ is the length of the $\mathrm{RF}$ pulse and the RF frequency is randomly sampled during each pulse sequence.

$\mathrm{X}$ and Q-band HYSCORE spectra were acquired using the 4-pulse sequence $\left(\pi / 2-\tau-\pi / 2-t_{1}-\pi\right.$ $-t_{2}-\pi / 2-$ echo), where $\tau$ is a fixed delay, while $t_{1}$ and $t_{2}$ are independently incremented by $\Delta t_{1}$ and $\Delta t_{2}$, respectively. The time domain data was baseline-corrected (third-order polynomial) to eliminate the exponential decay in the echo intensity, apodized with a Hamming window function, zero-filled to eightfold points, and fast Fourier-transformed to yield the 2-dimensional frequency domain. Contour plots of the $2 \mathrm{D}$ frequency spectra are plotted in logarithmic scale, with contours plotted in colors ranging from blue $\rightarrow$ yellow $\rightarrow$ red in increasing intensity.

In general, the ENDOR spectrum for a given nucleus with spin $I=1 / 2\left({ }^{1} \mathrm{H},{ }^{13} \mathrm{C},{ }^{31} \mathrm{P}\right)$ coupled to the $S=1 / 2$ electron spin exhibits a doublet at frequencies 


$$
v_{ \pm}=\left|\frac{A}{2} \pm v_{N}\right|
$$

Where $v_{N}$ is the nuclear Larmor frequency and $A$ is the hyperfine coupling. For nuclei with $I \geq 1\left({ }^{14} \mathrm{~N}\right.$, ${ }^{2} \mathrm{H}$ ), an additonal splitting of the $v_{ \pm}$manifolds is produced by the nuclear quadrupole interaction $(\mathrm{P})$

$$
v_{ \pm, m_{I}}=\left|v_{N} \pm \frac{3 P\left(2 m_{I}-1\right)}{2}\right|
$$

In HYSCORE spectra, these signals manifest as cross-peaks or ridges in the 2-D frequency spectrum which are generally symmetric about the diagonal of a given quadrant. This technique allows hyperfine levels corresponding to the same electron-nuclear submanifold to be differentiated, as well as separating features from hyperfine couplings in the weak-coupling regime $\left(|A|<2\left|v_{I}\right|\right)$ in the $(+,+)$ quadrant from those in the strong coupling regime $\left(|A|>2\left|\nu_{I}\right|\right)$ in the $(-,+)$ quadrant. The $(-,-)$ and $(+,-)$ quadrants of these frequency spectra are symmetric to the $(+,+)$ and $(-,+)$ quadrants, thus only two of the quadrants are typically displayed in literature.

For systems with appreciable hyperfine anisotropy in frozen solutions or solids, HYSCORE spectra typically do not exhibit sharp cross peaks, but show ridges that represent the sum of cross peaks from selected orientations within the excitation bandwidth of the MW pulses at the magnetic field position at which the spectrum is collected. The length and curvature of these correlation ridges can allow for the separation and estimation of the magnitude of the isotropic and dipolar components of the hyperfine tensor, as shown in Fig. S1. 

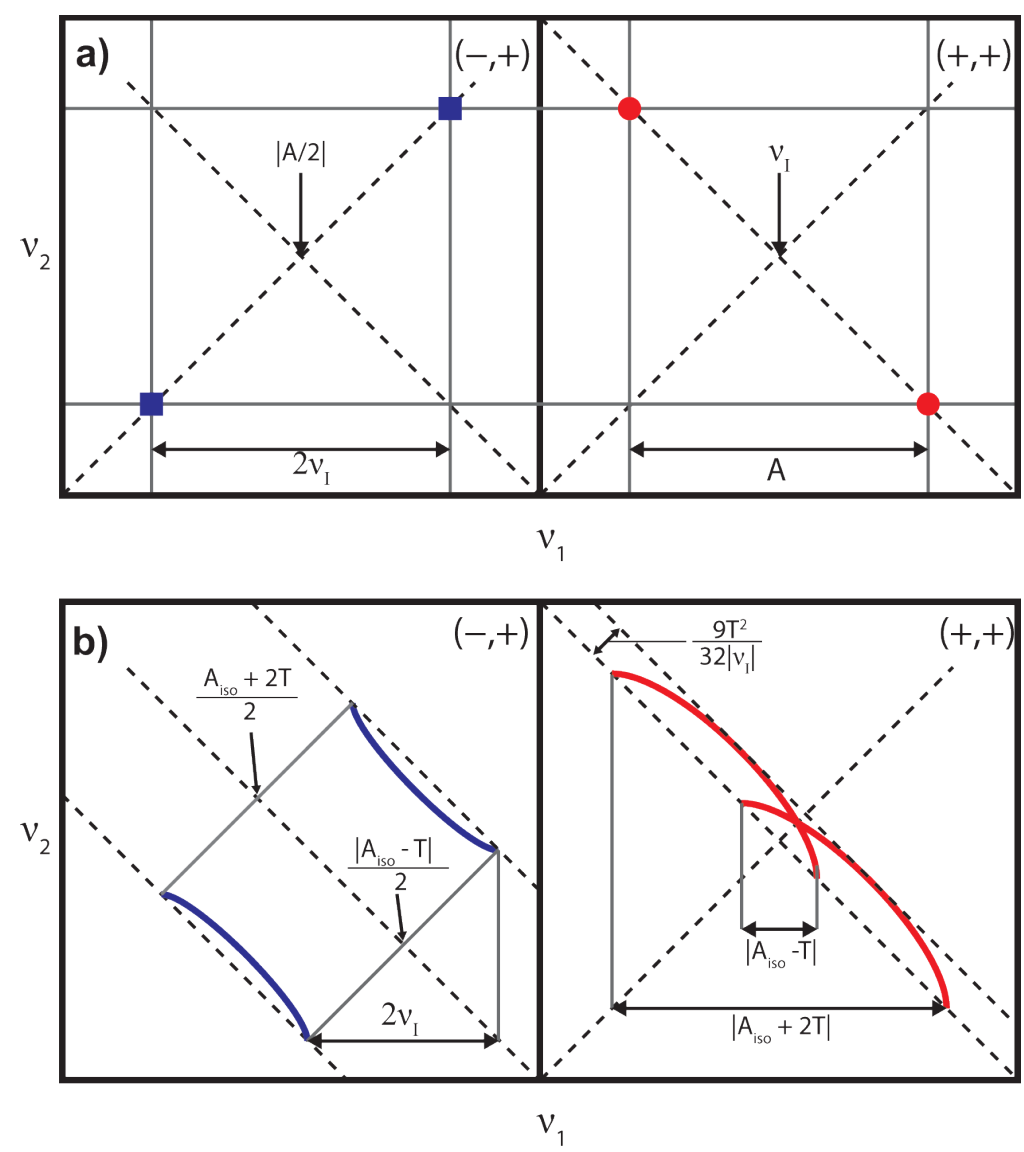

Figure S1-a) HYSCORE powder patterns for an $S=1 / 2, I=1 / 2$ spin system with an isotropic hyperfine tensor A. b) HYSCORE powder patterns foran $S=1 / 2, I=1 / 2$ spin system with an axial hyperfine tensor that contains isotropic $\left(a_{i s o}\right)$ and dipolar $(T)$ contributions. Blue correlation ridges represent the strong coupling case; red correlation ridges represent the weak coupling case.

EPR Simulations. Simulations of all CW and pulse EPR data were achieved using the EasySpin simulation toolbox (release 5.2.25) ${ }^{6}$ with Matlab 2019a using the following Hamiltonian:

$$
\widehat{H}=\mu_{B} \vec{B}_{0} g \hat{S}+\mu_{N} g_{N} \vec{B}_{0} \hat{I}+h \hat{S} \cdot \boldsymbol{A} \cdot \hat{I}+h \hat{I} \cdot \boldsymbol{P} \cdot \hat{I}
$$

In this expression, the first term corresponds to the electron Zeeman interaction term where $\mu_{B}$ is the Bohr magneton, $\mathrm{g}$ is the electron spin g-value matrix with principal components $\mathrm{g}=\left[\mathrm{g}_{\mathrm{xx}} \mathrm{g}_{\mathrm{yy}} \mathrm{g}_{\mathrm{zz}}\right]$, and $\hat{S}$ is the electron spin operator; the second term corresponds to the nuclear Zeeman interaction term where $\mu_{N}$ is the nuclear magneton, $g_{N}$ is the characteristic nuclear g-value for each nucleus $\left(\right.$ e.g. $\left.{ }^{1} \mathrm{H},{ }^{13} \mathrm{C},{ }^{31} \mathrm{P}\right)$ and $\hat{I}$ is the nuclear spin operator; the third term corresponds to the electron-nuclear hyperfine term, where $\boldsymbol{A}$ is the hyperfine coupling tensor with principal components $\boldsymbol{A}=\left[\mathrm{A}_{\mathrm{xx}}, \mathrm{A}_{\mathrm{yy}}, \mathrm{A}_{\mathrm{zz}}\right]$; and for nuclei with $I \geq 1$, the final term corresponds to the nuclear quadrupole (NQI) term which arises from the interaction of the 
nuclear quadrupole moment with the local electric field gradient (efg) at the nucleus, where $\boldsymbol{P}$ is the quadrupole coupling tensor. In the principal axis system (PAS), $\boldsymbol{P}$ is traceless and parametrized by the quadrupole coupling constant $e^{2} Q q / h$ and the asymmetry parameter $\eta$ such that:

$$
\boldsymbol{P}=\left(\begin{array}{ccc}
P_{x x} & 0 & 0 \\
0 & P_{y y} & 0 \\
0 & 0 & P_{z z}
\end{array}\right)=\frac{e^{2} Q q / h}{4 I(2 I-1)}\left(\begin{array}{ccc}
-(1-\eta) & 0 & 0 \\
0 & -(1+\eta) & 0 \\
0 & 0 & 2
\end{array}\right)
$$

where $\frac{e^{2} Q q}{h}=2 I(2 I-1) P_{z z}$ and $\eta=\frac{P_{x x}-P_{y y}}{P_{z z}}$. The asymmetry parameter may have values between 0 and 1, with 0 corresponding to an electric field gradient (EFG) with axial symmetry and 1 corresponding to a fully rhombic EFG.

The orientations between the hyperfine and NQI tensor principal axis systems and the g-matrix reference frame are defined by the Euler angles $(\alpha, \beta, \gamma)$, with rotations performed within the zyz convention where $\alpha$ rotates xyz counterclockwise about z-axis to give $x^{\prime} y^{\prime} z$ ', $\beta$ rotates $x^{\prime} y^{\prime} z$ counterclockwise about $y^{\prime}$-axis to give $x^{\prime \prime}, y^{\prime \prime}, z^{\prime \prime}, \gamma$ rotates xyz counterclockwise about $z^{\prime \prime}$-axis to give final frame orientation.

Estimation of spin density from hyperfine coupling parameters. Each hyperfine coupling tensor can be considered as the sum of an isotropic term, $a_{\text {iso, }}$, which is the average value of the three principal components of the hyperfine tensor, and an anisotopic term, $\boldsymbol{T}_{\text {obs. }}$. These hyperfine values can be compared to calculated hyperfine values for a unit of spin in an s, p, or $d$ orbital in order to obtain an estimate of the spin density at the nucleus in question.

Decomposition of the ${ }^{95 / 97}$ Mo and ${ }^{13}$ C hyperfine tensors and estimation of the spin density

[1][BAr ${ }^{\mathbf{F}}$ ] $:$ The ${ }^{95 / 97}$ Mo hyperfine coupling can be decomposed into $\mathrm{A}\left({ }^{95} \mathrm{Mo}\right)=[86,86,154]=a_{\text {iso }}$ $+\mathrm{A}_{\text {aniso }}=109+[-23,-23,47] \mathrm{MHz}$. Comparing to $\left|a_{\text {iso }}{ }^{0}\left({ }^{95} \mathrm{Mo}\right)\right|=1984 \mathrm{MHz}, a_{\text {iso }}=109$ corresponds to a small $5 \mathrm{~s}$ orbital density on Mo of $\rho_{s} \sim 0.05 \mathrm{e}^{-}$. This is unsurprising considering that the majority of the unpaired spin resides in a valence orbital of $\mathrm{d}_{\mathrm{xy}}$ parentage, giving rise to the sizeable dipolar component. Taking a unit of unpaired spin in a $\mathrm{d}_{\mathrm{xy}}$ orbital of Mo $\mathbf{A}_{d x y}{ }^{0}=[-43.1,-43.1,86.2]$, the anisotropic term $\boldsymbol{A}_{\text {aniso }}\left({ }^{95} \mathrm{Mo}\right)=[-23,-23,47]$ corresponds to a $4 d_{x y}$ orbital spin density of $\rho_{d x y} \sim 0.53$ $\mathrm{e}^{-}$. Between these two contributions, the total spin density at Mo is estimated to be $\rho_{M o} \sim 0.58 \mathrm{e}^{-}$, in good agreement with the DFT-predicted Löwdin spin density of $0.55 \mathrm{e}^{-}$.

The anisotropic ${ }^{13} \mathrm{C}$ hyperfine coupling tensors for the carbide and ${ }^{13} \mathrm{CO}$ ligands can likewise be decomposed following the procedures of Hoffman and coworkers. It is not initially known which hyperfine tensor corresponds to which ${ }^{13} \mathrm{C}$ nucleus, however, and so both possibilities must be considered in turn. Assuming first assume that $\mathrm{A}\left({ }^{13} \mathrm{C}\right)=[15,11,9]$ corresponds to the carbide ligand, we decompose this anisotropic tensor into its constituent $s$ - and $p$-orbital origins:

$$
\begin{gathered}
\mathrm{A}\left({ }^{13} \mathrm{C}\right)=[15,11,9] \\
=a_{\text {iso }}+\boldsymbol{T}_{\mathrm{obs}}
\end{gathered}
$$




$$
=11.7+[3.3,-0.7,-2.7]
$$

Taking $a_{\text {iso }}{ }^{0}\left({ }^{13} \mathrm{C}\right)=3777 \mathrm{MHz}$ for a single electron in a $2 s$ orbital, the isotropic hyperfine $a_{\text {iso }}\left({ }^{13} \mathrm{C}\right)=$ 11.7 MHz corresponds to a small 2s orbital density on the carbide of $\rho_{s} \sim 0.003 \mathrm{e}^{-}$, indicating that the terminal carbide can be treated as having a filled $2 \mathrm{~s}$ orbital with little hybridization with $\mathrm{p}$-orbitals containing the unpaired spin density.

The remaining dipolar term $\boldsymbol{T}_{\text {obs }}$ can be decomposed into two separate axial contributions: one local contribution, $\boldsymbol{T}^{\mathrm{x}, \mathrm{y}} \mathrm{loc}_{\mathrm{c}}$, from spin density at $\mathrm{C}$ with its unique axis along an axis (x or $\mathrm{y}$ ) orthogonal to the Mo-C bond vector, and a second component, $\boldsymbol{T}^{\mathrm{z}}{ }_{\mathrm{obs}}$, with its unique axis parallel to the $\mathrm{Mo}-\mathrm{C}$ bond vector. In turn, $\boldsymbol{T}^{\mathbf{z}}$ obs is a composite of the nonlocal contribution $\left(\boldsymbol{T}^{\mathbf{z}}\right.$ nloc $)$ due to the throughspace dipolar interaction between the ${ }^{13} \mathrm{C}$ nucleus and unpaired spin density at the Mo nucleus, and a local contribution $\left(\boldsymbol{T}_{\text {loc }}\right)$ from spin density at $\mathrm{C}$ in a $\mathrm{p}$ orbital with its unique axis parallel to the Mo-C bond vector. The nonlocal contribution $\boldsymbol{T}_{\text {nloc }}$ can be estimated using the point-dipole approximation, with the unique axis parallel to the Mo-C axis in the molecular frame:

$$
\boldsymbol{T}_{\text {nloc }}^{z}=[-a,-a, 2 a] ; \quad a=\frac{\rho_{M o} g_{e} \mu_{b} g_{n} \mu_{n}}{r^{3}}
$$

Using $\mathrm{r}=1.75 \AA$ (the average $\mathrm{Mo} \equiv \mathrm{C}$ distance determined crystallographically for the carbyne complexes [2] $\left.\left[\mathbf{B A r}^{\mathbf{F}}{ }_{4}\right]-[\mathbf{4}]\left[\mathbf{B} \mathbf{A r}{ }^{\mathbf{F}_{4}}\right]\right)$ and $\rho_{M o} \sim 0.58 \mathrm{e}^{-}$determined from the previous section, we find that $\boldsymbol{T}_{\text {nloc }}=[-2.2,-2.2,4.5] \mathrm{MHz}$. Subtraction of this nonlocal contribution $\boldsymbol{T}_{\text {nloc }}$ from $\boldsymbol{T}_{\text {obs }}$ yields the sum of the local contributions:

$$
\begin{aligned}
& \boldsymbol{T}_{\text {loc }}=\boldsymbol{T}_{\mathrm{obs}}-\boldsymbol{T}_{\mathrm{nloc}}^{\mathrm{z}} \\
& =[5.6,1.6,-7.1]
\end{aligned}
$$

$\boldsymbol{T}_{\text {loc }}$ can be decomposed in turn into two orthogonal axis vectors. Two solutions exist, where $\boldsymbol{T}_{\text {loc }}=$ $[-4.2,-4.2,8.4]$ and $\boldsymbol{T}^{\mathrm{x}, \mathrm{y}}{ }_{1 \mathrm{loc}}=[-1.3,2.6,-1.3]$, or $\boldsymbol{T}^{\mathrm{x}_{\text {loc }}}=[8.4,-4.2,-4.2]$ and $\boldsymbol{T}^{\mathrm{y}}{ }_{\text {loc }}=[-2.9,5.8,-2.9]$. In the first case, considering a single unit of unpaired spin in the $p_{\mathrm{y}}$ orbital of ${ }^{13} \mathrm{C}$ corresponding to $\boldsymbol{A}_{\mathrm{py}}^{0}=[-107.4,214.8,-107.4], \boldsymbol{T}^{\mathrm{x}, \mathrm{y}}{ }_{\mathrm{loc}}$ corresponds to a $p$-orbital spin density of $\rho_{p y} \sim 0.039 \mathrm{e}^{-}$, while $\boldsymbol{T}^{\mathrm{z}}$ loc corresponds to a $p_{z}$-orbital spin density parallel to the Mo-C axis of $\rho_{p \mathrm{z}} \sim 0.012 \mathrm{e}^{-}$, for a total spin density (including $\rho_{s}$ ) of $\sim 0.055 \mathrm{e}^{-}$distributed primarily across the two p orbitals. In the second case, applying a similar analysis again yields $\rho_{p \mathrm{x}} \sim 0.039 \mathrm{e}^{-}$and $\rho_{p \mathrm{y}} \sim 0.027 \mathrm{e}-$, for a total spin density of $\sim 0.07 \mathrm{e}^{-}$. These two solutions are in reasonable agreement with the DFT-computed Löwdin spin population of $-0.07 \mathrm{e}^{-}$.

Proceeding next with $\mathrm{A}\left({ }^{13} \mathrm{C}\right)=[8,22,8]$, we likewise assume that this vector corresponds to the ${ }^{13} \mathrm{CO}$ ligand, which points $\sim 90^{\circ}$ perpendicular to the carbide ligand, in the $\mathrm{x}$ or $\mathrm{y}$ direction of the molecular frame. Both of these two orientations must be considered. The mathematical treatment for this tensor proceeds identically to that for the carbide above, only $\boldsymbol{T}_{\text {nloc }}^{z}$ extends either in the x or y direction, respectively, such that $\boldsymbol{T}_{\text {nloc }}^{z}=[2 a,-a,-a]$ or $\boldsymbol{T}_{\text {nloc }}^{z}=[-a, 2 a,-a]$, respectively. For calculation of the constant $a$, the average Mo-CO bond distance for $[2]\left[\mathbf{B A r}^{\mathbf{F}}\right]-[4]\left[\mathbf{B A r}^{\mathbf{F}}\right]$ is applied $(\mathrm{r}=2.10 \AA)$. 


$$
\begin{aligned}
& \mathrm{A}\left({ }^{13} \mathrm{C}\right)=[8,22,8] \\
& =a_{\text {iso }}+\boldsymbol{T}_{\mathrm{obs}} \\
& =12.7+[-4.7,9.3,-4.7] \\
& \boldsymbol{T}_{\text {nloc }}^{Z}=[2 a,-a,-a] \\
& =[2.6,-1.3,-1.3] \\
& \boldsymbol{T}_{\text {loc }}=\boldsymbol{T}_{\mathrm{obs}}-\boldsymbol{T}_{\text {nloc }} \\
& =[-7.3,10.6,-3.4] \\
& \boldsymbol{T}_{\text {nloc }}^{Z}=[-a, 2 a,-a] \\
& =[-1.3,2.6,-1.3] \\
& \boldsymbol{T}_{\text {loc }}=\boldsymbol{T}_{\text {obs }}-\boldsymbol{T}_{\text {nloc }}^{\mathrm{z}} \\
& =[-3.4,6.7,-3.4] \\
& =[-1.3,-1.3,2.6] \\
& =[-6.0,12.1,-6.0] \\
& \rho_{p z} \sim 0.012 \mathrm{e}^{-} \text {and } \rho_{p \mathrm{x}} \sim 0.056 \mathrm{e}^{-} \\
& \rho_{p y} \sim 0.012 \mathrm{e}^{-} \\
& =[-6.0,12.1,-6.0] \\
& \rho_{p \mathrm{x}} \sim 0.012 \mathrm{e}^{-} \text {and } \rho_{p \mathrm{x}} \sim 0.043 \mathrm{e}^{-}
\end{aligned}
$$

\section{Solution 2:}

\begin{tabular}{|c|c|c|c|c|c|c|c|c|c|c|}
\hline \multirow[b]{2}{*}{ Complex } & & \multicolumn{9}{|c|}{ EPR } \\
\hline & & $A_{x}$ & $A_{y}$ & $A_{z}$ & $a_{\text {iso }}$ & & $T_{\mathrm{ob}}$ & & $\rho\left(\mathrm{e}^{-}\right)$ & orbital $^{d}$ \\
\hline \multirow[t]{5}{*}[1]{$\left[\mathrm{BAr}^{\mathrm{F}} 4\right]$} & ${ }^{95 / 97}$ Mo1 & 86 & 86 & 154 & 109 & -23 & -23 & 45 & 0.58 & $91 \% \mathrm{~d}_{\mathrm{xy}}$ \\
\hline & ${ }^{31} \mathbf{P} 1$ & 75 & 80 & 52 & 69 & 6 & 11 & -17 & - & - \\
\hline & ${ }^{31} \mathbf{P 2}$ & 45 & 58 & 50 & 51 & -6 & 7 & -1 & - & - \\
\hline & ${ }^{13} C_{A}$ & 15 & 11 & 9 & 11.7 & 3 & -1 & -2 & $0.06-0.09^{a}$ & $>95 \% \mathrm{p}$ \\
\hline & ${ }^{13} C_{B}$ & 8 & 22 & 8 & 12.7 & -5 & 9 & -5 & $0.05-0.07^{b}$ & $>95 \% \mathrm{p}$ \\
\hline
\end{tabular}

$\boldsymbol{T}_{n l o c}^{z}=[2 a,-a,-a]$ yields two solutions that are in reasonable agreement with the DFT-predicted Löwdin spin population for ${ }^{13} \mathrm{CO}$ of $0.06-0.07 \mathrm{e}^{-}$. Likewise, moving onto the ${ }^{31} \mathrm{P}$ nuclei $\left(\mathrm{A}\left({ }^{31} \mathrm{P} 1\right)=\right.$ $[56,65,62])$, treating this nucleus as if the Mo-P bond extends orthogonally to the Mo-CO bond in the $y$ direction yields a reasonable spin density of $0.010-0.015 \mathrm{e}^{-}$(computed Löwdin spin population $0.03 \mathrm{e}^{-}$). Therefore, while we cannot rule out the opposite scenario, we favor an interpretation where the Mo- $\mathrm{CO}$ bond extends in the $\mathrm{y}$ direction, and the Mo-P bonds are placed along the $\mathrm{x}$ axis.

Considering next the alternative scenario whereby $\mathrm{A}\left({ }^{13} \mathrm{C}\right)=[8,22,8]$ corresponds to the carbide ligand and $\mathrm{A}\left({ }^{13} \mathrm{C}\right)=[15,11,9]$ corresponds to the ${ }^{13} \mathrm{CO}$ ligand, and pursuing the same mathematical treatment as above, we find solutions whereby $\rho_{\text {tot }}($ carbide $)=0.07-0.09 \mathrm{e}^{-}$, while $\rho_{\text {tot }}\left({ }^{13} \mathrm{CO}\right)=0.05$ $\mathrm{e}^{-}$, this time with the Mo-CO ligand extending in the y direction. Treatment of the ${ }^{31} \mathrm{P}$ hyperfine tensor as if the Mo-P bond extends in the $\mathrm{x}$ direction, we again find a reasonable spin density of $0.02-0.025 \mathrm{e}^{-}$.

$[3]\left[\mathbf{B A r}^{\mathbf{F}}{ }_{4}\right],[4]\left[\mathbf{B A r}^{\mathbf{F}}\right]$, and $[\mathbf{K}][1]$ : The same mathematical treatment was applied as above. The results are presented in Table $\mathrm{S} 1$ below.

Table S1-Hyperfine coupling tensors in $\mathrm{MHz}$ measured for open-shell carbide complexes [1][BA $\mathrm{r}_{4]}^{\mathrm{F}}$ and $[\mathrm{K}][1]$ along with the corresponding spin populations. 


\begin{tabular}{llllll|lll|cc} 
[K][1] & ${ }^{95 / 97} \mathbf{M o 1}$ & 46 & 46 & 59 & 50.3 & -4 & -4 & 9 & 0.13 & $80 \% \mathrm{~d}_{\mathrm{xy}}$ \\
& ${ }^{31} \mathbf{P 1}$ & 8.4 & 3.6 & 3.6 & 5.2 & 3.2 & -1.6 & -1.6 & - & - \\
& ${ }^{31} \mathbf{P 2}$ & 8.4 & 3.6 & 3.6 & 5.2 & 3.2 & -1.6 & -1.6 & - & - \\
& ${ }^{13} \mathbf{C 3 1}$ & -0.05 & -0.05 & 4.5 & 1.5 & -1.55 & -1.55 & 3.0 & $0.06-0.09$ & $>95 \% \mathrm{p}$ \\
& ${ }^{13} \mathbf{C 3 2}$ & 4.6 & 5.5 & 5.5 & 5.2 & -0.6 & 0.3 & 0.3 & $0.05-0.07$ & $>95 \% \mathrm{p}$ \\
\hline
\end{tabular}

${ }^{a}$ Estimated spin density for the carbide $\mathrm{C} 31 .{ }^{b}$ Estimated spin density for the CO ligand C32. ${ }^{\mathrm{c}}$ Hyperfine coupling parameters were determined through simulations of the CW-EPR spectra - Davies ENDOR and HYSCORE experiments were not performed for this complex. ${ }^{d}$ Proportion of localized spin density in $\mathrm{d}$ or $\mathrm{p}$ orbitals on each nucleus.

Table S2-Hyperfine coupling tensors in $\mathrm{MHz}$ measured for open-shell carbyne complexes [2][BAr ${ }_{4}^{\mathrm{F}}$, $[3]\left[\mathrm{BAr}^{\mathrm{F}}{ }_{4}\right]$, and $[4]\left[\mathrm{BAr}^{\mathrm{F}}{ }_{4}\right]$ along with the corresponding spin populations.

\begin{tabular}{|c|c|c|c|c|c|c|c|c|c|c|}
\hline \multirow{2}{*}{ Complex } & & \multicolumn{9}{|c|}{ EPR } \\
\hline & & $A_{x}$ & $A_{y}$ & $A_{z}$ & $A_{\text {iso }}$ & & $T_{\text {obs }}$ & & $\rho\left(\mathrm{e}^{-}\right)$ & orbital $^{d}$ \\
\hline \multirow[t]{5}{*}[2]{$\left[\mathrm{BAr}^{\mathrm{F}}{ }_{4}\right]^{c}$} & ${ }^{95 / 97}$ Mo1 & 95 & 75 & 155 & 107 & -12 & -32 & 48 & - & - \\
\hline & ${ }^{31} \mathbf{P 1}$ & 35 & 72 & 20 & 42 & -7 & 30 & -22 & - & - \\
\hline & ${ }^{31} \mathbf{P 2}$ & 46 & 35 & 20 & 34 & 12 & 1 & -14 & - & - \\
\hline & ${ }^{13} C_{A}$ & 24 & 30 & 20 & 24 & -1 & 5 & -4.7 & - & - \\
\hline & ${ }^{13} C_{B}$ & 40 & 20 & 35 & 32 & 8.3 & -12 & 3.3 & - & - \\
\hline \multirow[t]{5}{*}[3]{$\left[\mathrm{BAr}_{4} \mathrm{~F}_{4}\right]$} & ${ }^{95 / 97}$ Mo1 & 86 & 86 & 165 & 110 & -24 & -24 & 55 & 0.64 & $91 \% d_{x y}$ \\
\hline & ${ }^{31} \mathbf{P 1}$ & 16 & 40 & 9 & 22 & -6 & 18 & -13 & - & - \\
\hline & ${ }^{31} \mathbf{P 2}$ & 9 & 50 & 16 & 22 & -13 & 28 & 6 & - & - \\
\hline & ${ }^{13} C_{A}$ & 27.5 & 27.5 & 22.5 & 26 & 1.5 & 1.5 & -3.5 & $0.05-0.07^{a}$ & $>85 \% \mathrm{p}$ \\
\hline & ${ }^{13} C_{B}$ & 31 & 18 & 33 & 27 & 4 & -9 & 6 & $0.02-0.24^{b}$ & $>87 \% \mathrm{p}$ \\
\hline \multirow[t]{4}{*}[4]{$\left[\mathrm{BAr}^{\mathrm{F}}{ }_{4}\right]$} & ${ }^{95 / 97}$ Mo1 & 100 & 100 & 190 & 130 & -30 & -30 & 60 & 0.77 & $91 \% d_{x y}$ \\
\hline & ${ }^{31} \mathbf{P 1}$ & 60 & 70 & 60 & 63 & -3 & 7 & -3 & - & - \\
\hline & ${ }^{31} \mathbf{P 2}$ & 60 & 70 & 60 & 63 & -3 & 7 & -3 & - & - \\
\hline & ${ }^{13} \mathrm{C} 31$ & 31 & 31 & 17 & 26 & 5 & 5 & -9 & 0.08 & $91 \% \mathrm{p}_{\mathrm{z}}$ \\
\hline
\end{tabular}




\section{SPECTRA}

\section{EPR spectra}

CW-EPR spectra
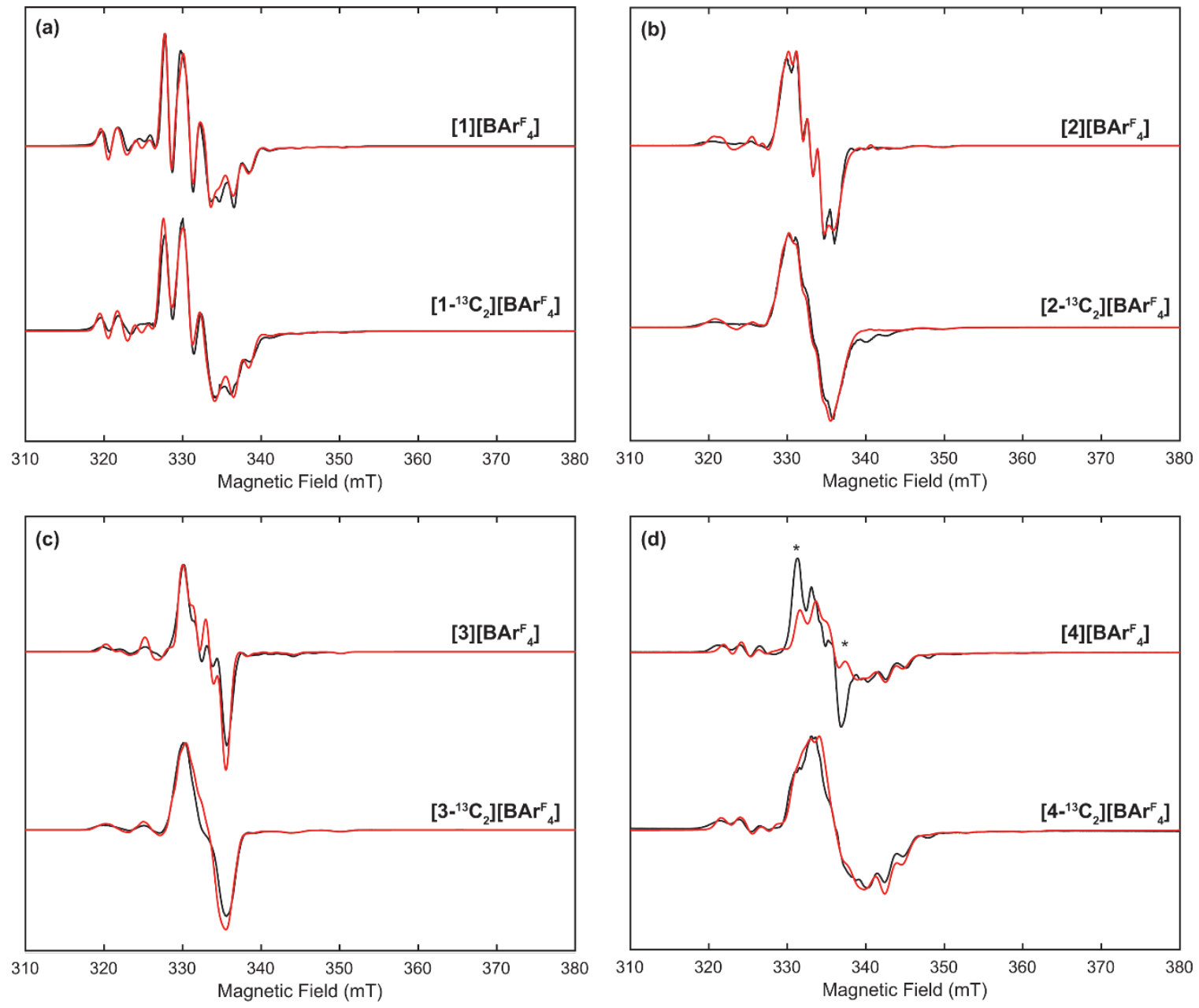

Figure S2-X-band CW-EPR spectra (black) of oxidized natural abundance (top) and ${ }^{13} \mathrm{C}$-labelled (bottom) complexes at a temperature of $77 \mathrm{~K}$ with spectral simulations overlaid (red) using parameters in Table 2. Asterisks above [4] $\left[\mathbf{B A r}^{\mathrm{F}}{ }_{4}\right]$ indicate features associated with residual [3][BAr $\left.{ }_{4}{ }_{4}\right]$ due to incomplete $\mathrm{CO}$ loss. Acquisition parameters: MW frequency $=9.324-9.385 \mathrm{GHz}$; MW power $=200 \mu \mathrm{W}$; modulation amplitude $=0.2 \mathrm{mT}$; conversion time $=82 \mathrm{~ms}$. 

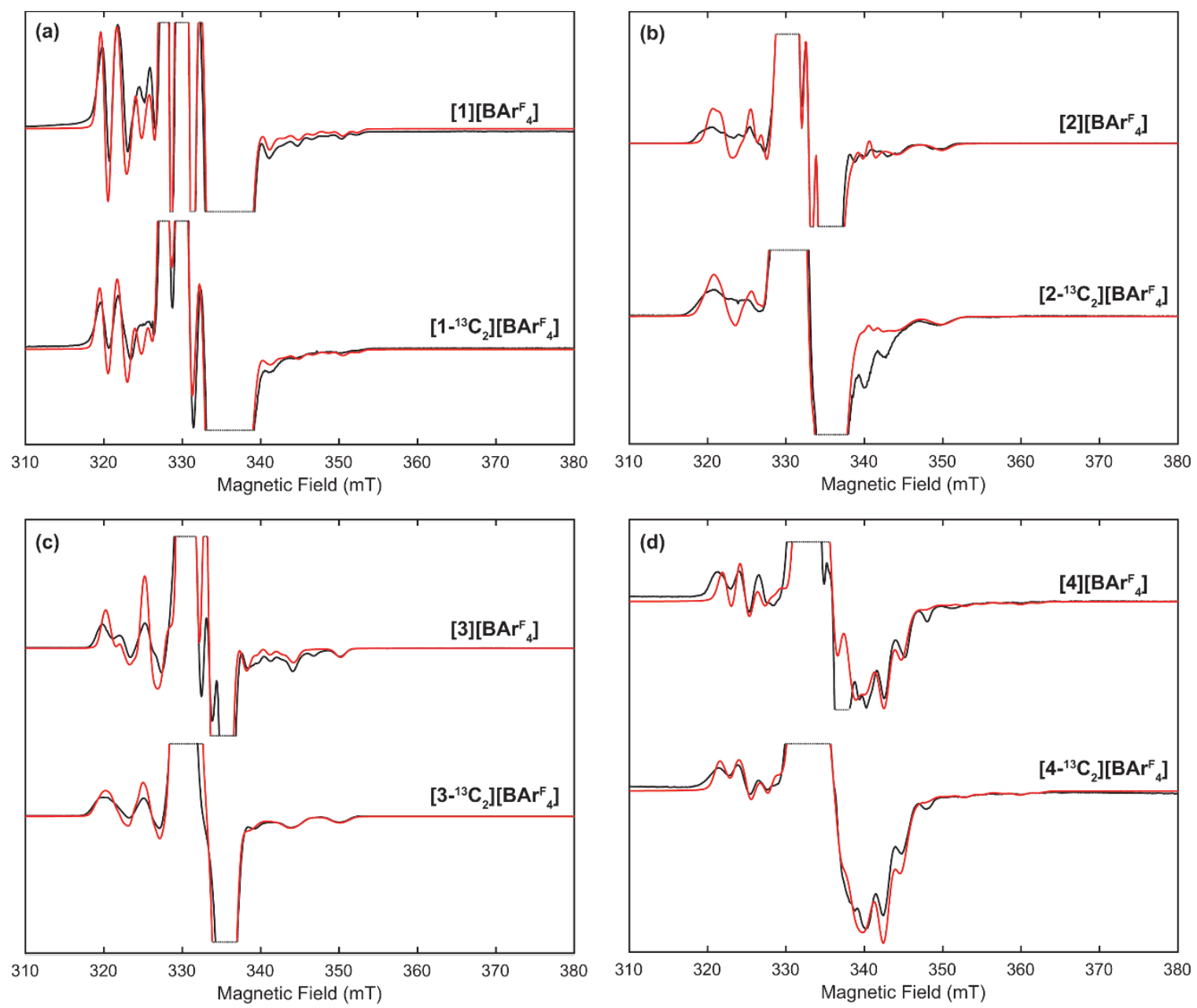

Figure S3-X-band CW-EPR spectra zoomed in on Mo hyperfine satellite peaks (black) of oxidized natural abundance (top) and ${ }^{13} \mathrm{C}$-labelled (bottom) complexes at a temperature of $77 \mathrm{~K}$ with spectral simulations overlaid (red) using parameters in Table 2. Asterisks above $[4]\left[\mathbf{B} \mathbf{A} \mathbf{r}^{\mathrm{F}}{ }_{4}\right]$ indicate features associated with residual [3][BAAr$\left.{ }_{4}{ }_{4}\right]$ due to incomplete CO loss. Acquisition parameters: MW frequency $=9.324-9.385 \mathrm{GHz}$; MW power $=200 \mu \mathrm{W}$; modulation amplitude $=0.2 \mathrm{mT}$; conversion time $=82 \mathrm{~ms}$. 


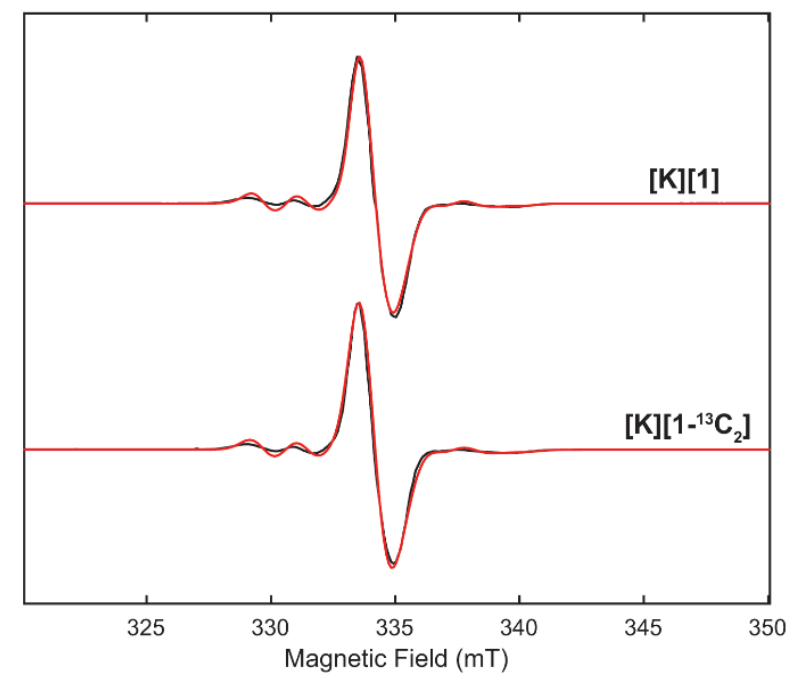

Figure S4-X-band CW-EPR spectra (black) of [K][1] with natural abundance (top) and $[\mathbf{K}]\left[\mathbf{1}-{ }^{13} \mathbf{C}_{2}\right]$ (bottom) at a temperature of $77 \mathrm{~K}$ with spectral simulations overlaid (red) using parameters in Table 2. Acquisition parameters: MW frequency $=9.366 \mathrm{GHz}$; MW power $=20 \mu \mathrm{W}$; modulation amplitude $=0.2 \mathrm{mT}$; conversion time $=82 \mathrm{~ms}$.

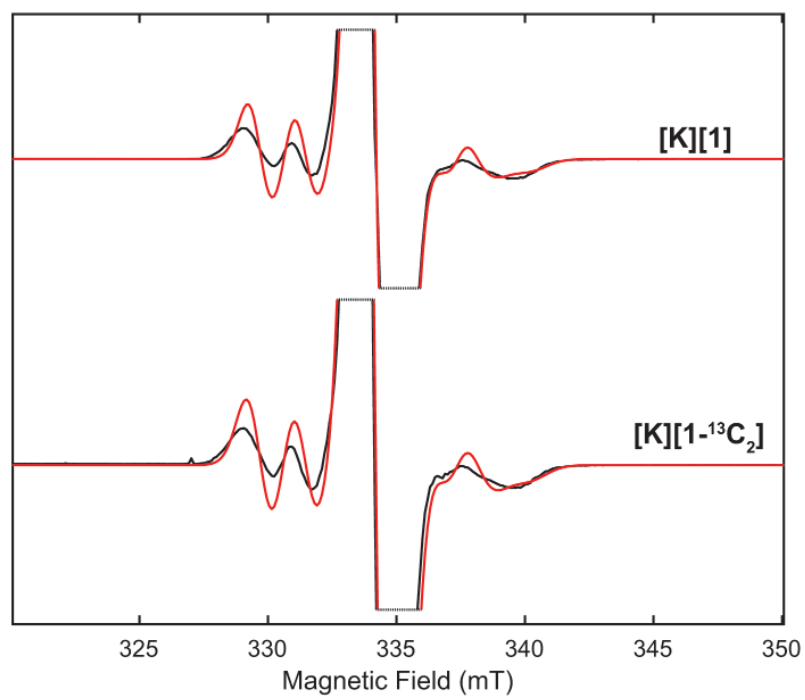

Figure S5-X-band CW-EPR spectra zoomed in on Mo hyperfine satellite peaks (black) of [K][1] with natural abundance (top) and $[\mathbf{K}]\left[1-{ }^{13} \mathbf{C}_{2}\right]$ (bottom) at a temperature of $77 \mathrm{~K}$ with spectral simulations overlaid (red) using parameters in Table 2. Acquisition parameters: MW frequency $=9.366 \mathrm{GHz}$; $\mathrm{MW}$ power $=20 \mu \mathrm{W}$; modulation amplitude $=0.2 \mathrm{mT}$; conversion time $=82 \mathrm{~ms}$. 


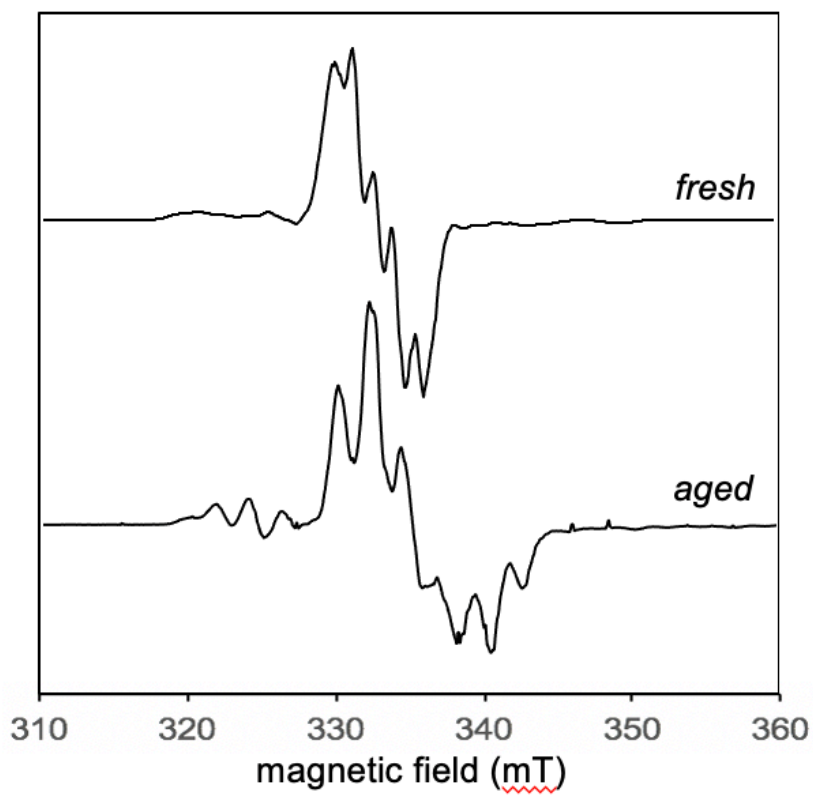

Figure S6-77 K X-band EPR spectra of (top) freshly prepared [2][BA $\left.\mathbf{r r}^{\mathbf{F}}{ }_{4}\right]$ and (bottom) an aged sample (stored in the solid state at RT for weeks). An accompanying change in color from green (top) to purple (bottom) is observed. For the corresponding IR spectra, see Figure S32. 


\section{Davies ENDOR and HYSCORE spectra}

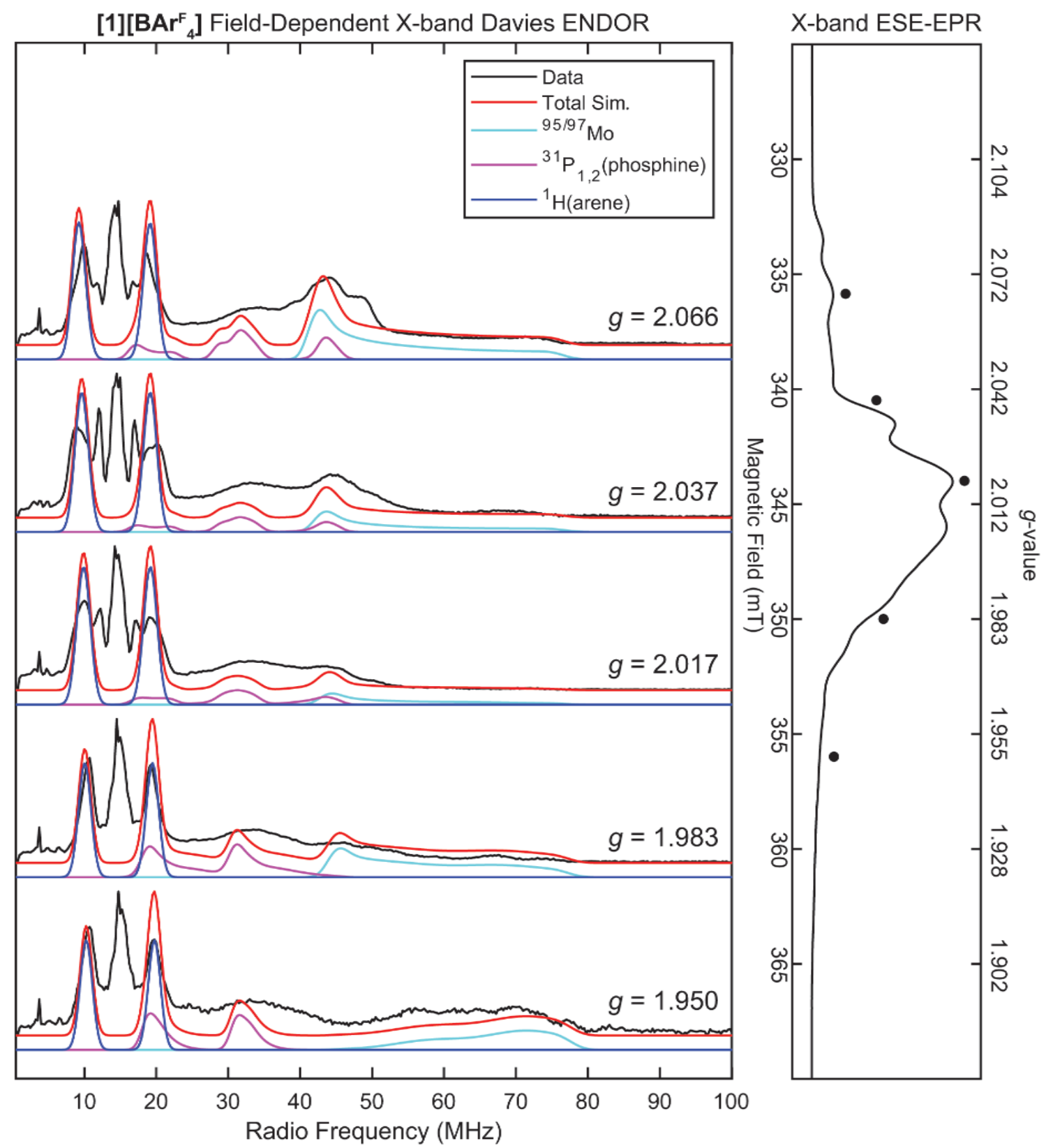

Figure S7-Field-Dependent X-band Davies ENDOR spectra of natural abundance [1][BAr ${ }^{\mathbf{F}}$ ] (black) with simulations overlaid using parameters in Table 2. The electron spin echo (ESE) detected EPR spectrum is shown to the right, with fields at which ENDOR was acquired denoted with black circles. Acquisition parameters: temperature $=25 \mathrm{~K}$; MW frequency $=9.716 \mathrm{GHz}$; MW $\pi$ pulse length $=80 \mathrm{~ns}$; interpulse delay $\tau=240 \mathrm{~ns} ; \pi_{\mathrm{RF}}$ pulse length $=$ $15 \mu \mathrm{s} ; \mathrm{T}_{\mathrm{RF}}$ delay $=2 \mu \mathrm{s}$; shot repetition time $(\mathrm{srt})=5 \mathrm{~ms}$. Duplicated from Figure 2 in the main text for the reader's convenience. 

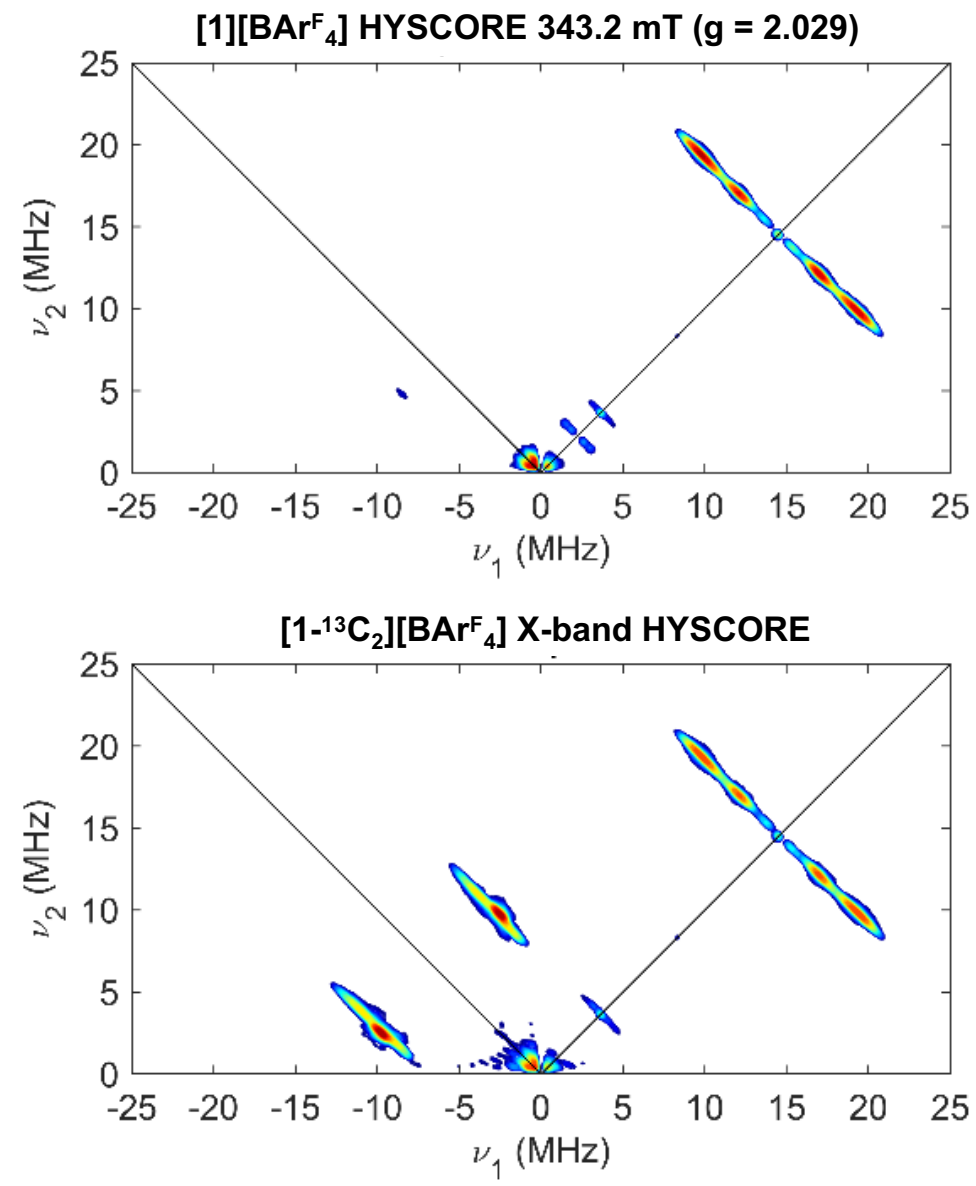

Figure S8-(Top) X-band HYSCORE of natural abundance [1] [BAAr $\left.{ }_{4}{ }_{4}\right]$ collected at $340.8 \mathrm{mT}(\mathrm{g}=2.044)$. (Bottom) $\mathrm{X}$-band HYSCORE of $\left[\mathbf{1 1}^{13} \mathbf{C}_{2}\right]\left[\mathbf{B A r} \mathbf{F}_{4}\right]$ collected at $340.8 \mathrm{mT}(\mathrm{g}=2.044)$. Acquisition parameters: temperature $=$ $25 \mathrm{~K}$; MW frequency $=9.715 \mathrm{GHz}$; MW pulse length $(\pi / 2, \pi)=8 \mathrm{~ns}, 16 \mathrm{~ns} ; \tau=136 \mathrm{~ns} ; \mathrm{t}_{1}=\mathrm{t}_{2}=100 \mathrm{~ns} ; \Delta \mathrm{t}_{1}=\Delta \mathrm{t}_{2}$ $=16 \mathrm{~ns}$; shot repetition time $(\mathrm{srt})=3 \mathrm{~ms}$. 

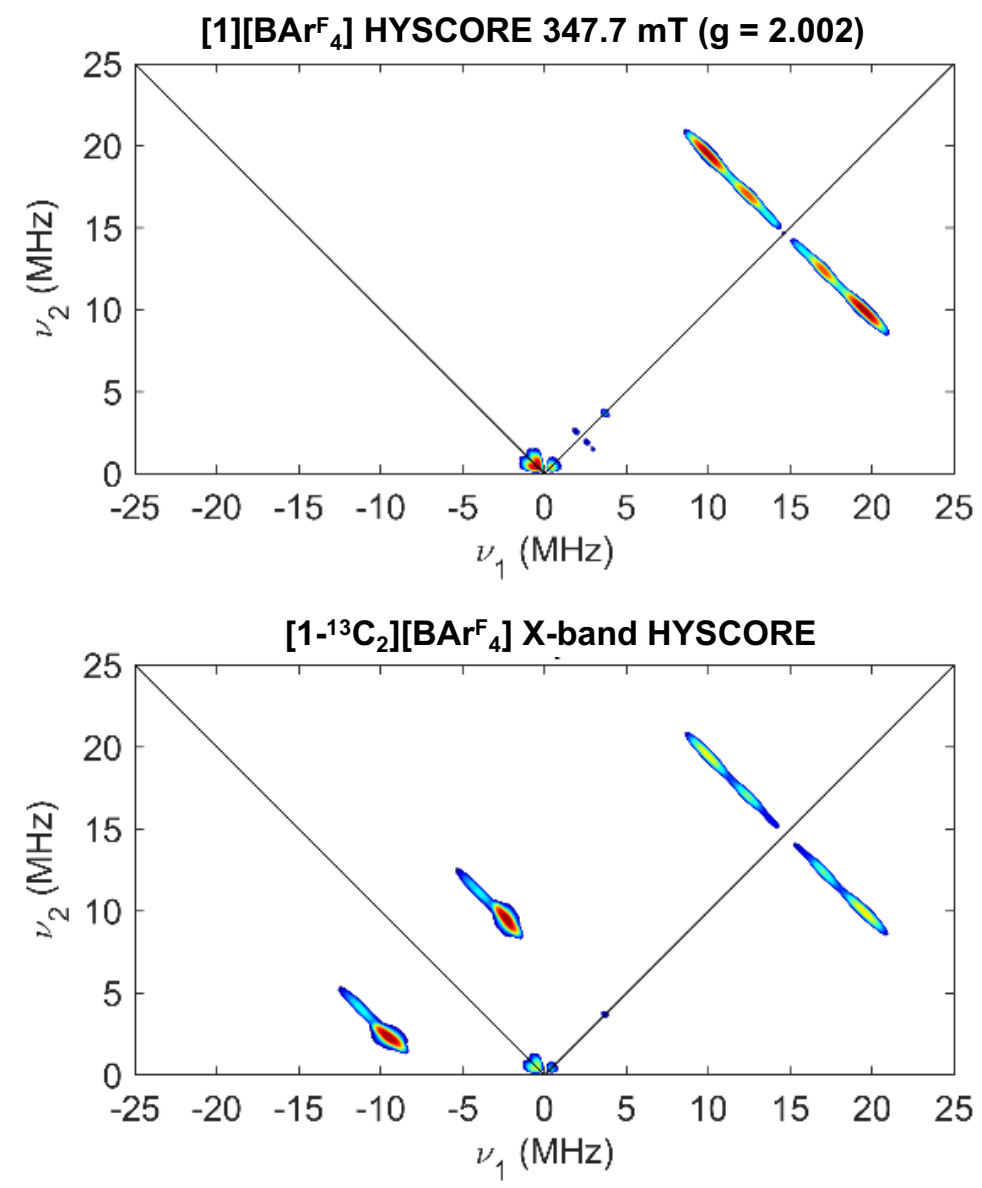

Figure S9-(Top) X-band HYSCORE of natural abundance [1][BAtr $\left.{ }_{4}{ }_{4}\right]$ collected at $344.2 \mathrm{mT}(g=2.024)$. (Bottom) $\mathrm{X}$-band HYSCORE of $\left[\mathbf{1}^{13} \mathbf{C}_{2}\right]\left[\mathbf{B A r} \mathbf{r}_{4}{ }_{4}\right]$ collected at $344.2 \mathrm{mT}(g=2.024)$. Acquisition parameters: temperature $=$ $25 \mathrm{~K}$; MW frequency $=9.715 \mathrm{GHz}$; MW pulse length $(\pi / 2, \pi)=8 \mathrm{~ns}, 16 \mathrm{~ns} ; \tau=136 \mathrm{~ns} ; \mathrm{t}_{1}=\mathrm{t}_{2}=100 \mathrm{~ns} ; \Delta \mathrm{t}_{1}=\Delta \mathrm{t}_{2}$ $=16 \mathrm{~ns}$; shot repetition time $(\mathrm{srt})=3 \mathrm{~ms}$. 

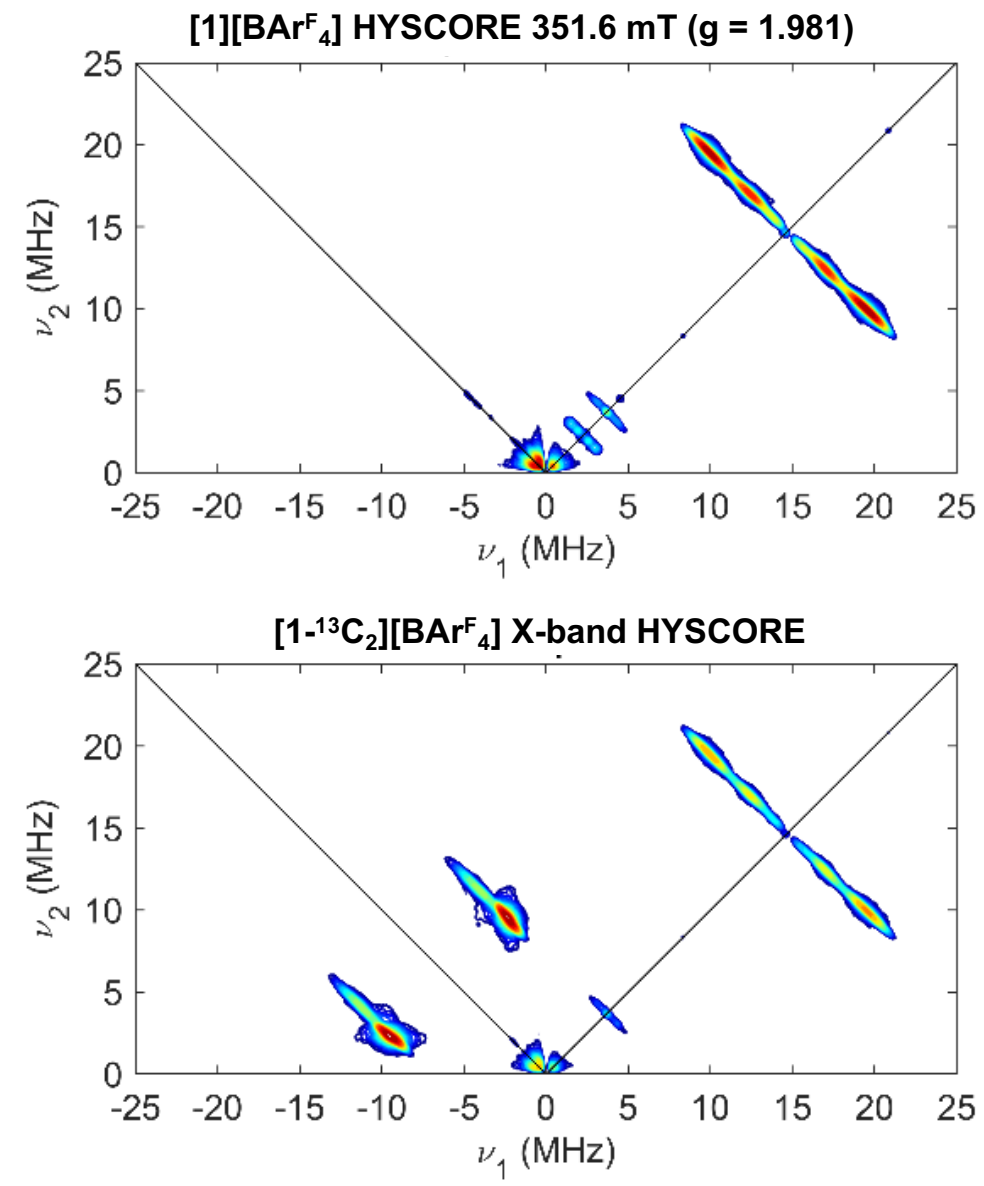

Figure S10 - (Top) X-band HYSCORE of natural abundance [1] [BAAr $\left.{ }_{4}{ }_{4}\right]$ collected at $350.0 \mathrm{mT}(\mathrm{g}=1.991)$. (Bottom) X-band HYSCORE of $\left[\mathbf{1 -}^{13} \mathbf{C}_{2}\right]\left[\mathbf{B A r}^{\mathrm{F}}{ }_{4}\right]$ collected at $350.0 \mathrm{mT}(\mathrm{g}=1.991)$. Acquisition parameters: temperature $=25 \mathrm{~K} ; \mathrm{MW}$ frequency $=9.715 \mathrm{GHz} ; \mathrm{MW}$ pulse length $(\pi / 2, \pi)=8 \mathrm{~ns}, 16 \mathrm{~ns} ; \tau=136 \mathrm{~ns} ; \mathrm{t}_{1}=\mathrm{t}_{2}=100 \mathrm{~ns} ; \Delta \mathrm{t}_{1}=\Delta \mathrm{t}_{2}$ $=16 \mathrm{~ns}$; shot repetition time $(\mathrm{srt})=3 \mathrm{~ms}$. 

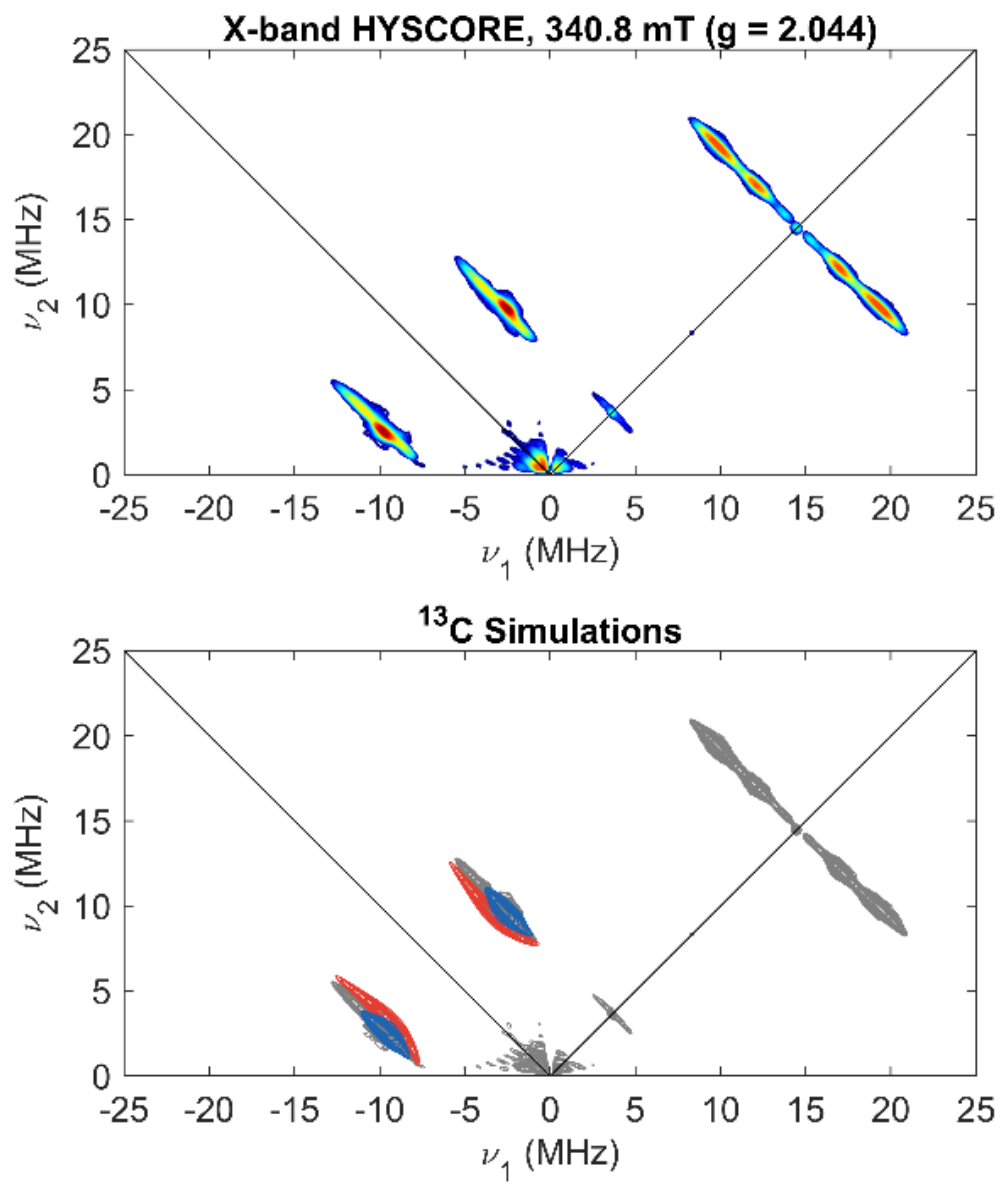

Figure S11-(Top) X-band HYSCORE of $\left[\mathbf{1 -}^{{ }^{13}} \mathbf{C}_{2}\right]\left[\mathbf{B A A r}{ }^{\mathbf{F}}\right]$ collected at $340.8 \mathrm{mT}(\mathrm{g}=2.044)$. (Bottom) Monochromatic representations of the HYSCORE data (grey), with simulations using parameters in Table 2 overlaid in red and blue for ${ }^{13} \mathrm{C}_{\mathrm{A}}$ and ${ }^{13} \mathrm{C}_{\mathrm{B}}$, respectively. Acquisition parameters: temperature $=25 \mathrm{~K}$; MW frequency $=9.715$ GHz; MW pulse length $(\pi / 2, \pi)=8 \mathrm{~ns}, 16 \mathrm{~ns} ; \tau=136 \mathrm{~ns} ; \mathrm{t}_{1}=\mathrm{t}_{2}=100 \mathrm{~ns} ; \Delta \mathrm{t}_{1}=\Delta \mathrm{t}_{2}=16 \mathrm{~ns}$; shot repetition time $(\mathrm{srt})=3 \mathrm{~ms}$. 

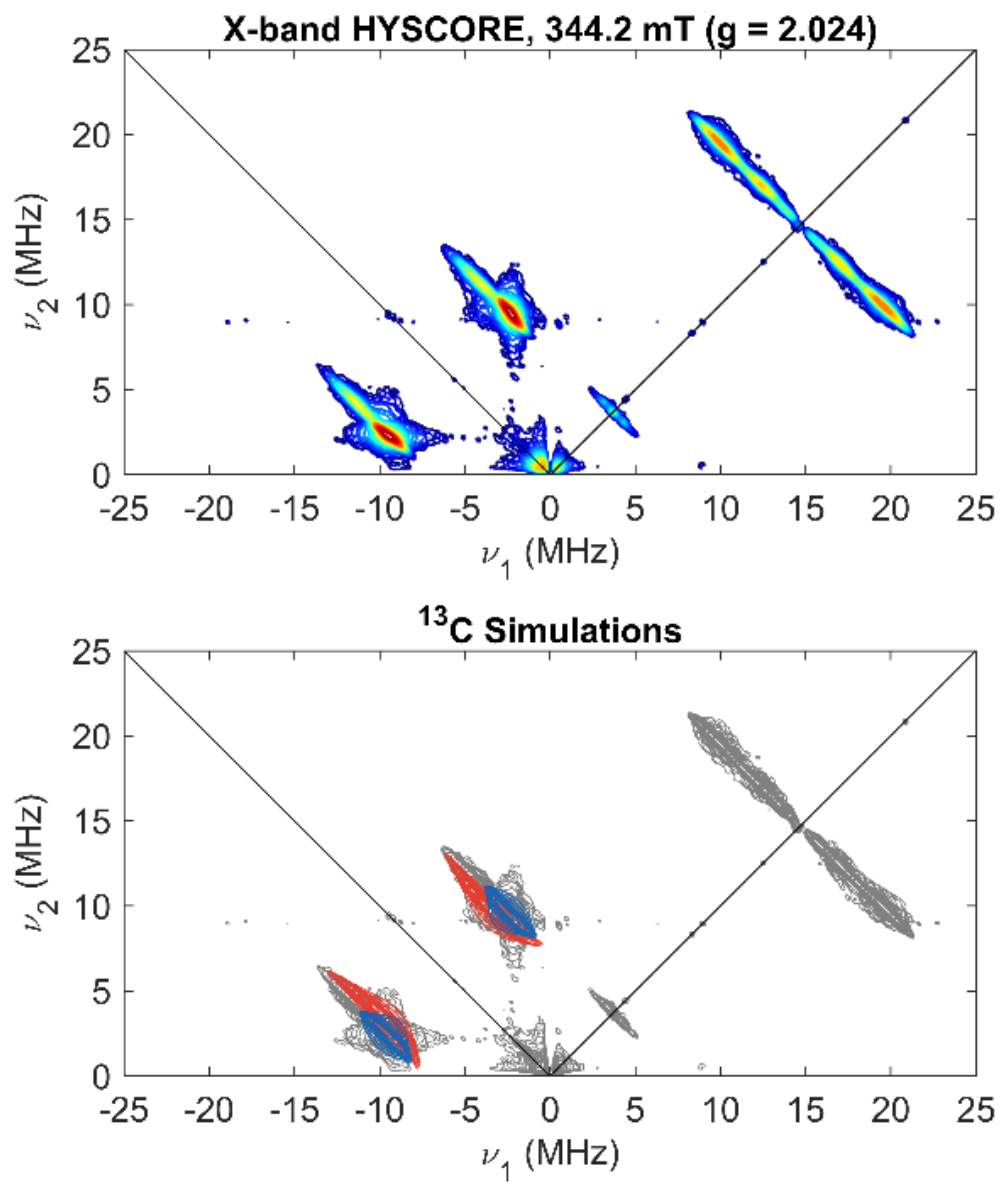

Figure S12-X-band HYSCORE spectrum of $\left[\mathbf{1}^{{ }^{13}} \mathbf{C}_{2}\right]\left[\mathbf{B} \mathbf{A} \mathbf{r}^{\mathbf{F}}\right.$ ] $]$ (top) measured at $344.2 \mathrm{mT}(g=2.024)$. (Bottom) Monochromatic representations of the HYSCORE data (grey), with simulations using parameters in Table 2 overlaid in red and blue for ${ }^{13} \mathrm{C}_{\mathrm{A}}$ and ${ }^{13} \mathrm{C}_{\mathrm{B}}$, respectively. Acquisition parameters: temperature $=25 \mathrm{~K}$; MW frequency $=$ 9.715 GHz; MW pulse length $(\pi / 2, \pi)=8 \mathrm{~ns}, 16 \mathrm{~ns} ; \tau=136 \mathrm{~ns} ; \mathrm{t}_{1}=\mathrm{t}_{2}=100 \mathrm{~ns} ; \Delta \mathrm{t}_{1}=\Delta \mathrm{t}_{2}=16 \mathrm{~ns}$; shot repetition time $(\mathrm{srt})=3 \mathrm{~ms}$. 

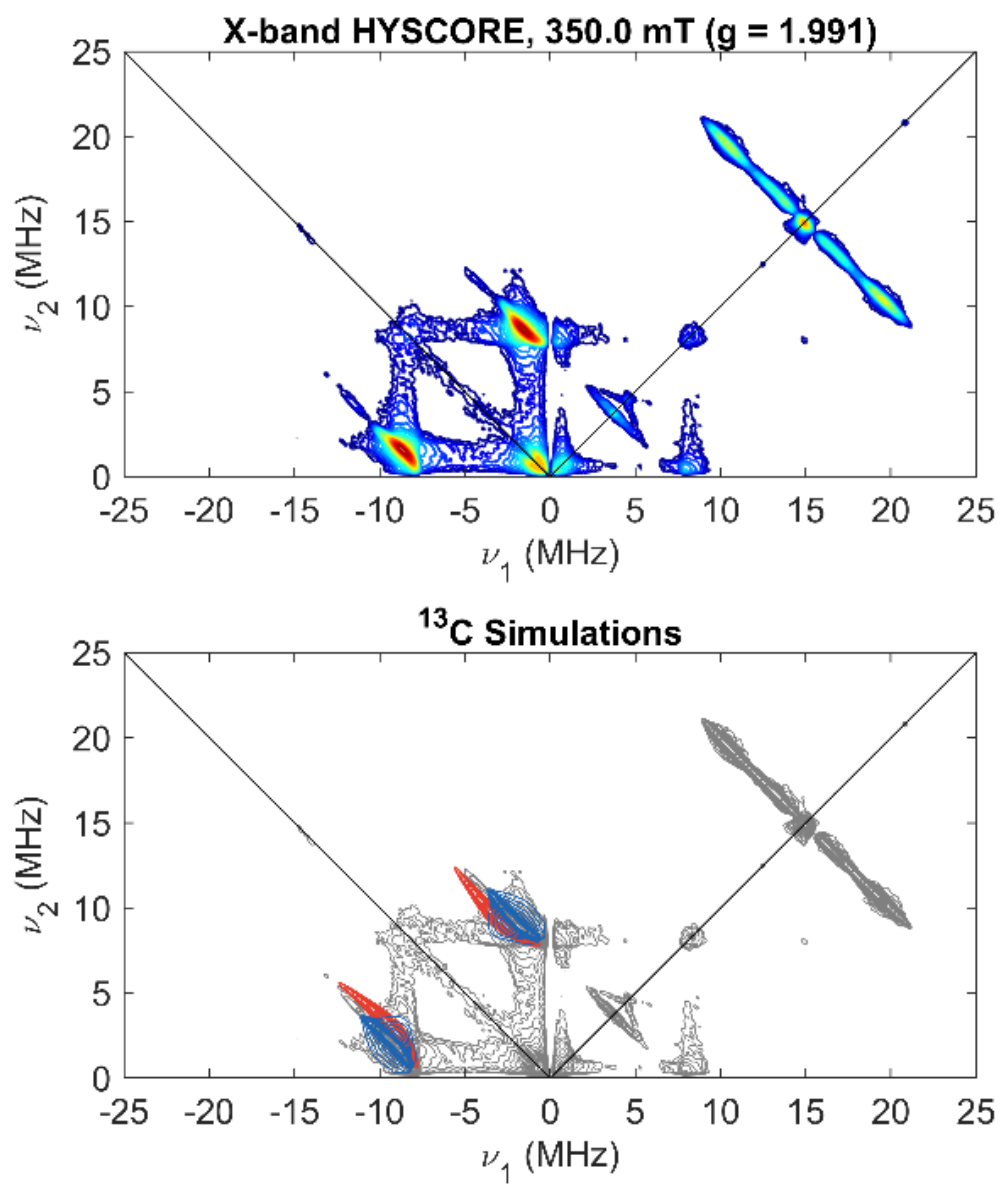

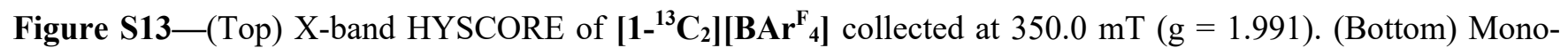
chromatic representations of the HYSCORE data (grey), with simulations using parameters in Table 2 overlaid in red and blue for ${ }^{13} \mathrm{C}_{\mathrm{A}}$ and ${ }^{13} \mathrm{C}_{\mathrm{B}}$, respectively. Acquisition parameters: temperature $=25 \mathrm{~K}$; MW frequency $=9.715$ GHz; MW pulse length $(\pi / 2, \pi)=8 \mathrm{~ns}, 16 \mathrm{~ns} ; \tau=138 \mathrm{~ns}, \mathrm{t}_{1}=\mathrm{t}_{2}=100 \mathrm{~ns} ; \Delta \mathrm{t}_{1}=\Delta \mathrm{t}_{2}=16 \mathrm{~ns}$; shot repetition time (srt) $=3 \mathrm{~ms}$. 
[K][1] Field-Dependent X-band Davies ENDOR

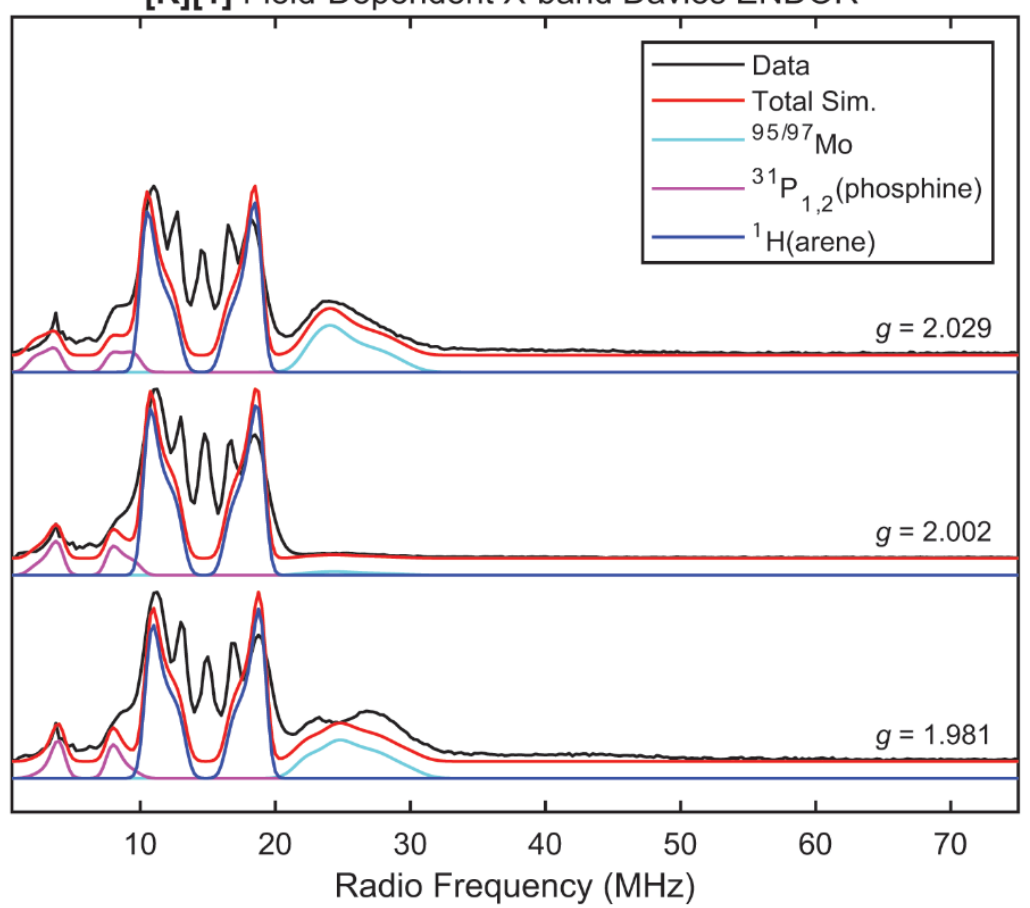

X-band

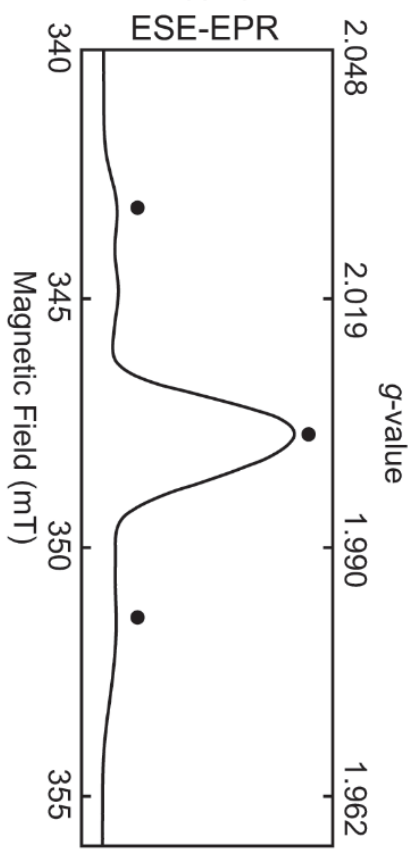

Figure S14-Field-dependent X-band Davies ENDOR of [K][1] (black) with simulations using parameters in Table 2 overlaid. The electron spin echo (ESE) detected EPR spectrum is shown to the right, with fields at which ENDOR was acquired denoted with black circles. Acquisition parameters: temperature $=35 \mathrm{~K}$; $\mathrm{MW}$ frequency $=$ $9.748 \mathrm{GHz}$; MW pulse length $(\pi / 2, \pi)=40 \mathrm{~ns}, 80 \mathrm{~ns} ; \tau=240 \mathrm{~ns}$; RF pulse length $=15 \mu \mathrm{s} ; \mathrm{T}_{\mathrm{RF}}=2 \mu \mathrm{s}$; shot repetition time $=5 \mathrm{~ms}$. 

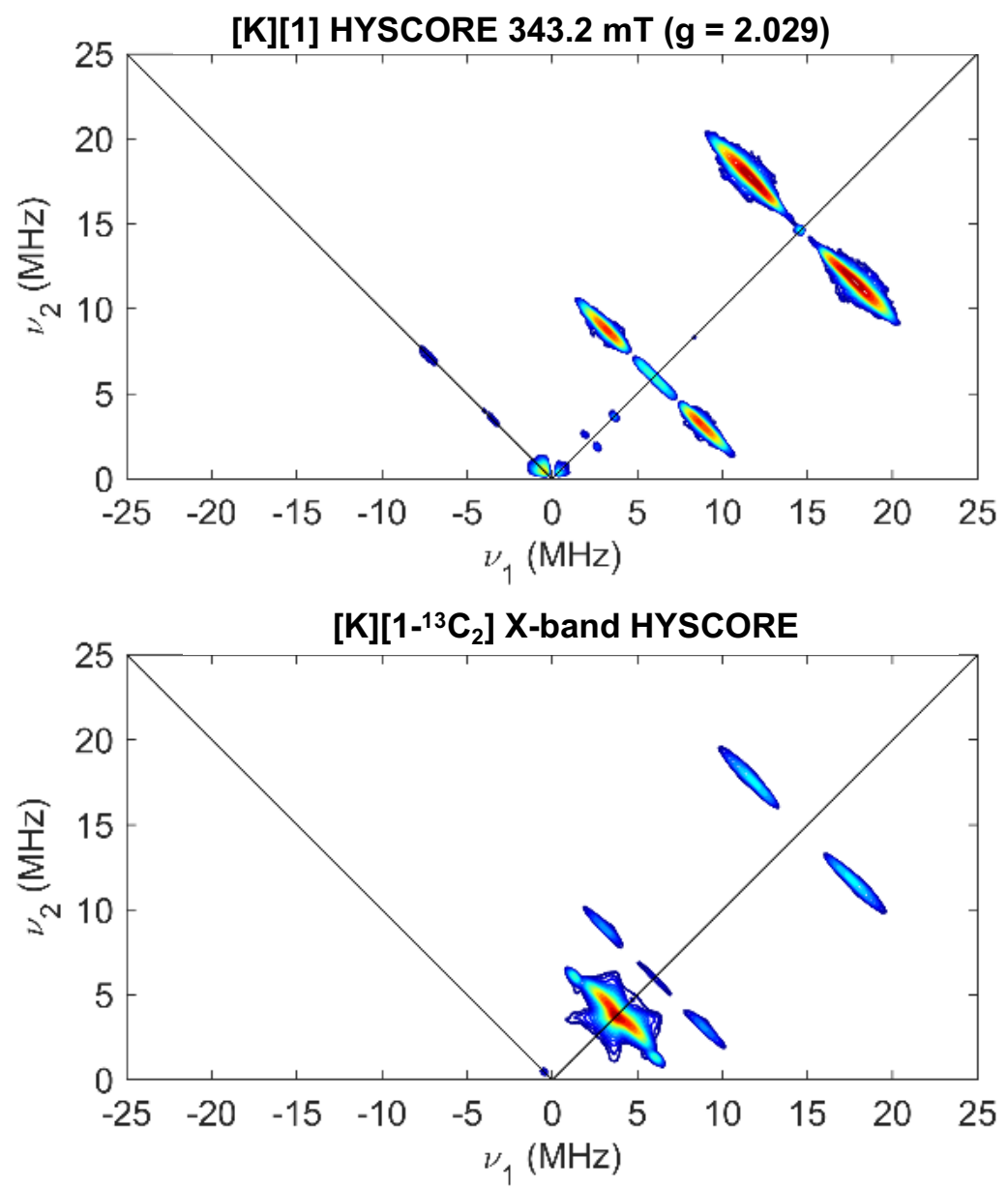

Figure S15-(Top) X-band HYSCORE of natural abundance [K][1] collected at $351.6 \mathrm{mT}$ (g=1.981). (Bottom) $\mathrm{X}$-band HYSCORE of $[\mathbf{K}]\left[1 \mathbf{1}^{13} \mathbf{C}_{2}\right]$ collected at $351.6 \mathrm{mT}(\mathrm{g}=1.981)$. Acquisition parameters: temperature $=55 \mathrm{~K}$; MW frequency $=9.747 \mathrm{GHz}$; MW pulse length $(\pi / 2, \pi)=8 \mathrm{~ns}, 16 \mathrm{~ns} ; \tau=136 \mathrm{~ns}, \mathrm{t}_{1}=\mathrm{t}_{2}=100 \mathrm{~ns} ; \Delta \mathrm{t}_{1}=\Delta \mathrm{t}_{2}=16 \mathrm{~ns}$; shot repetition time $(\mathrm{srt})=1 \mathrm{~ms}$. 

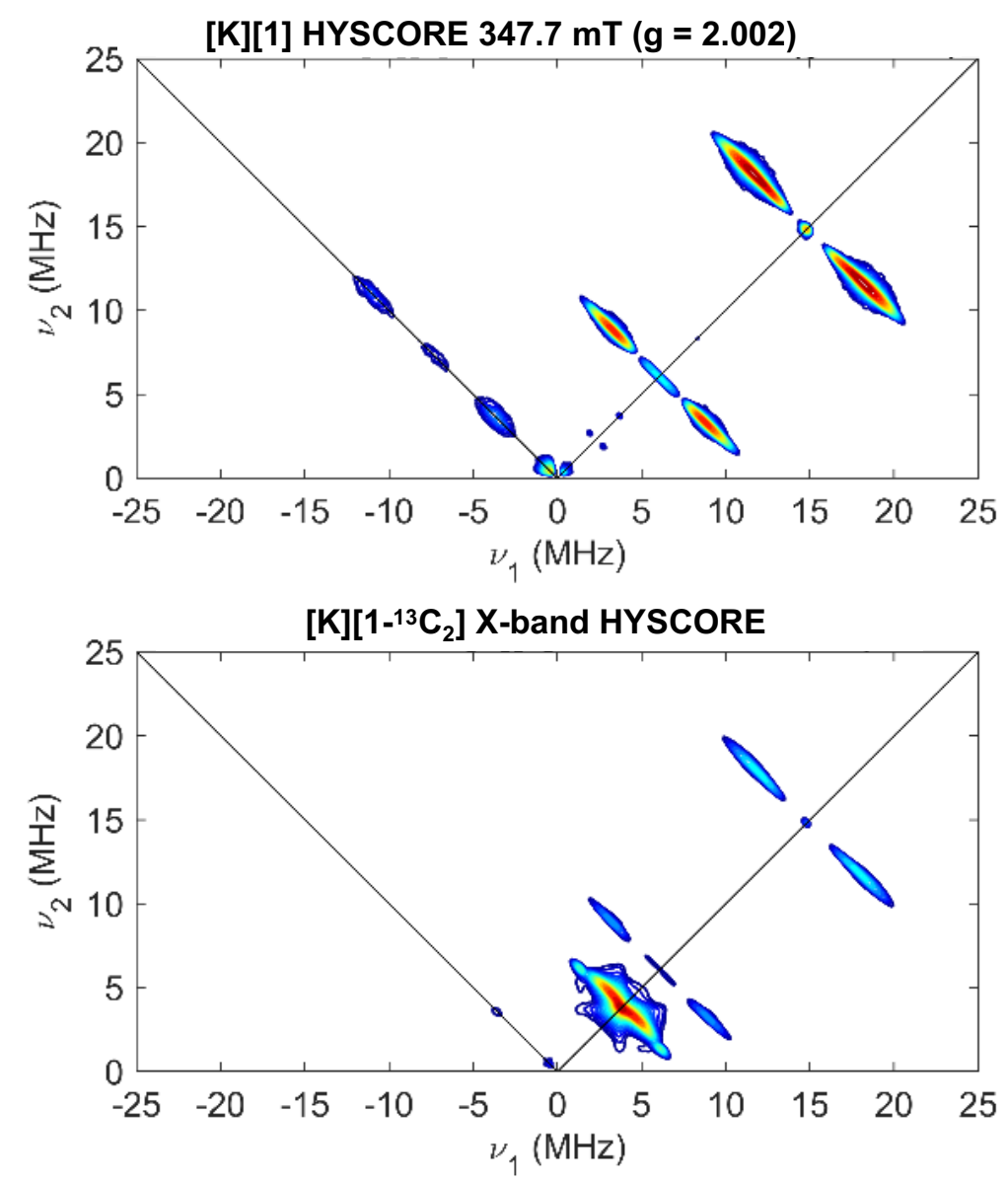

Figure S16-(Top) X-band HYSCORE of [K][1] collected at $347.7 \mathrm{mT}(\mathrm{g}=2.002)$. (Bottom) X-band HYSCORE of $[\mathbf{K}]\left[1 \mathbf{1}^{13} \mathbf{C}_{2}\right]$ collected at $347.7 \mathrm{mT}(\mathrm{g}=2.002)$. Acquisition parameters: temperature $=55 \mathrm{~K}$; $\mathrm{MW}$ frequency $=$ 9.747 GHz; MW pulse length $(\pi / 2, \pi)=8 \mathrm{~ns}, 16 \mathrm{~ns} ; \tau=136 \mathrm{~ns}, \mathrm{t}_{1}=\mathrm{t}_{2}=100 \mathrm{~ns} ; \Delta \mathrm{t}_{1}=\Delta \mathrm{t}_{2}=16 \mathrm{~ns}$; shot repetition time $(\mathrm{srt})=1 \mathrm{~ms}$. 

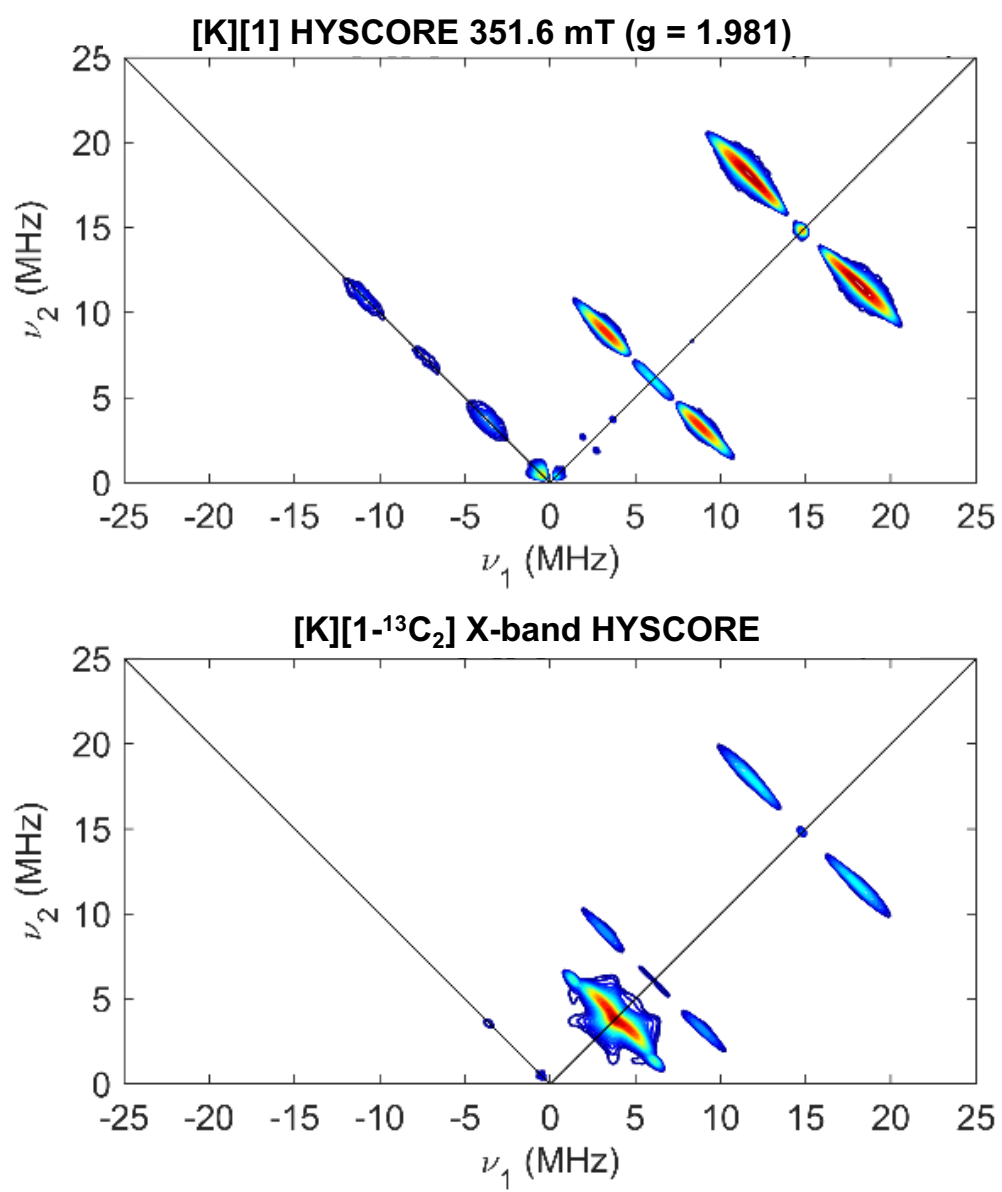

Figure S17-(Top) X-band HYSCORE of [K][1] collected at $351.6 \mathrm{mT}(\mathrm{g}=1.981)$. (Bottom) X-band HYSCORE of $[\mathbf{K}]\left[1-{ }^{13} \mathbf{C}_{2}\right]$ collected at $351.6 \mathrm{mT}(\mathrm{g}=1.981)$. Acquisition parameters: temperature $=55 \mathrm{~K}$; MW frequency $=9.747 \mathrm{GHz}$; MW pulse length $(\pi / 2, \pi)=8 \mathrm{~ns}, 16 \mathrm{~ns} ; \tau=136 \mathrm{~ns}, \mathrm{t}_{1}=\mathrm{t}_{2}=100 \mathrm{~ns} ; \Delta \mathrm{t}_{1}=\Delta \mathrm{t}_{2}=16 \mathrm{~ns}$; shot repetition time $(\mathrm{srt})=1 \mathrm{~ms}$. 

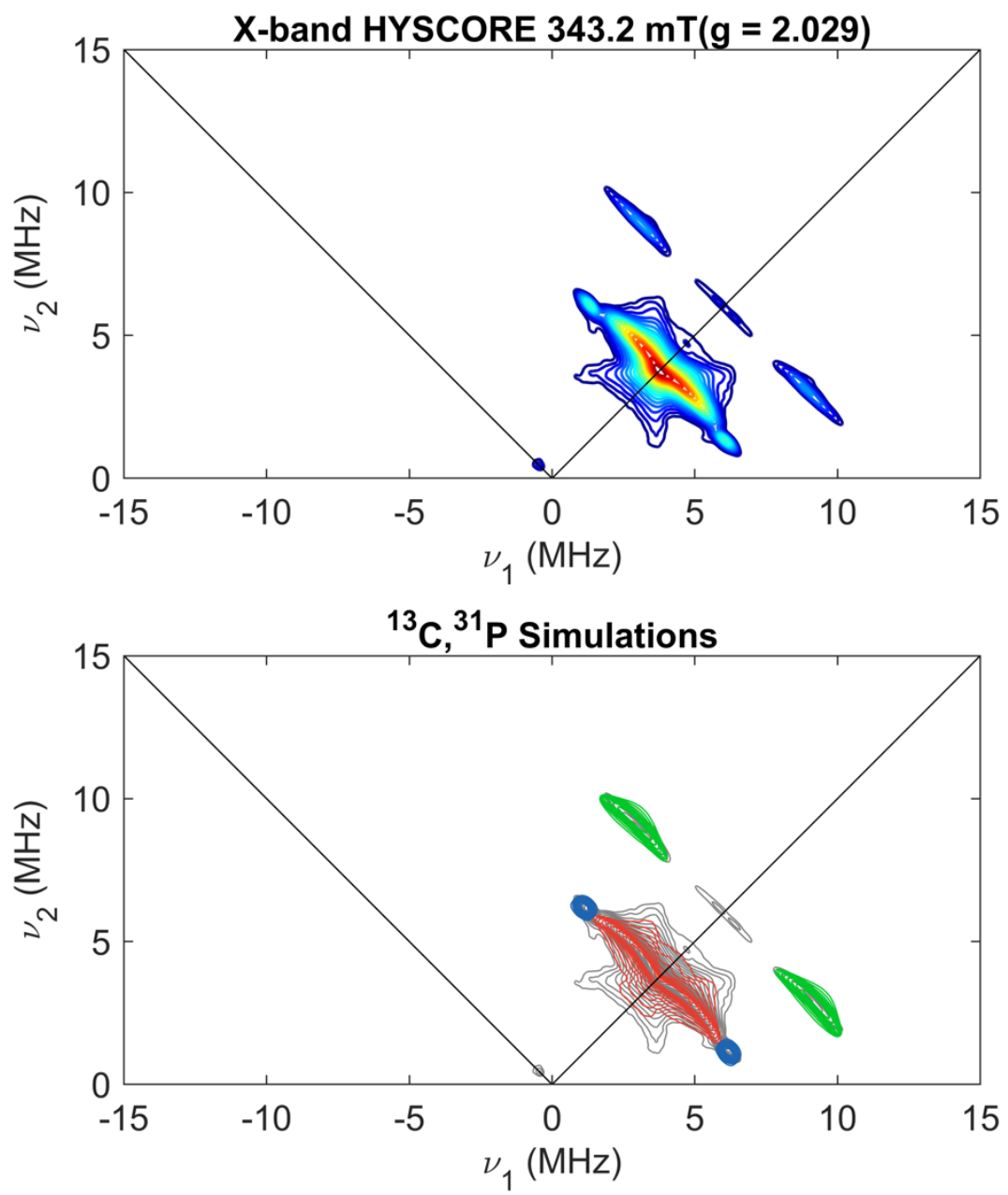

Figure S18-(Top) X-band HYSCORE of $[\mathbf{K}]\left[1 \mathbf{1}^{\mathbf{1 3}} \mathbf{C}_{2}\right]$ collected at $343.2 \mathrm{mT}(\mathrm{g}=2.029)$. (Bottom) Monochromatic representations of the HYSCORE data (grey), with simulations using parameters in Table 2 overlaid: (red) ${ }^{13} \mathrm{C}_{\mathrm{A}}$, (blue) ${ }^{13} \mathrm{C}_{\mathrm{B}}$, (green) ${ }^{31} \mathrm{P}_{1,2}$. Acquisition parameters: temperature $=55 \mathrm{~K}$; MW frequency $=9.747 \mathrm{GHz}$; MW pulse length $(\pi / 2, \pi)=8 \mathrm{~ns}, 16 \mathrm{~ns} ; \tau=136 \mathrm{~ns}, \mathrm{t}_{1}=\mathrm{t}_{2}=100 \mathrm{~ns} ; \Delta \mathrm{t}_{1}=\Delta \mathrm{t}_{2}=16 \mathrm{~ns}$; shot repetition time $(\mathrm{srt})=1 \mathrm{~ms}$. 

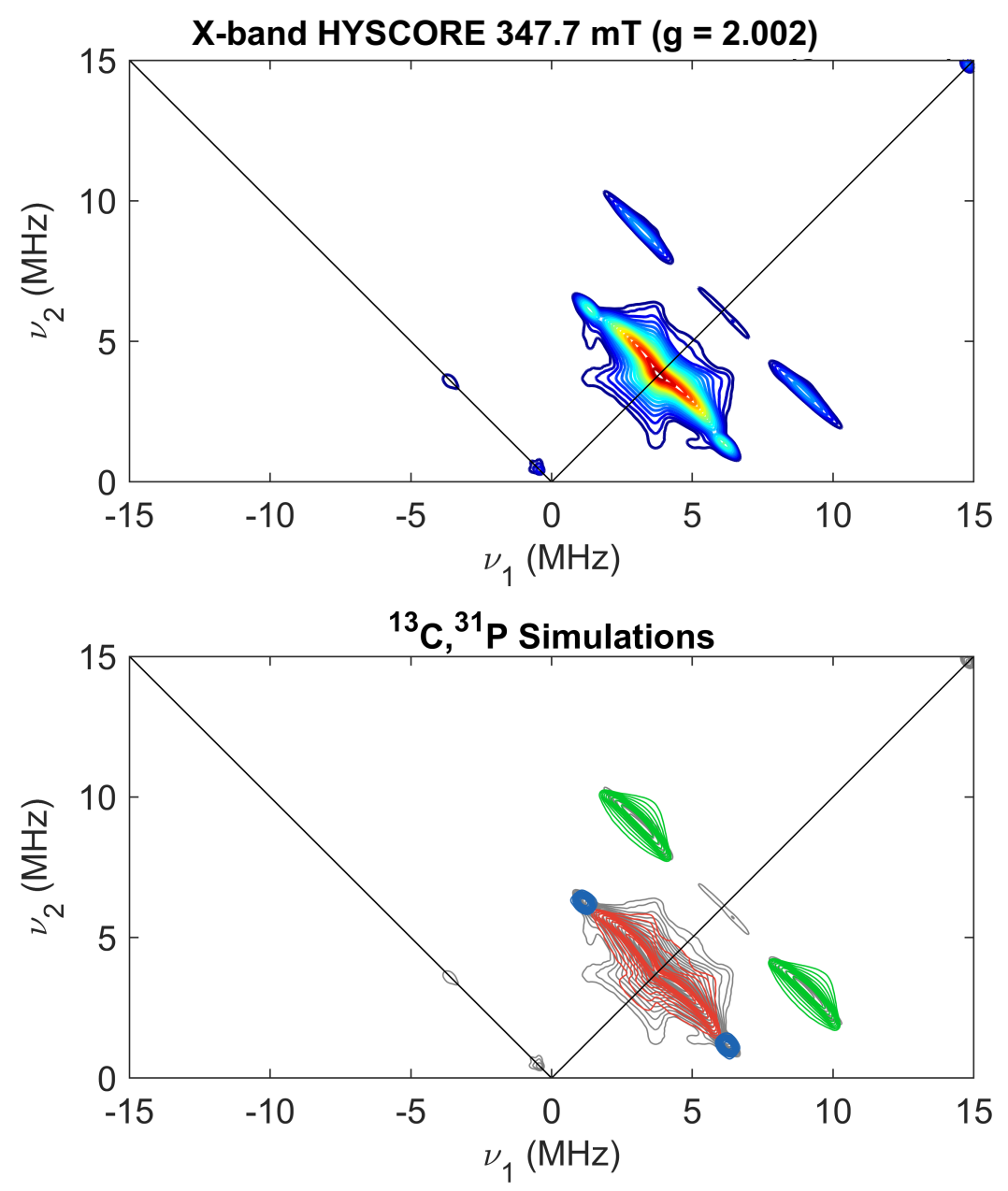

Figure S19-(Top) X-band HYSCORE of $[\mathbf{K}]\left[1 \mathbf{1}^{\mathbf{1 3}} \mathbf{C}_{2}\right]$ collected at $347.7 \mathrm{mT}(\mathrm{g}=2.002)$. (Bottom) Monochromatic representations of the HYSCORE data (grey), with simulations using parameters in Table 2 overlaid: (red) ${ }^{13} \mathrm{C}_{\mathrm{A}}$, (blue) ${ }^{13} \mathrm{C}_{\mathrm{B}}$, (green) ${ }^{31} \mathrm{P}_{1,2}$. Acquisition parameters: temperature $=55 \mathrm{~K}$; MW frequency $=9.747 \mathrm{GHz}$; MW pulse length $(\pi / 2, \pi)=8 \mathrm{~ns}, 16 \mathrm{~ns} ; \tau=136 \mathrm{~ns}, \mathrm{t}_{1}=\mathrm{t}_{2}=100 \mathrm{~ns} ; \Delta \mathrm{t}_{1}=\Delta \mathrm{t}_{2}=16 \mathrm{~ns}$; shot repetition time $(\mathrm{srt})=1 \mathrm{~ms}$. 

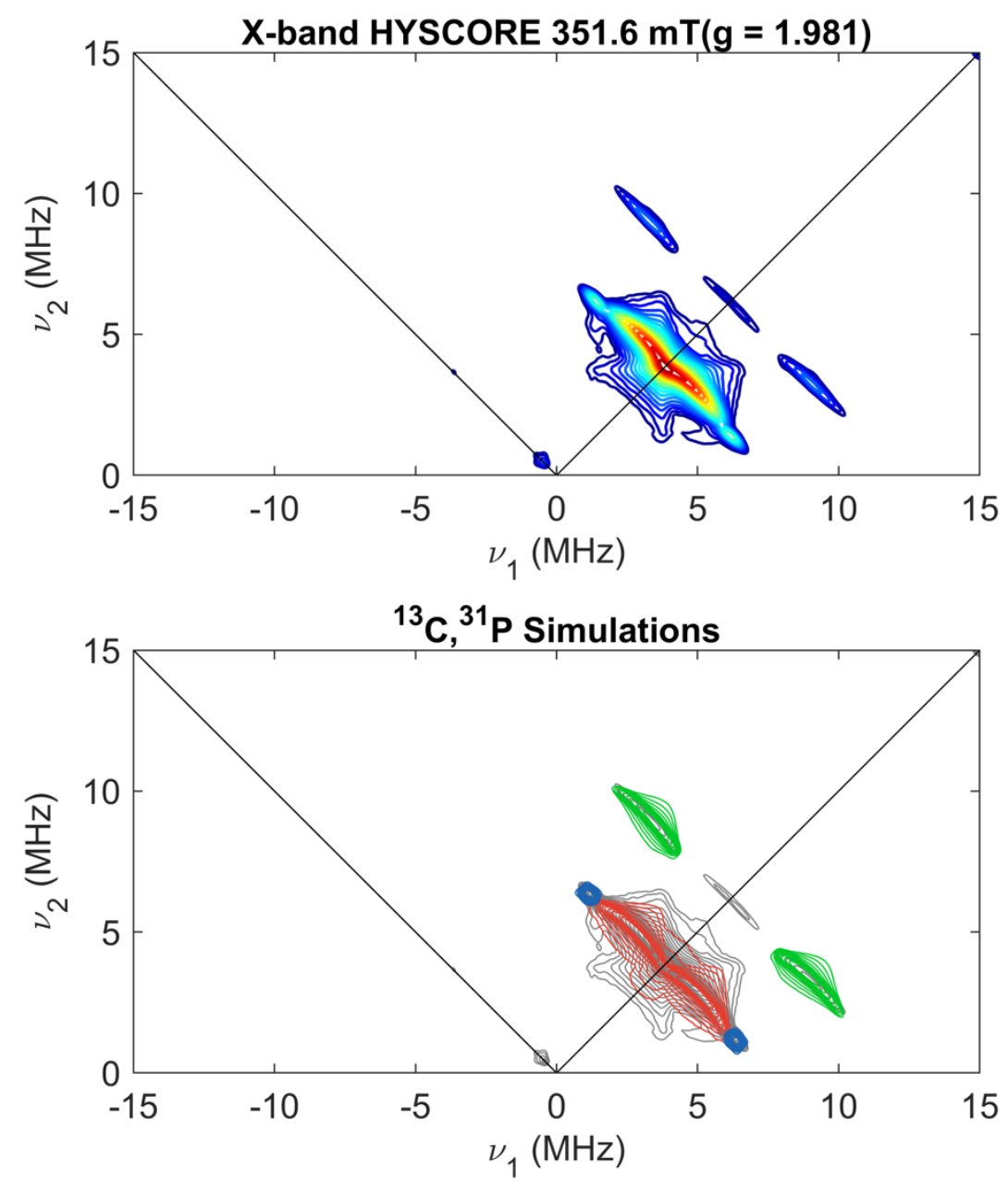

Figure S20 - (Top) X-band HYSCORE of $[\mathbf{K}]\left[1 \mathbf{1}^{13} \mathbf{C}_{2}\right]$ collected at $351.6 \mathrm{mT}$ (g=1.981). (Bottom) Monochromatic representations of the HYSCORE data (grey), with simulations using parameters in Table 2 overlaid: (red) ${ }^{13} \mathrm{C}_{\mathrm{A}}$, (blue) ${ }^{13} \mathrm{C}_{\mathrm{B}}$, (green) ${ }^{31} \mathrm{P}_{1,2}$. Acquisition parameters: temperature $=55 \mathrm{~K}$; MW frequency $=9.747 \mathrm{GHz}$; $\mathrm{MW}$ pulse length $(\pi / 2, \pi)=8 \mathrm{~ns}, 16 \mathrm{~ns} ; \tau=136 \mathrm{~ns}, \mathrm{t}_{1}=\mathrm{t}_{2}=100 \mathrm{~ns} ; \Delta \mathrm{t}_{1}=\Delta \mathrm{t}_{2}=16 \mathrm{~ns}$; shot repetition time (srt) $=1 \mathrm{~ms}$. 
[3][BArF $\left.{ }_{4}\right]$ Field-Dependent X-band Davies ENDOR

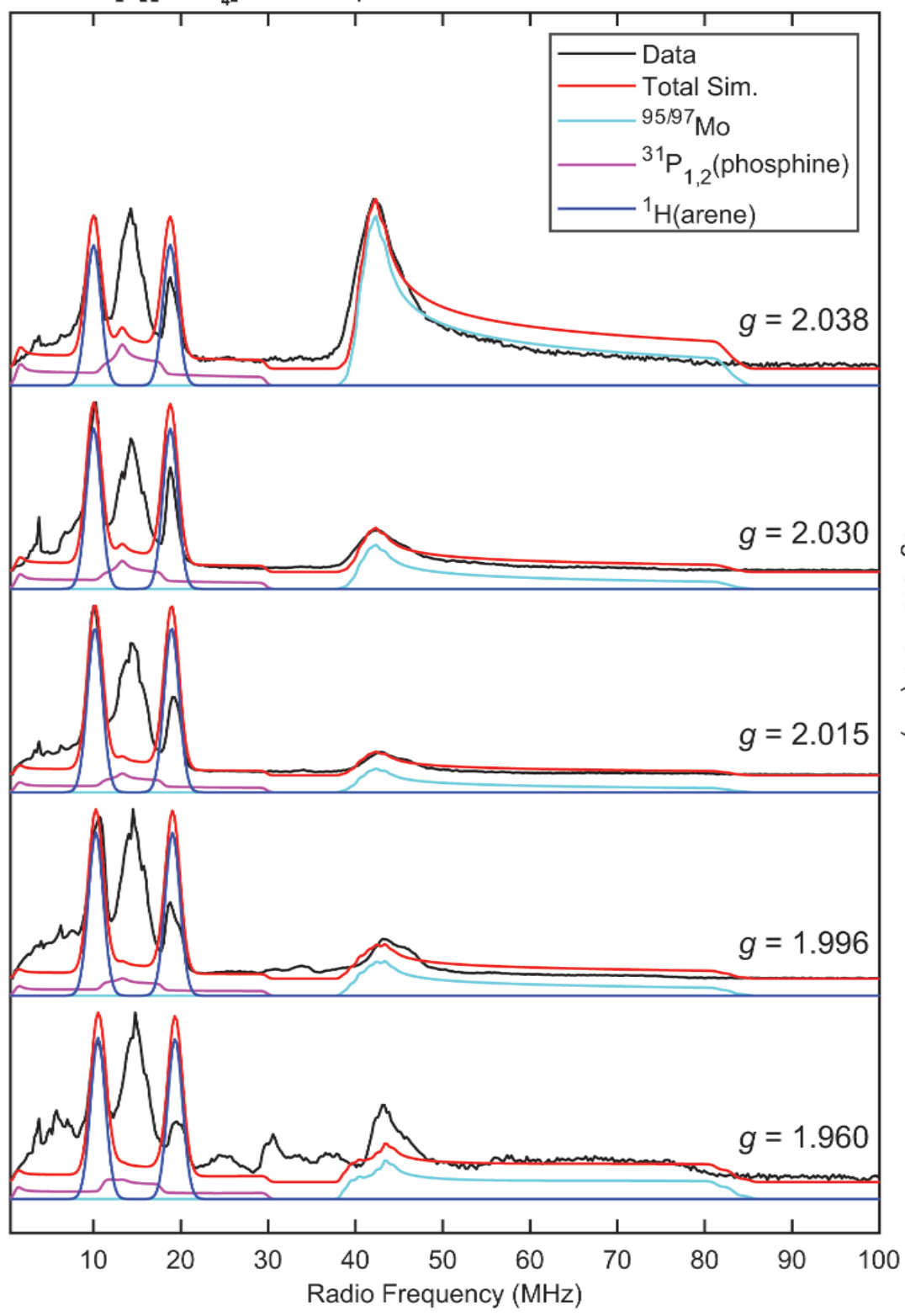

X-band

ESE-EPR

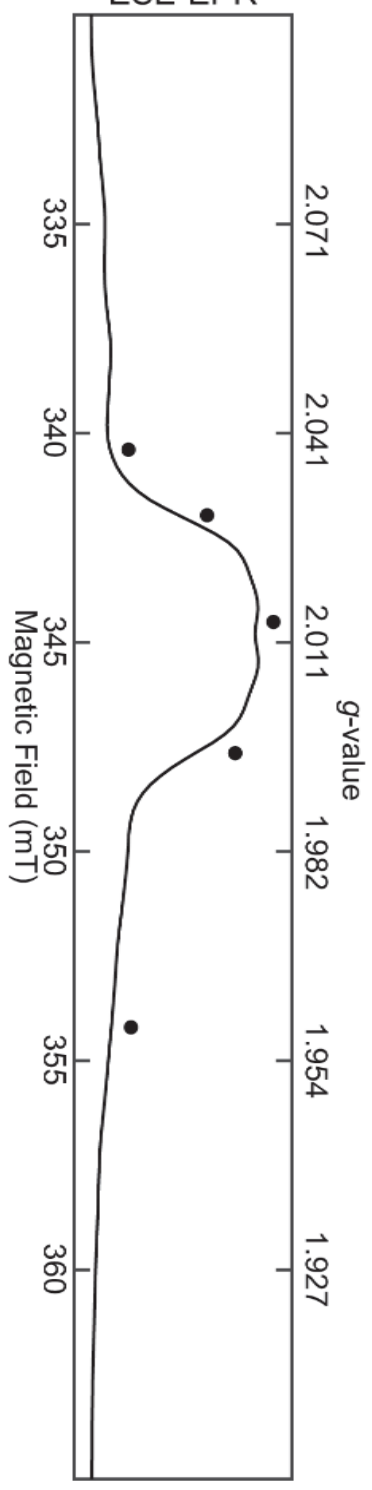

Figure S21-Field-Dependent X-band Davies ENDOR spectra of natural abundance [3][BAr ${ }^{\mathbf{F}}$ ] (black) with simulations overlaid using parameters in Table 4. The electron spin echo (ESE) detected EPR spectrum is shown to the right, with fields at which ENDOR was acquired denoted with black circles. Acquisition parameters: temperature $=25 \mathrm{~K} ; \mathrm{MW}$ frequency $=9.708 \mathrm{GHz} ; \mathrm{MW} \pi$ pulse length $=80 \mathrm{~ns}$; interpulse delay $\tau=240 \mathrm{~ns} ; \pi_{\mathrm{RF}}$ pulse length $=$ $15 \mu \mathrm{s} ; \mathrm{T}_{\mathrm{RF}}$ delay $=2 \mu \mathrm{s}$; shot repetition time $(\mathrm{srt})=5 \mathrm{~ms}$. 


\section{[3][BAr $\left.{ }_{4}^{\mathrm{F}}\right]{ }^{13} \mathrm{C}$ vs Nat. Abund. ENDOR}

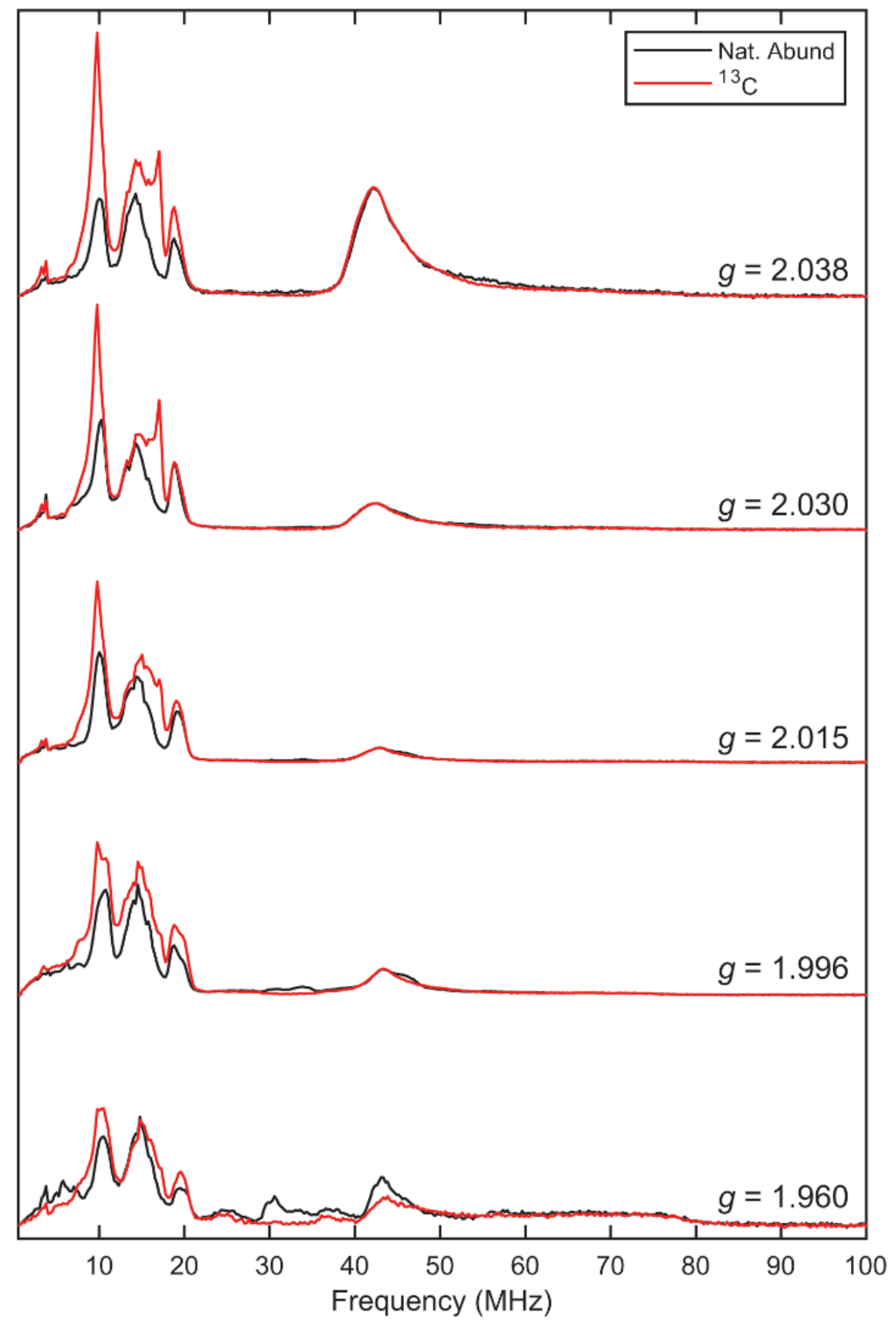

Figure S22-Field-Dependent X-band Davies ENDOR spectra of natural abundance [3][BA $\mathbf{r}^{\mathbf{F}}$ ] (black) and [3$\left.{ }^{13} \mathbf{C}_{2}\right]\left[\mathbf{B A r}^{\mathbf{F}}{ }_{4}\right]$ (red). Acquisition parameters: temperature $=25 \mathrm{~K}$; MW frequency $=9.708 \mathrm{GHz}$; $\mathrm{MW} \pi$ pulse length $=80 \mathrm{~ns}$; interpulse delay $\tau=240 \mathrm{~ns} ; \pi_{\mathrm{RF}}$ pulse length $=15 \mu \mathrm{s} ; \mathrm{T}_{\mathrm{RF}}$ delay $=2 \mu \mathrm{s}$; shot repetition time $(\mathrm{srt})=5 \mathrm{~ms}$. 


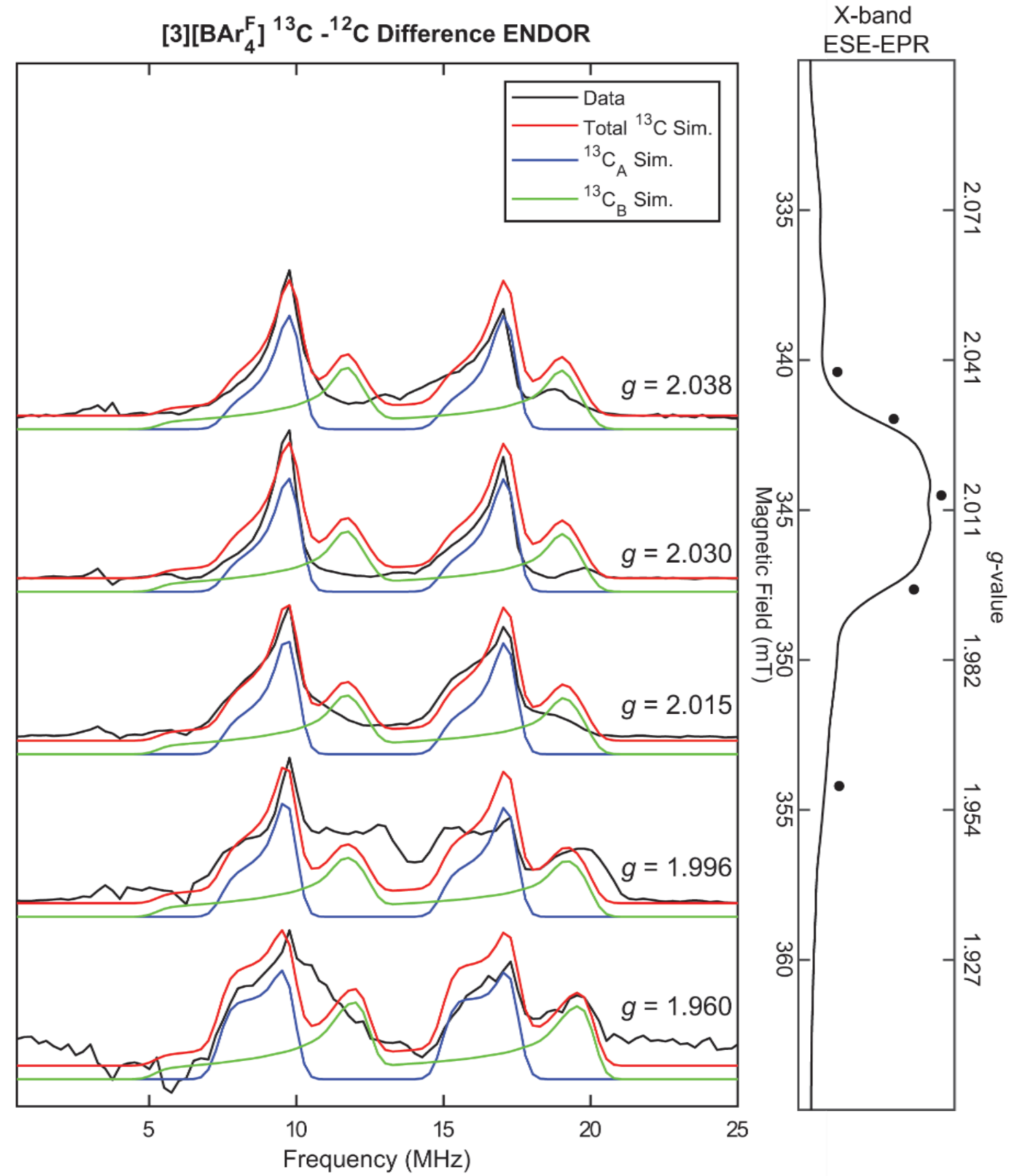

Figure S23-Field-Dependent ${ }^{13} \mathrm{C}$-minus-natural abundance $\mathrm{X}$-band Davies ENDOR spectra of [3][BA $\left.\mathbf{B r}^{\mathbf{F}} \mathbf{4}\right]$ (black), with simulations of two inequivalent ${ }^{13} \mathrm{C}$ couplings overlaid using parameters in Table 4 . The electron spin echo (ESE) detected EPR spectrum is shown to the right, with fields at which ENDOR was acquired denoted with black circles. Acquisition parameters: temperature $=25 \mathrm{~K}$; MW frequency $=9.708 \mathrm{GHz}$; MW $\pi$ pulse length $=80$ $\mathrm{ns}$; interpulse delay $\tau=240 \mathrm{~ns} ; \pi_{\mathrm{RF}}$ pulse length $=15 \mu \mathrm{s} ; \mathrm{T}_{\mathrm{RF}}$ delay $=2 \mu \mathrm{s}$; shot repetition time $(\mathrm{srt})=5 \mathrm{~ms}$. 
[4][BAr $\left.{ }_{4}\right]$ X-band Davies ENDOR

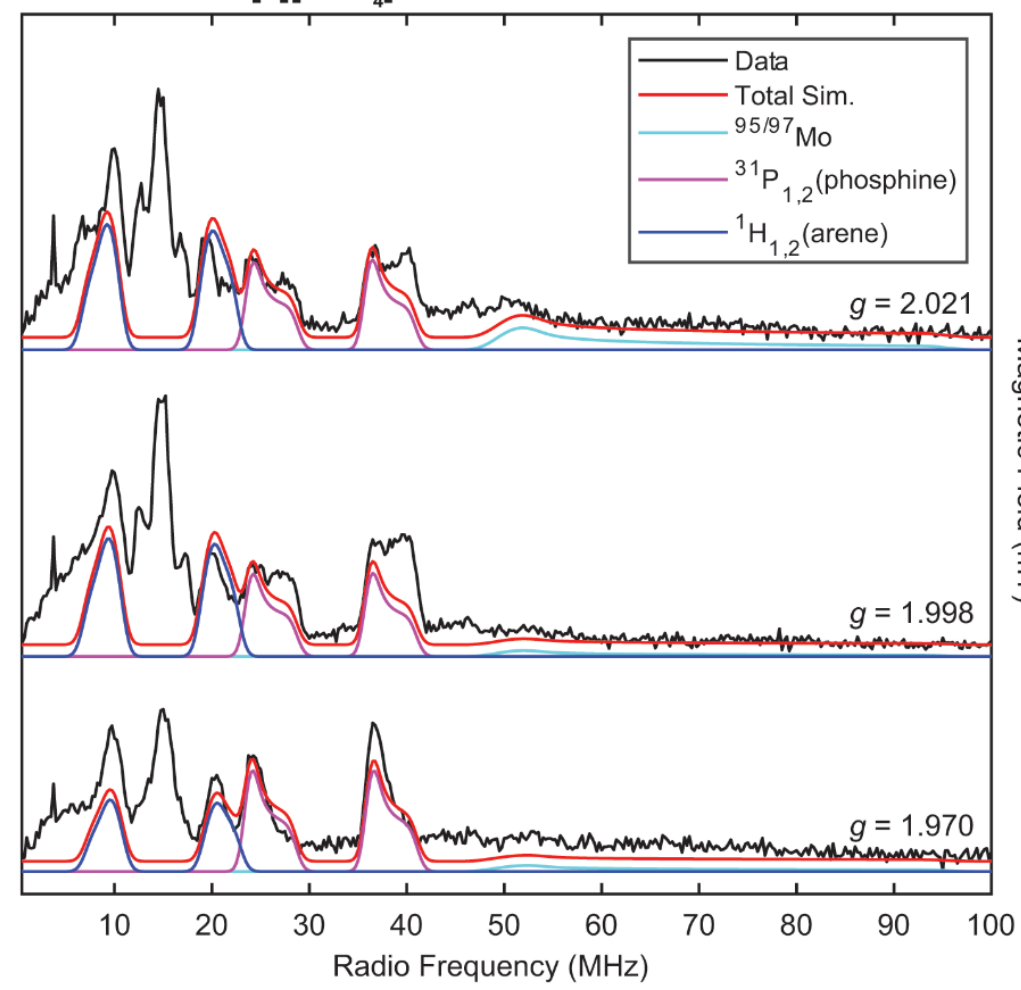

\section{X-band ESE-EPR}

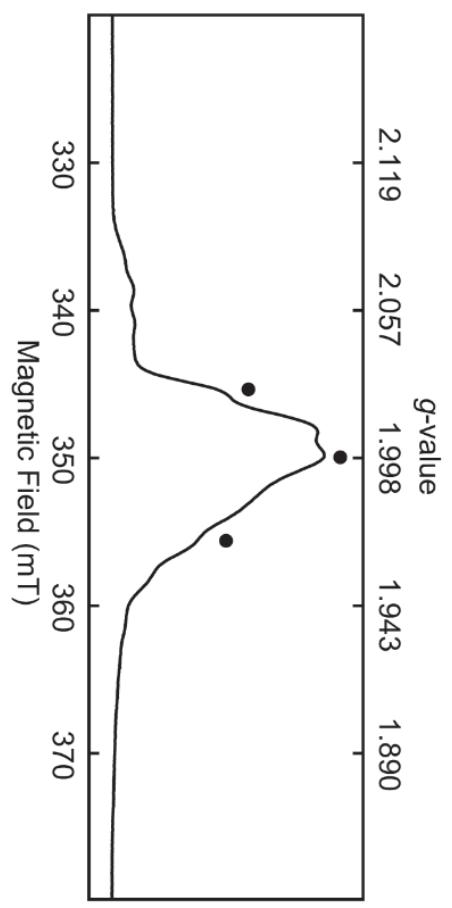

Figure S24-Field-Dependent X-band Davies ENDOR spectra of natural abundance [4][BAr ${ }^{\mathrm{F}}$ ] (black) with simulations overlaid using parameters in Table 4. The electron spin echo (ESE) detected EPR spectrum is shown to the right, with fields at which ENDOR was acquired denoted with black circles. Acquisition parameters: temperature $=25 \mathrm{~K}$; MW frequency $=9.708 \mathrm{GHz}$; MW $\pi$ pulse length $=80 \mathrm{~ns}$; interpulse delay $\tau=240 \mathrm{~ns}$; $\pi_{\mathrm{RF}}$ pulse length $=$ $15 \mu \mathrm{s} ; \mathrm{T}_{\mathrm{RF}}$ delay $=2 \mu \mathrm{s}$; shot repetition time $(\mathrm{srt})=5 \mathrm{~ms}$. 


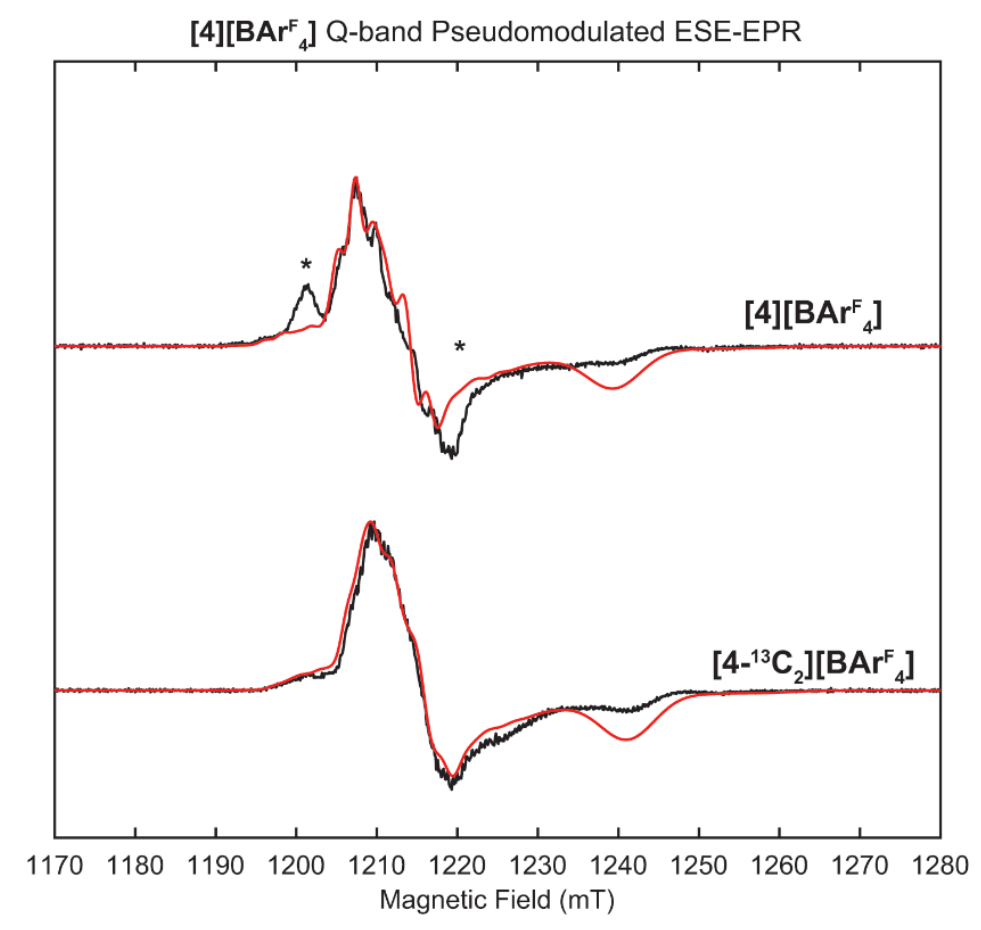

Figure S25-Q-band Pseudomodulated ESE-EPR spectra of [4][BAr $\left.{ }_{4}{ }_{4}\right]$ with natural abundance (top) and ${ }^{13} \mathrm{C}$ enrichment (bottom) represented in black with simulations using parameters in Table 4. Pseudomodulation function amplitude $=0.2 \mathrm{mT}$. Experimental conditions: microwave frequency $=34.089 \mathrm{GHz} ; \pi$ pulse length $=160 \mathrm{~ns}$; interpulse delay $\tau=300 \mathrm{~ns}$; shot repitition time $(\mathrm{srt})=1 \mathrm{~ms}$; temperature $=35 \mathrm{~K}$. Asterisks indicate features associated with residual [3][BAr $\left.{ }_{4}^{\mathrm{F}}\right]$ due to incomplete $\mathrm{CO}$ loss. 


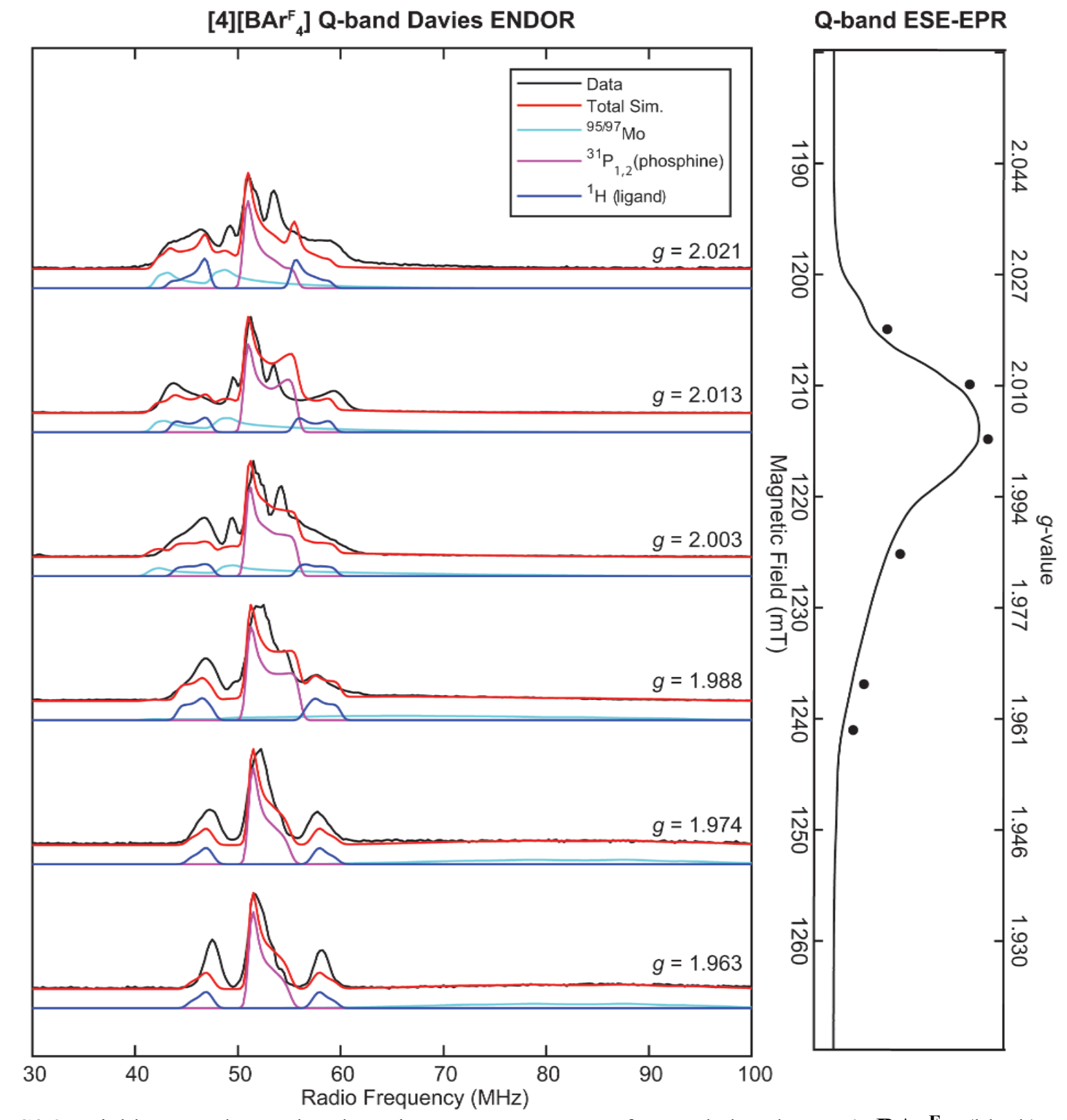

Figure S26-Field-Dependent Q-band Davies ENDOR spectra of natural abundance [4][BA $\mathbf{r}^{\mathbf{F}}$ ] (black) with simulations overlaid using parameters in Table 4. The electron spin echo (ESE) detected EPR spectrum is shown to the right, with fields at which ENDOR was acquired denoted with black circles. Acquisition parameters: temperature $=25 \mathrm{~K} ; \mathrm{MW}$ frequency $=34.092 \mathrm{GHz} ; \mathrm{MW} \pi$ pulse length $=80 \mathrm{~ns}$; interpulse delay $\tau=240 \mathrm{~ns} ; \pi_{\mathrm{RF}}$ pulse length $=$ $15 \mu \mathrm{s} ; \mathrm{T}_{\mathrm{RF}}$ delay $=2 \mu \mathrm{s}$; shot repetition time $(\mathrm{srt})=5 \mathrm{~ms}$. 
$[4]\left[\mathrm{BAr}_{4}{ }_{4}\right]{ }^{13} \mathrm{C}$ vs Nat. Abund. Q-band Davies ENDOR

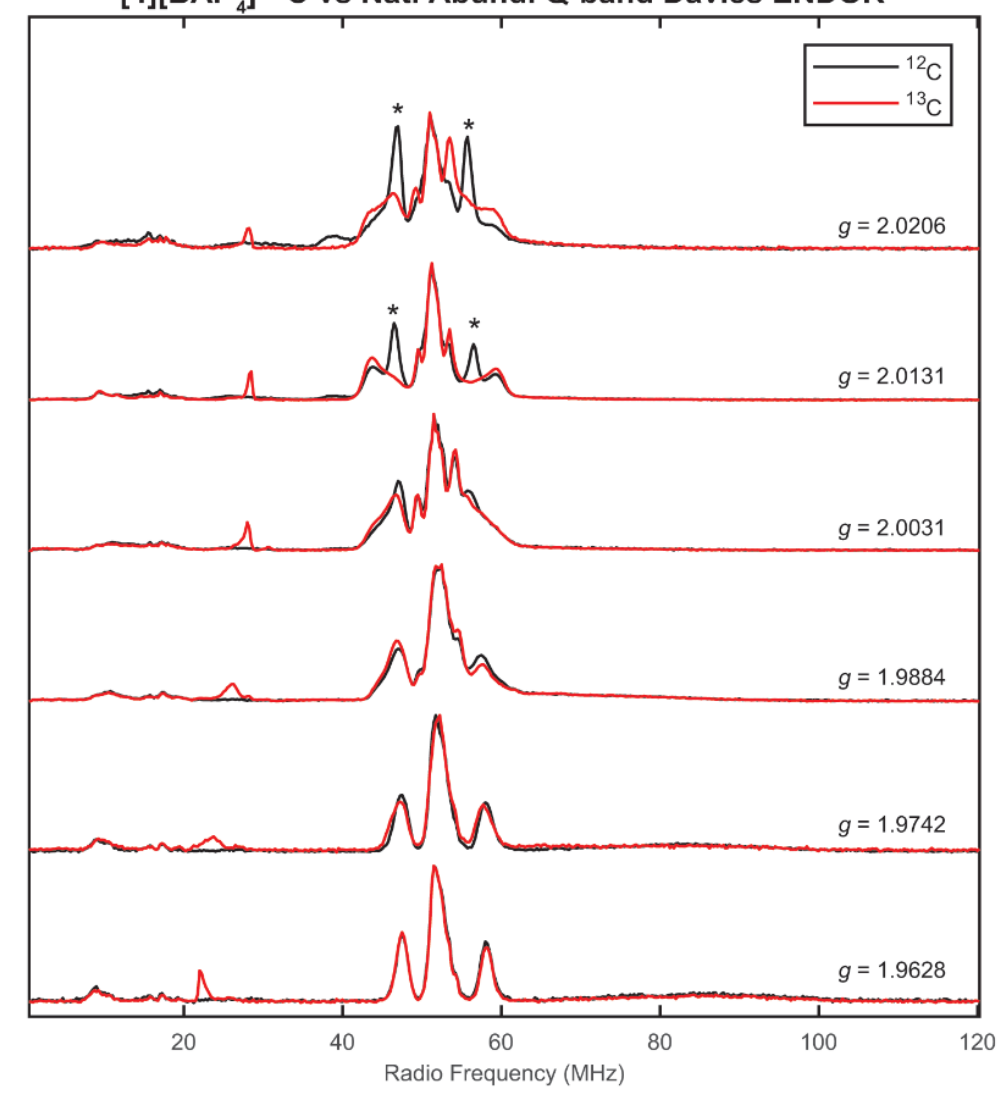

Figure S27- Field-Dependent Q-band Davies ENDOR spectra of natural abundance [4][BAr $\left.{ }_{4}{ }_{4}\right]$ (black) and [4$\left.{ }^{13} \mathbf{C}\right]\left[\mathbf{B A r}^{\mathbf{F}}{ }_{4}\right]$ (red). Asterisks indicate features arising from residual [3] $\left[\mathbf{B A r} \mathbf{r}_{4}{ }_{4}\right]$ present in only the natural abundance sample. Acquisition parameters: temperature $=25 \mathrm{~K}$; MW frequency $=34.092 \mathrm{GHz}$; MW $\pi$ pulse length $=80 \mathrm{~ns}$; interpulse delay $\tau=240 \mathrm{~ns} ; \pi_{\mathrm{RF}}$ pulse length $=15 \mu \mathrm{s}$; $\mathrm{T}_{\mathrm{RF}}$ delay $=2 \mu \mathrm{s}$; shot repetition time $(\mathrm{srt})=5 \mathrm{~ms}$. 
[4][BArF ${ }_{4}{ }^{13} \mathrm{C}$ - Nat. Abund. Q-band Davies ENDOR

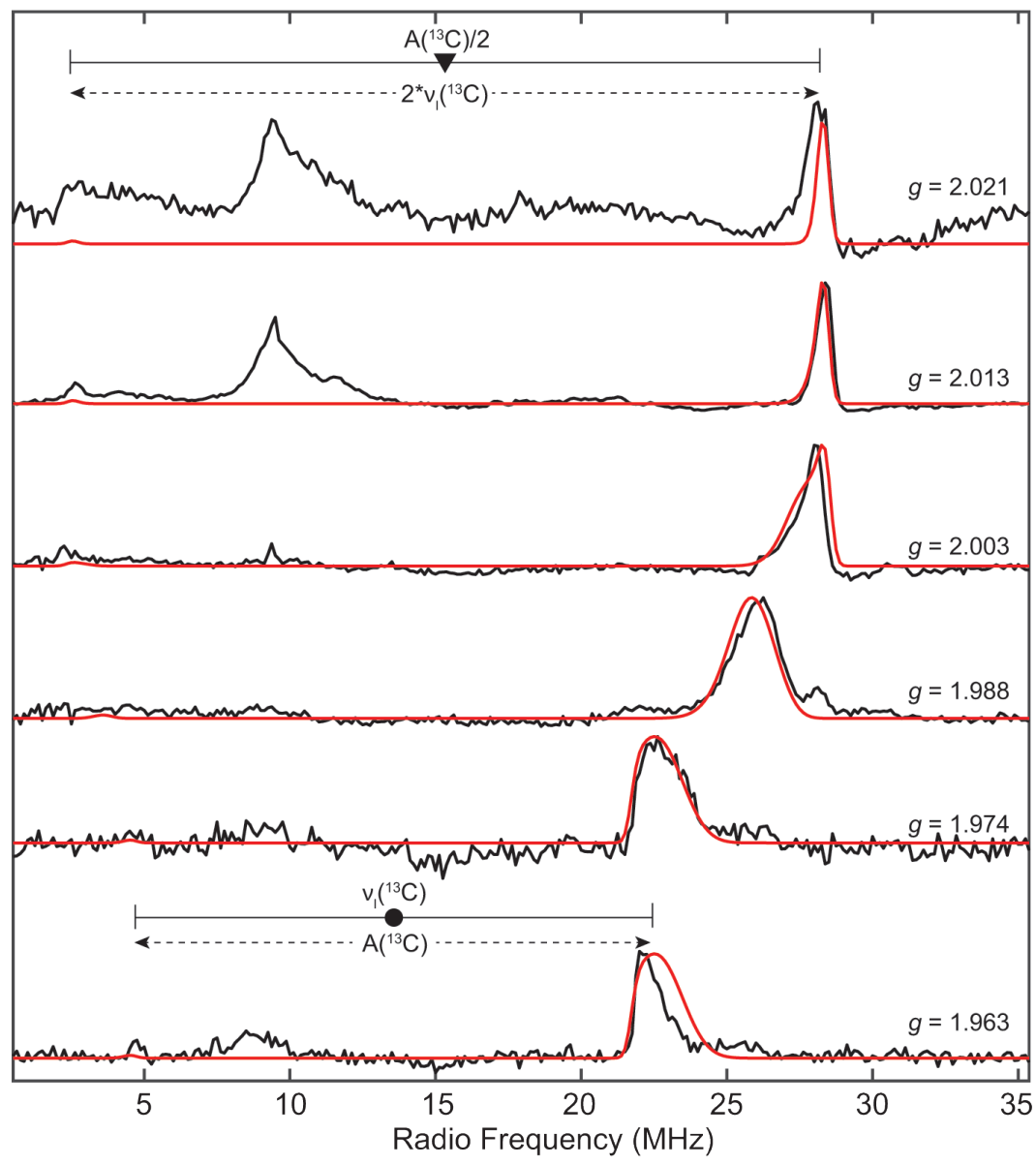

Q-band ESE-EPR

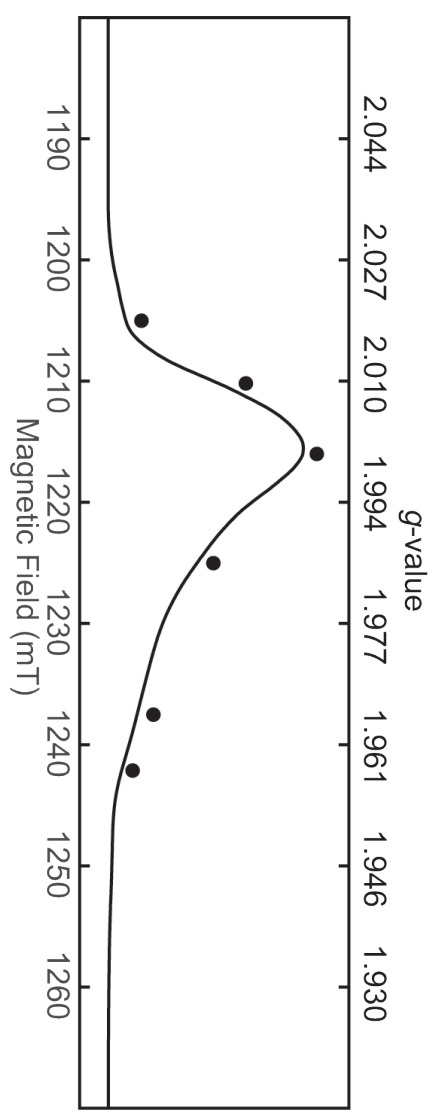

Figure S28 - Field-Dependent ${ }^{13} \mathrm{C}$-minus-natural abundance Q-band Davies ENDOR spectra of [4][BAr ${ }^{\mathrm{F}}$ ] $($ black), with simulations of ${ }^{13} \mathrm{C}$ coupling overlaid in red using parameters in Table 4. Acquisition parameters: temperature $=25 \mathrm{~K}$; MW frequency $=34.092 \mathrm{GHz} ; \mathrm{MW} \pi$ pulse length $=80 \mathrm{~ns}$; interpulse delay $\tau=240 \mathrm{~ns} ; \pi_{\mathrm{RF}}$ pulse length $=$ $60 \mu \mathrm{s} ; \mathrm{T}_{\mathrm{RF}}$ delay $=2 \mu \mathrm{s}$; shot repetition time $(\mathrm{srt})=5 \mathrm{~ms}$. 

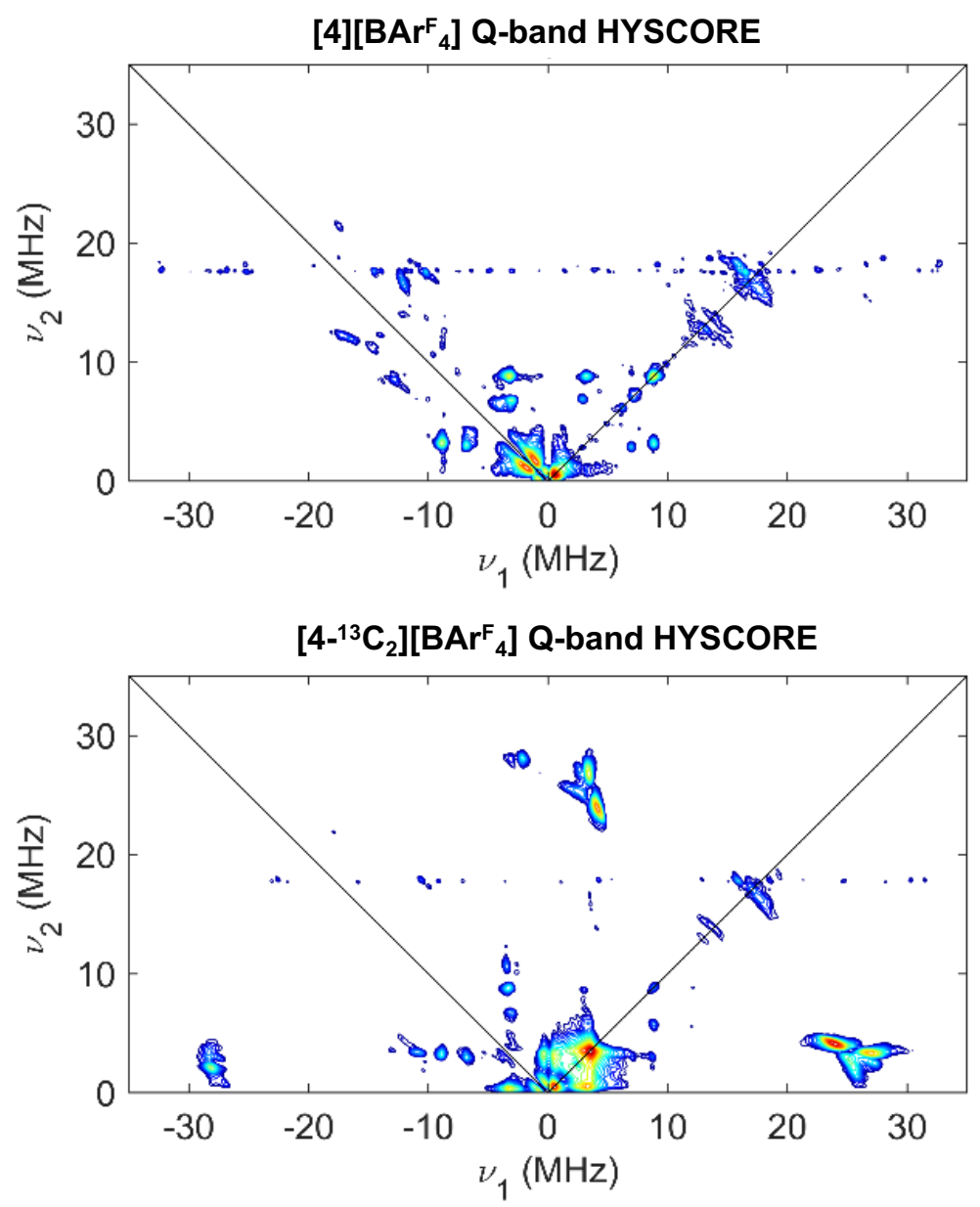

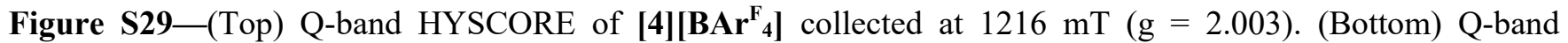
HYSCORE of $\left[\mathbf{4}_{-1}^{13} \mathbf{C}\right]\left[\mathbf{B A r}{ }^{F_{4}}\right]$ collected at $1216 \mathrm{mT}(\mathrm{g}=2.003)$. Acquisition parameters: temperature $=25 \mathrm{~K}$; $\mathrm{MW}$ frequency $=34.089 \mathrm{GHz}$; MW pulse length $(\pi / 2, \pi)=12 \mathrm{~ns}, 24 \mathrm{~ns} ; \tau=100 \mathrm{~ns}, \mathrm{t}_{1}=\mathrm{t}_{2}=100 \mathrm{~ns} ; \Delta \mathrm{t}_{1}=\Delta \mathrm{t}_{2}=8 \mathrm{~ns}$; shot repetition time $(\mathrm{srt})=1 \mathrm{~ms}$. 

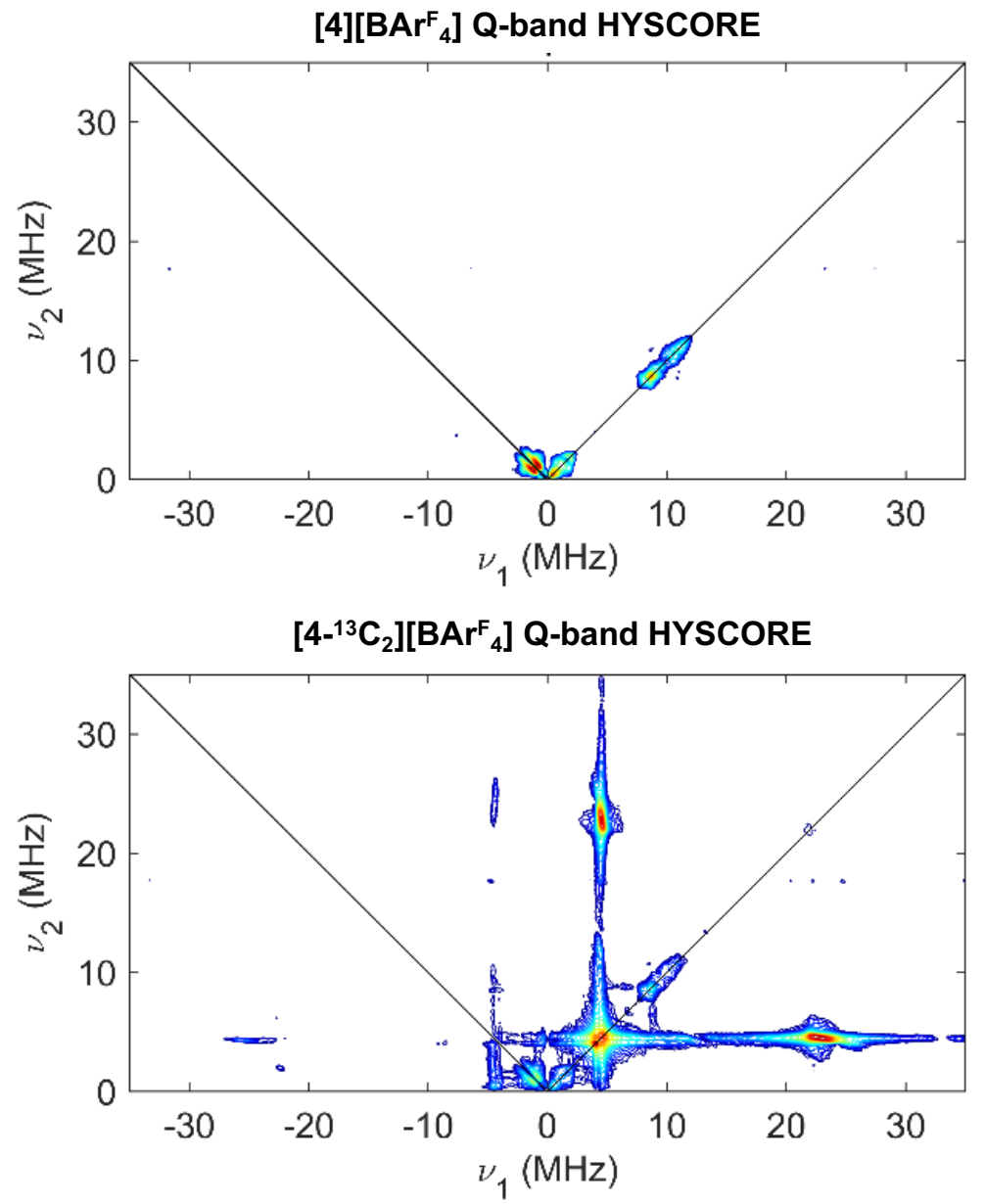

Figure S30-(Top) Q-band HYSCORE of [4][BAr ${ }^{\mathrm{F}}$ ] collected at $1241 \mathrm{mT}(\mathrm{g}=2.963)$. (Bottom) Q-band HYSCORE of $\left[4-{ }^{13} \mathbf{C}\right]\left[\mathbf{B A r}^{\mathrm{F}}{ }_{4}\right]$ collected at $1216 \mathrm{mT}(\mathrm{g}=2.963)$. Acquisition parameters: temperature $=25 \mathrm{~K}$; $\mathrm{MW}$ frequency $=34.089 \mathrm{GHz}$; MW pulse length $(\pi / 2, \pi)=12 \mathrm{~ns}, 24 \mathrm{~ns} ; \tau=100 \mathrm{~ns}, \mathrm{t}_{1}=\mathrm{t}_{2}=100 \mathrm{~ns} ; \Delta \mathrm{t}_{1}=\Delta \mathrm{t}_{2}=8 \mathrm{~ns}$; shot repetition time $(\mathrm{srt})=1 \mathrm{~ms}$. 

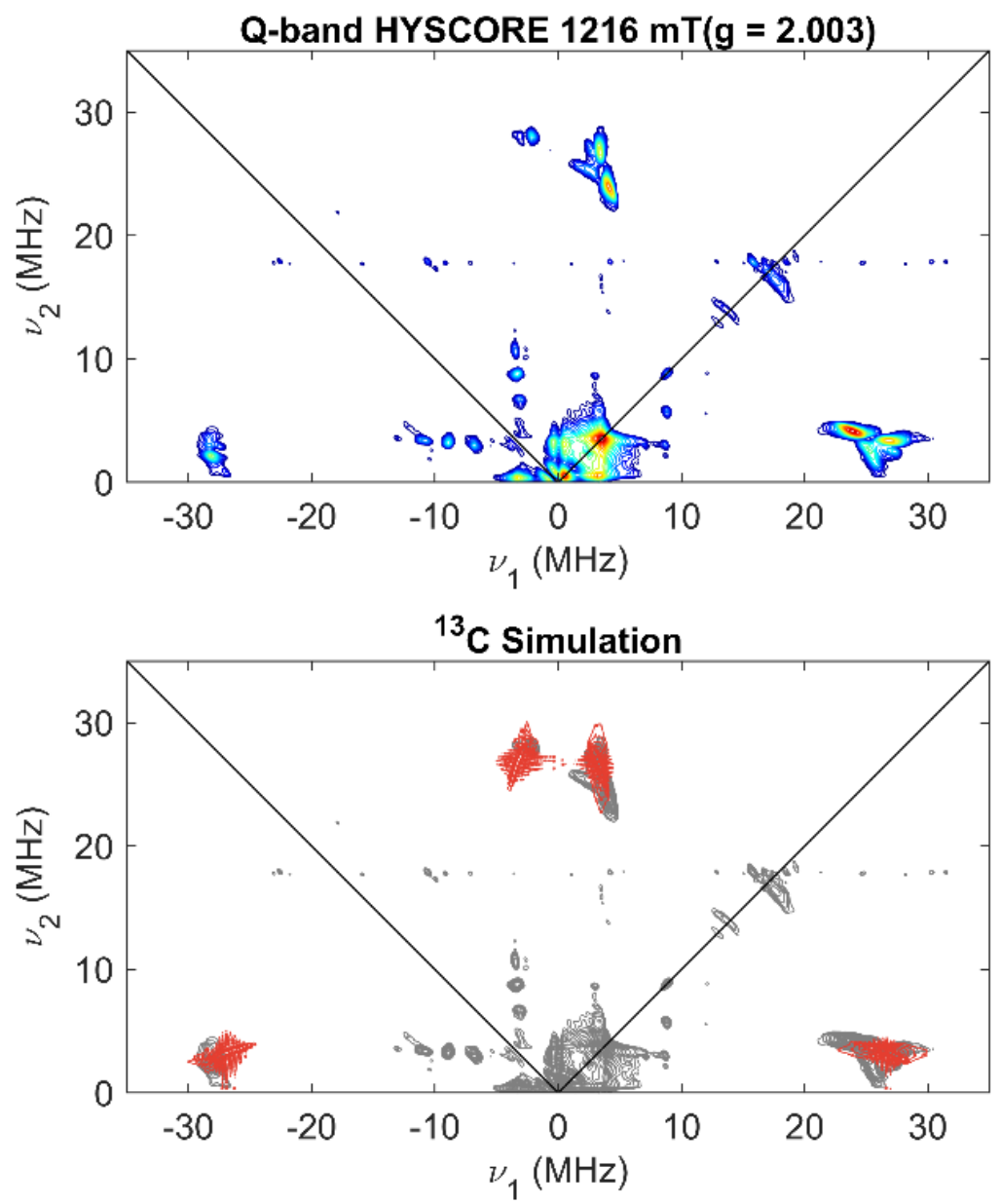

Figure S31-(Top) Q-band HYSCORE of $\left[4 \mathbf{4}^{\mathbf{1 3}} \mathbf{C}\right]\left[\mathbf{B A r}^{\mathrm{F}}{ }_{4}\right]$ collected at $1216 \mathrm{mT}(\mathrm{g}=2.003)$. (Bottom) Monochromatic representations of the HYSCORE data (grey), with ${ }^{13} \mathrm{C}$ simulation using parameters in Table 4 overlaid in red. Acquisition parameters: temperature $=25 \mathrm{~K} ; \mathrm{MW}$ frequency $=34.089 \mathrm{GHz} ; \mathrm{MW}$ pulse length $(\pi / 2, \pi)=12 \mathrm{~ns}$, $24 \mathrm{~ns} ; \tau=100 \mathrm{~ns}, \mathrm{t}_{1}=\mathrm{t}_{2}=100 \mathrm{~ns} ; \Delta \mathrm{t}_{1}=\Delta \mathrm{t}_{2}=8 \mathrm{~ns}$; shot repetition time $(\mathrm{srt})=1 \mathrm{~ms}$. 

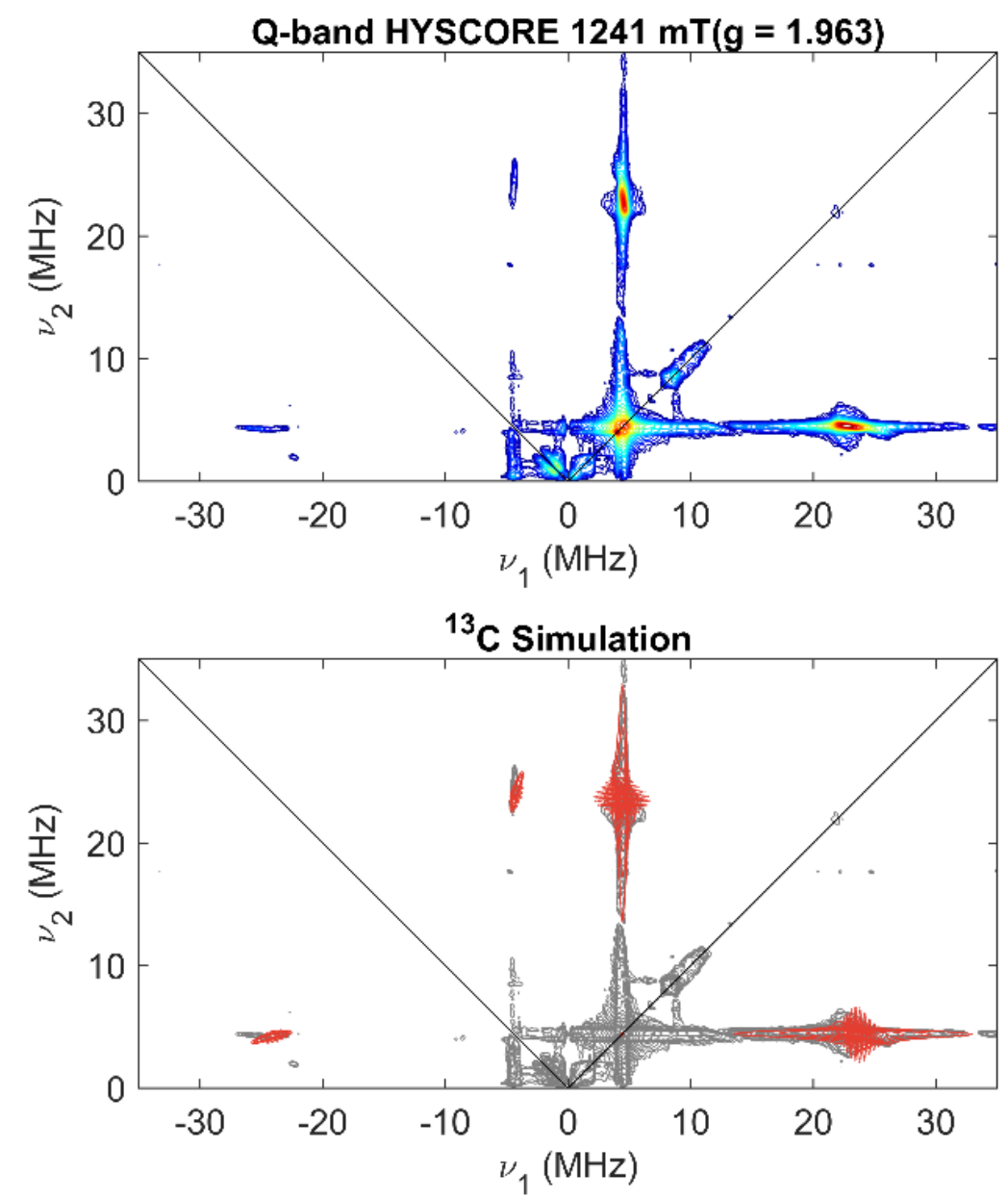

Figure S32-(Top) Q-band HYSCORE of ${ }^{13} \mathrm{C}$-enriched [4][BAr $\left.{ }_{4}{ }^{\mathrm{F}}\right]$ collected at $1241 \mathrm{mT}(\mathrm{g}=2.963)$. (Bottom) Monochromatic representations of the HYSCORE data (grey), with ${ }^{13} \mathrm{C}$ simulation using parameters in Table 4 overlaid in red. Acquisition parameters: temperature $=25 \mathrm{~K} ; \mathrm{MW}$ frequency $=34.089 \mathrm{GHz}$; MW pulse length $(\pi / 2$, $\pi)=12 \mathrm{~ns}, 24 \mathrm{~ns} ; \tau=100 \mathrm{~ns}, \mathrm{t}_{1}=\mathrm{t}_{2}=100 \mathrm{~ns} ; \Delta \mathrm{t}_{1}=\Delta \mathrm{t}_{2}=8 \mathrm{~ns}$; shot repetition time $(\mathrm{srt})=1 \mathrm{~ms}$. 


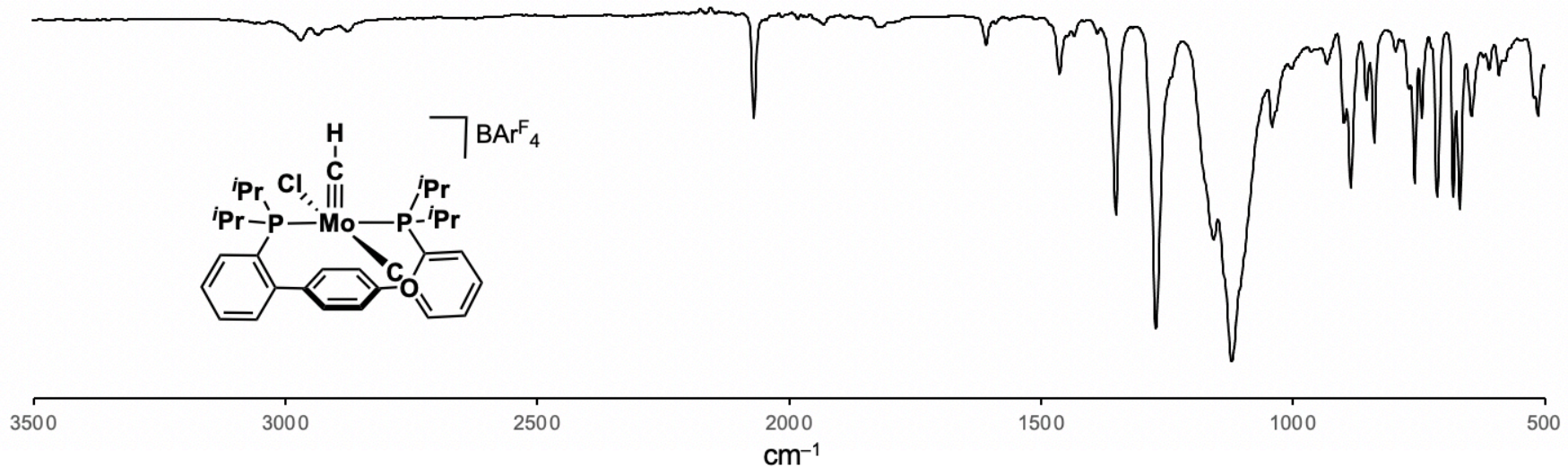

Figure S33-ATR-IR spectrum of [2][BAr $\left.{ }_{4}^{\mathrm{F}}\right]$.

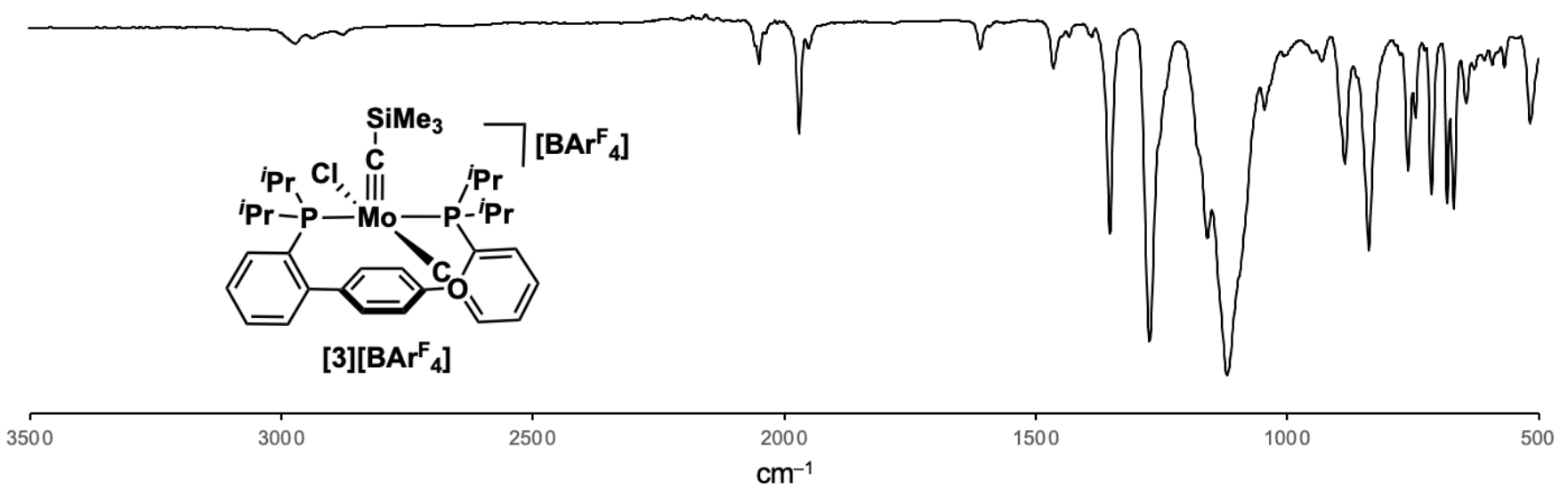

Figure S34-ATR-IR spectrum of [3][BAr $\left.{ }_{4}{ }_{4}\right]$. 

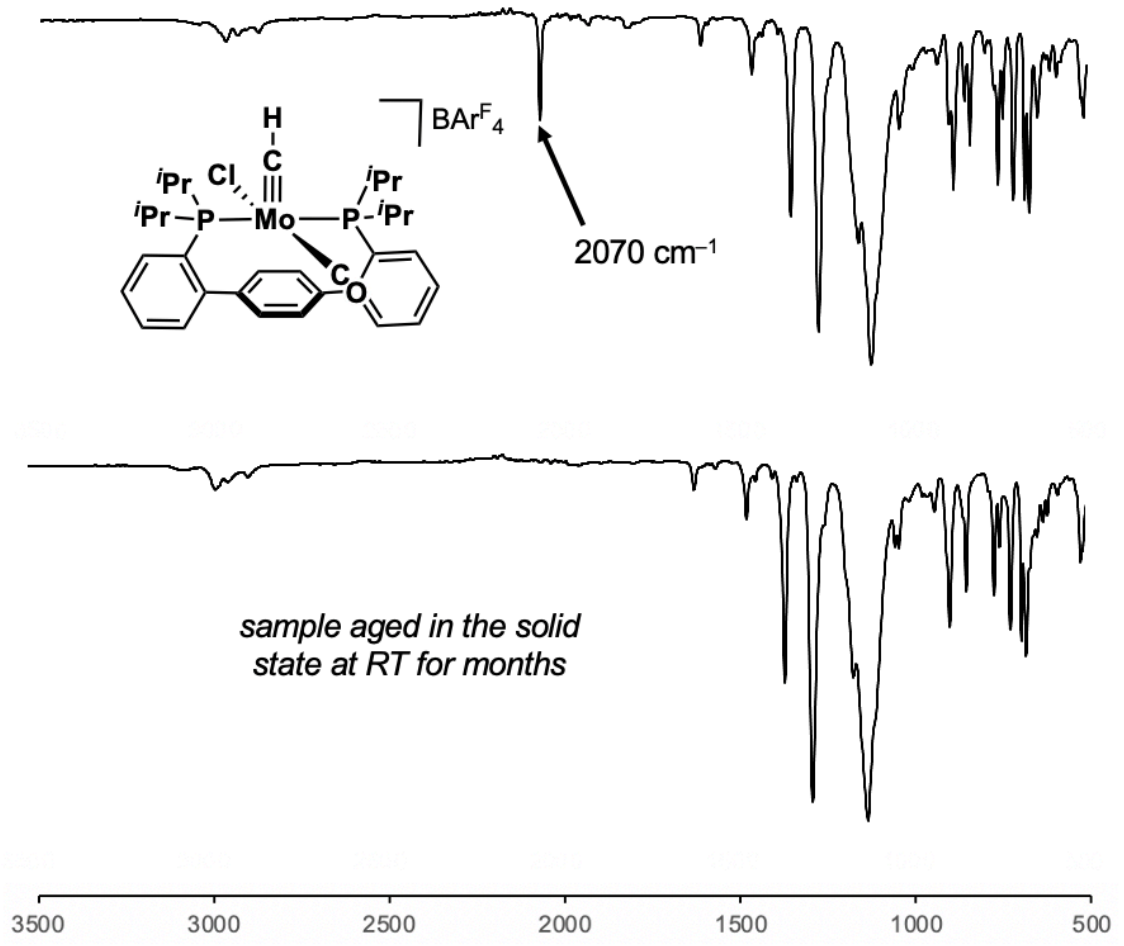

Figure S35-ATR-IR spectra of freshly-prepared [2][BAr $\left.{ }^{\mathrm{F}}{ }_{4}\right]$ (top) and a sample aged at RT in the solid state for a period of months (bottom) showing loss of CO. An accompanying color change from green to purple is observed. 


\section{COMPUTATIONAL DETAILS}

\section{General methods.}

Calculations were performed using an unrestricted Kohn-Sham approach to density functional theory (DFT) as implemented in ORCA, version $4.02,{ }^{8}$ Geometry optimizations and electronic structure calculations were performed using the revised BP86 functional and def2-TZVP basis set on all atoms. ${ }^{9}$ Optimizations were performed ignoring molecular symmetry, starting from crystallographic coordinates, but using a truncated ligand model with $\mathrm{PMe}_{2}$ substituents used in place of $\mathrm{P}^{i} \mathrm{Pr}_{2}$. Frequency calculations were performed on optimized geometries to ensure true minima with real vibrational modes. Molecular orbitals were visualized using UCSF Chimera. ${ }^{11}$ Löwdin spin populations were calculated in ORCA, using the Grid5 and Finalgrid6 specifications.

\section{DFT-optimized structures and spin density plots}

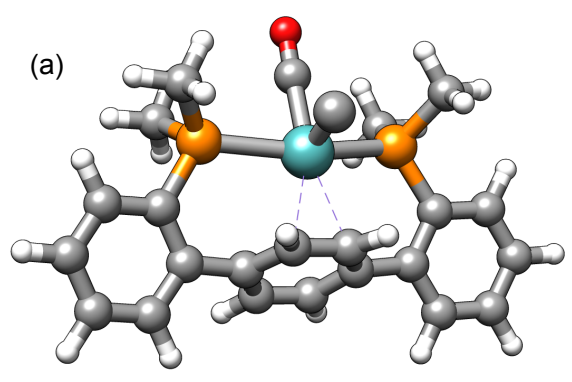

$[1]\left[\mathrm{BArF}_{4}\right]$

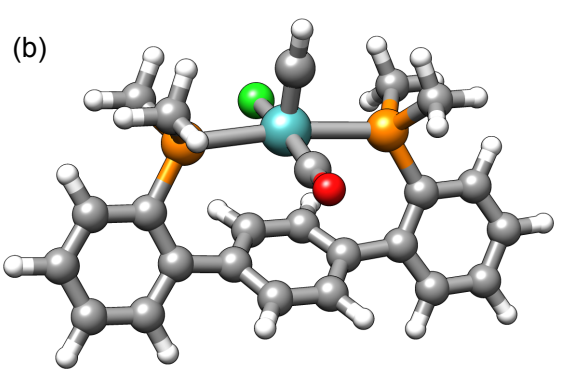

[2][BArF $\left.{ }_{4}\right]$

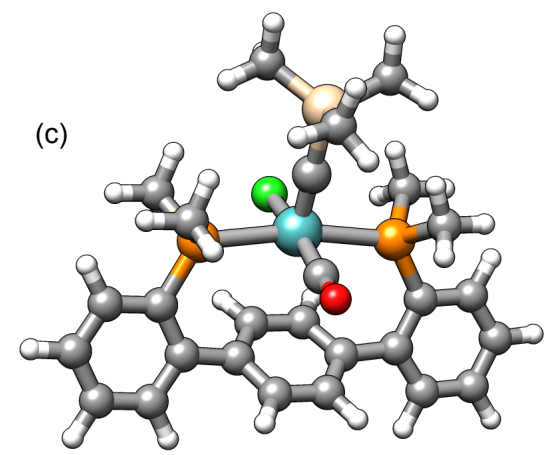

[3][BArF $\left.{ }_{4}\right]$

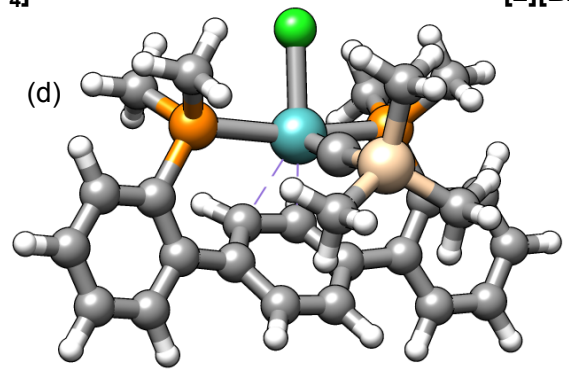

[4] $\left[\mathrm{BArF}_{4}{ }_{4}\right]$

(e)

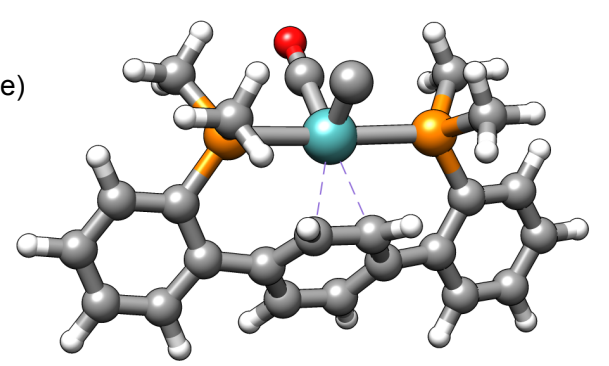

[K][1]

Figure S36-DFT-optimized structures for open-shell carbide and carbyne complexes studied (BP86/def2TZVP). Atom colors: Grey: C; Light cyan: Mo; Orange: P; Red: O; Light green: Cl; Tan: Si. 


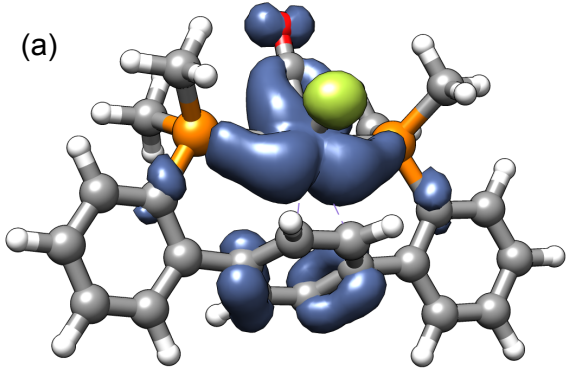

[1][BArF $\left.{ }_{4}\right]$ (b)

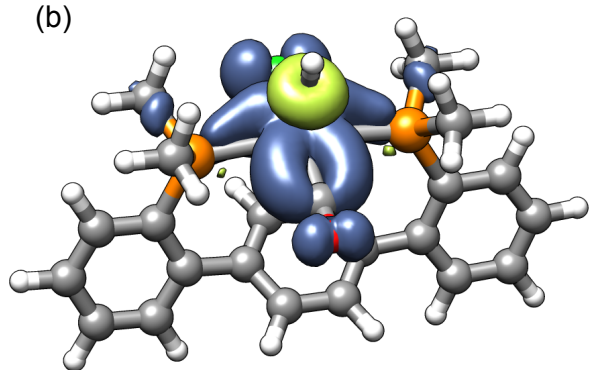

[2] BAArF $\left._{4}\right]$

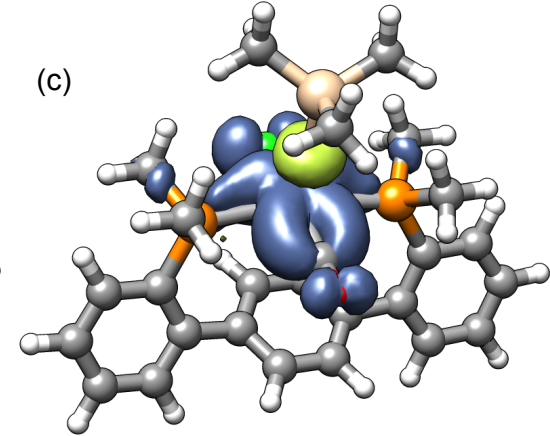

[3][BArF $\left.{ }_{4}\right]$
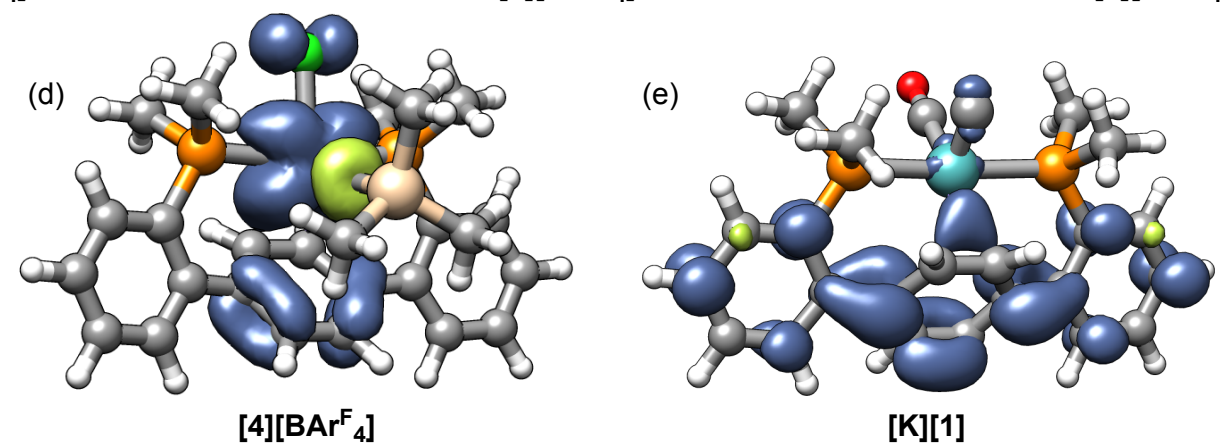

[K][1]

Figure S37-DFT-calculated spin density plots (BP86/def2-TZVP) for open-shell carbide and carbyne complexes studied. Isosurfaces shown at the $0.0016 \mathrm{e}^{-} \AA^{-3}$ level. Atom colors: Grey: C; Light cyan: Mo; Orange: P; Red: O; Light green: Cl; Tan: Si. 

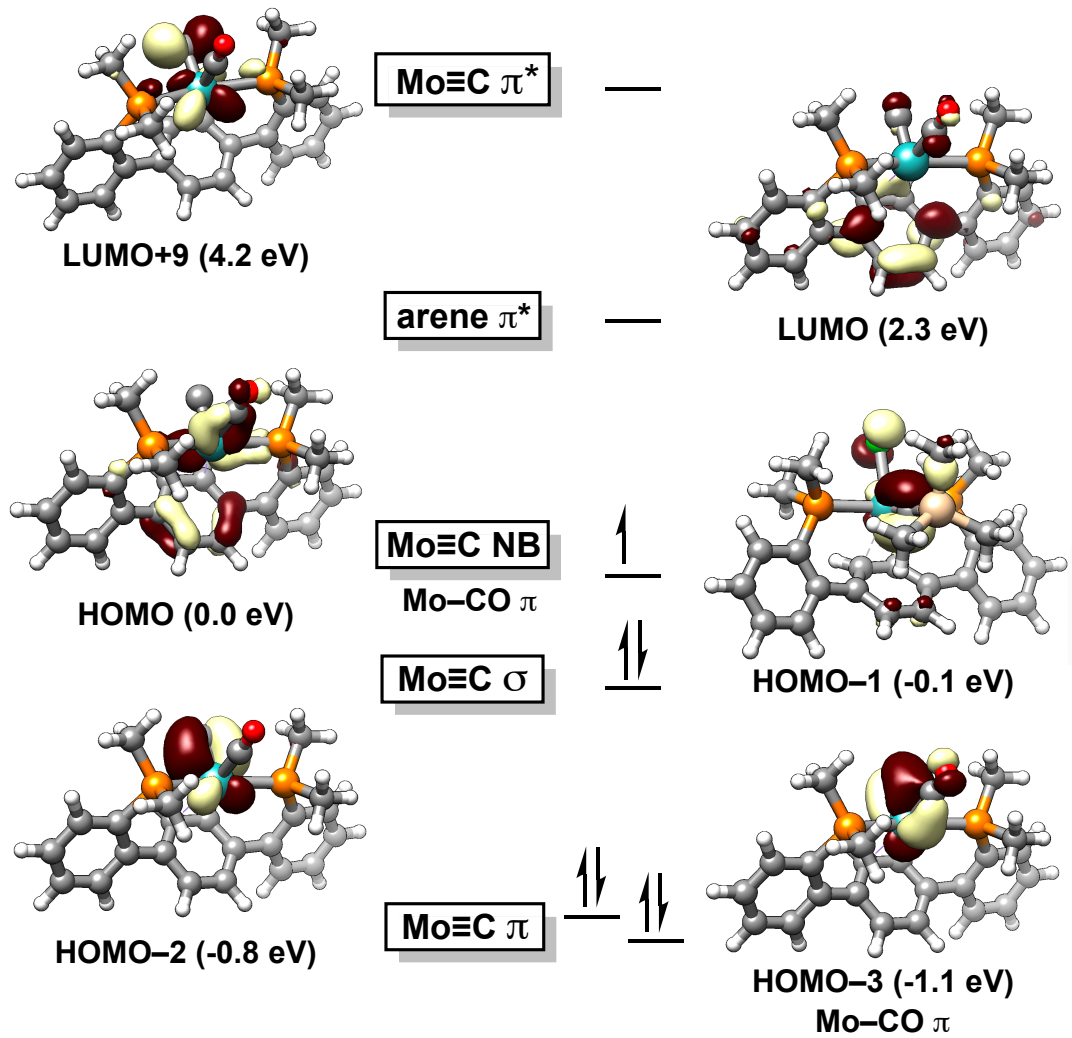

Figure S38 - Qualitative MO diagram for [1] $\left[\mathbf{B A r}^{\mathrm{F}}{ }_{4}\right]$ depicting the bonding interactions of Mo with the carbide ligand. Calculated $\alpha$-molecular orbitals are depicted with isosurfaces at the $0.05 \mathrm{e}^{-} \AA^{-3}$ level; the corresponding $\beta$ molecular orbitals are depicted in Figure S39. Orbital energies relative to the HOMO are given in eV. 

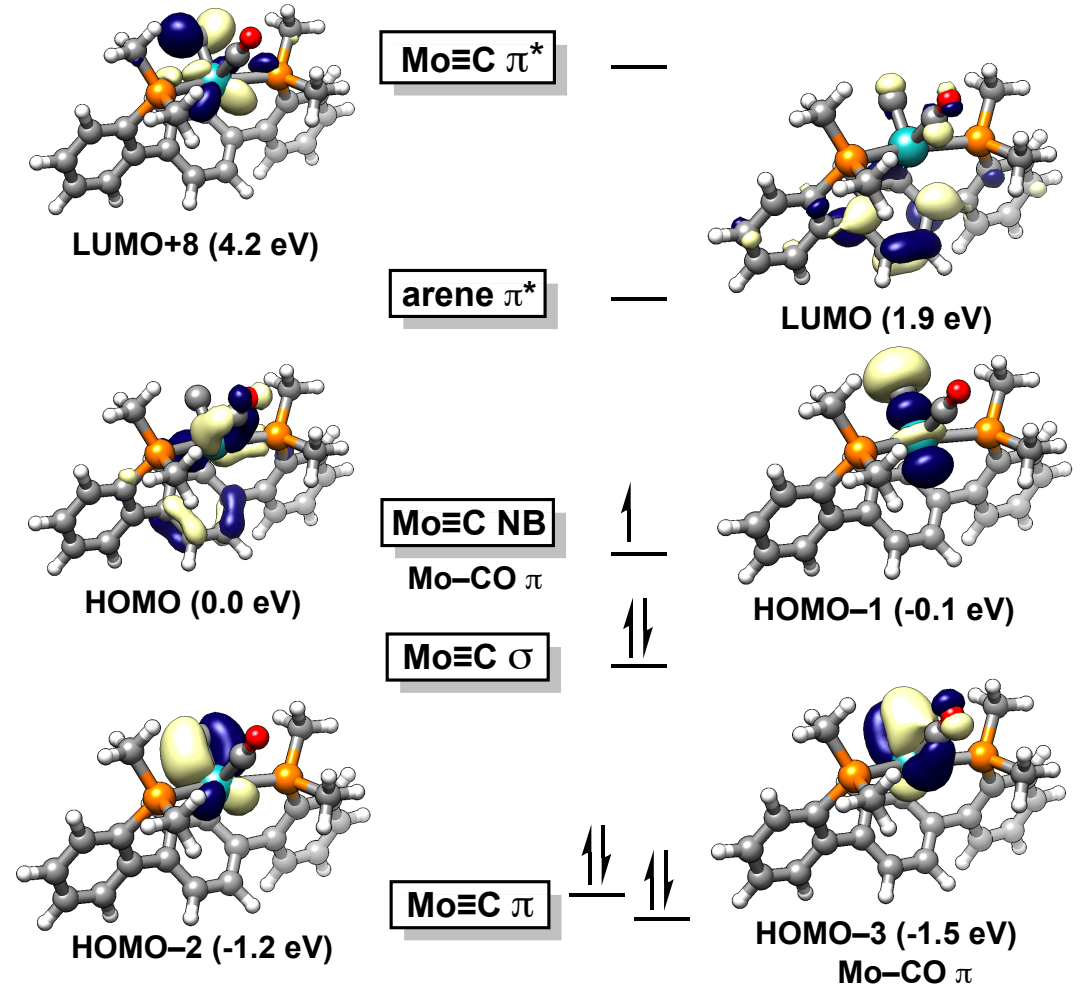

Figure S39-Qualitative MO diagram for [1][BA $\mathbf{B r}^{\mathbf{F}}$ ] depicting only the $\beta$-molecular orbitals with isosurfaces at the $0.05 \mathrm{e}^{-} \AA^{-3}$ level. Orbital energies relative to the $\mathrm{HOMO}$ are given in $\mathrm{eV}$. 

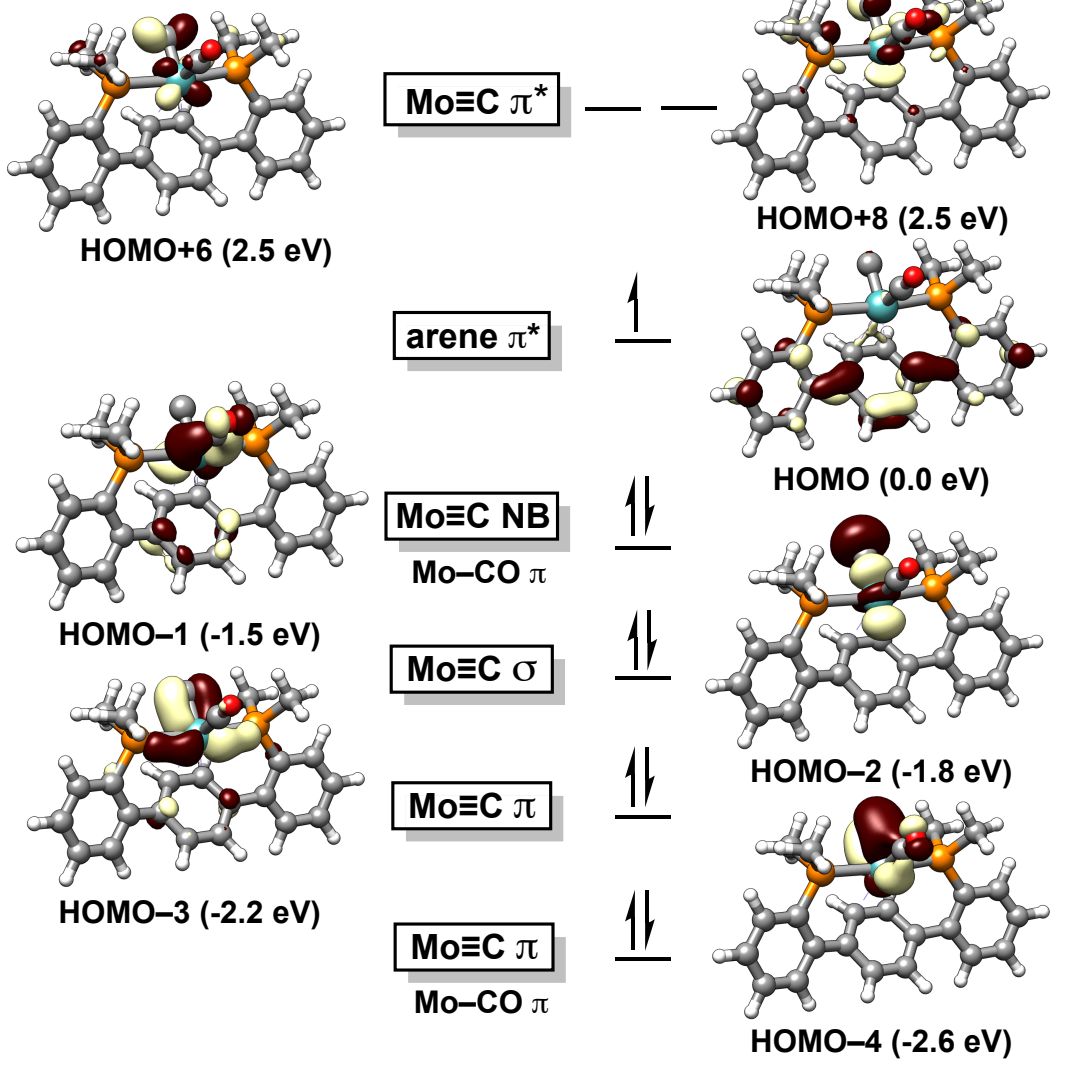

Figure S40 - Qualitative MO diagram for [K][1] depicting the bonding interactions of Mo with the carbide ligand. Calculated $\alpha$-molecular orbitals are depicted with isosurfaces at the $0.05 \mathrm{e}^{-} \AA^{-3}$ level; the corresponding $\beta$ molecular orbitals are depicted in Figure S38. Orbital energies relative to the HOMO are given in eV. 

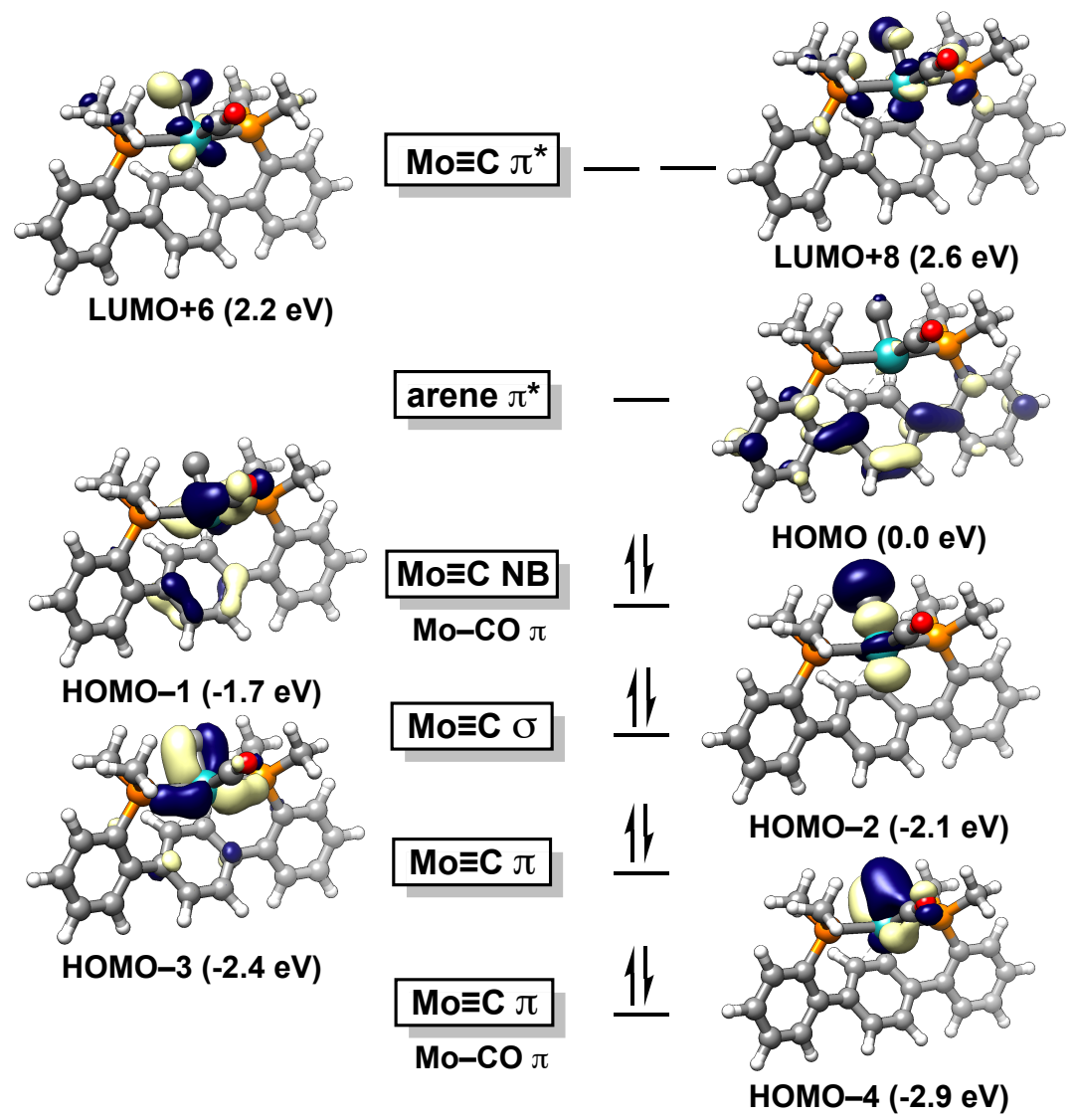

Figure S41-Qualitative MO diagram for [K][1] depicting only the $\beta$-molecular orbitals with isosurfaces at the $0.05 \mathrm{e}^{-} \AA^{-3}$ level. Orbital energies relative to the HOMO are given in $\mathrm{eV}$. 

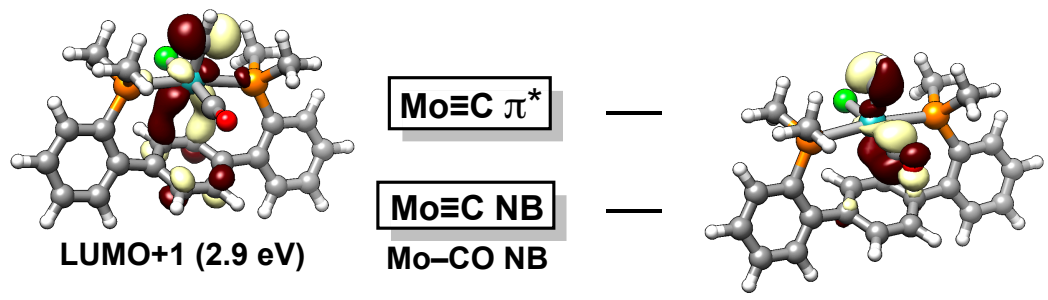

LUMO (2.8 eV)
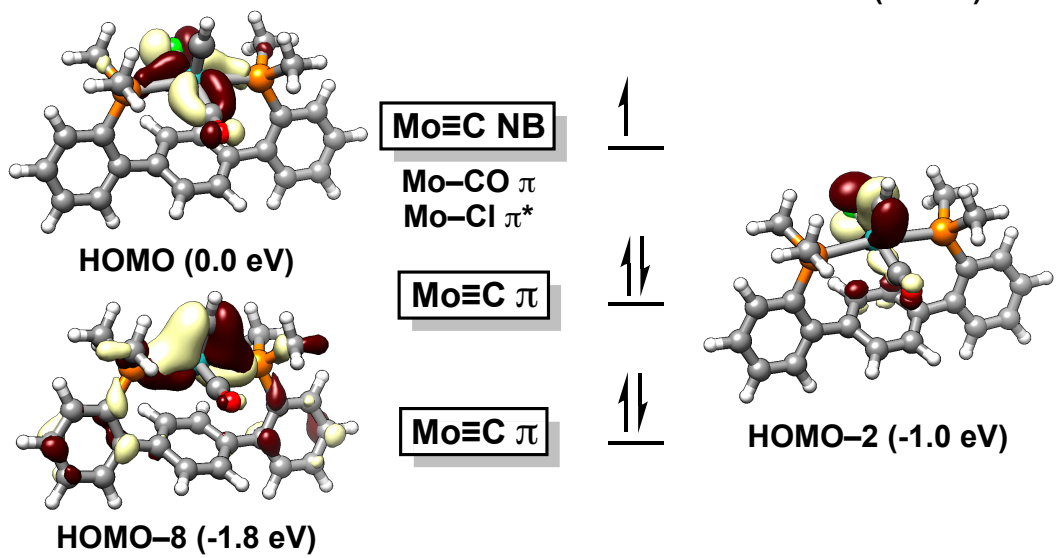

Figure S42-Qualitative MO diagram for $[2]\left[\mathbf{B A r}^{\mathrm{F}}{ }_{4}\right]$ depicting the bonding interactions of Mo with the carbide ligand. Calculated $\alpha$-molecular orbitals are depicted with isosurfaces at the $0.05 \mathrm{e}^{-} \AA^{-3}$ level; the corresponding $\beta$ molecular orbitals are depicted in Figure S40. Orbital energies relative to the HOMO are given in eV.
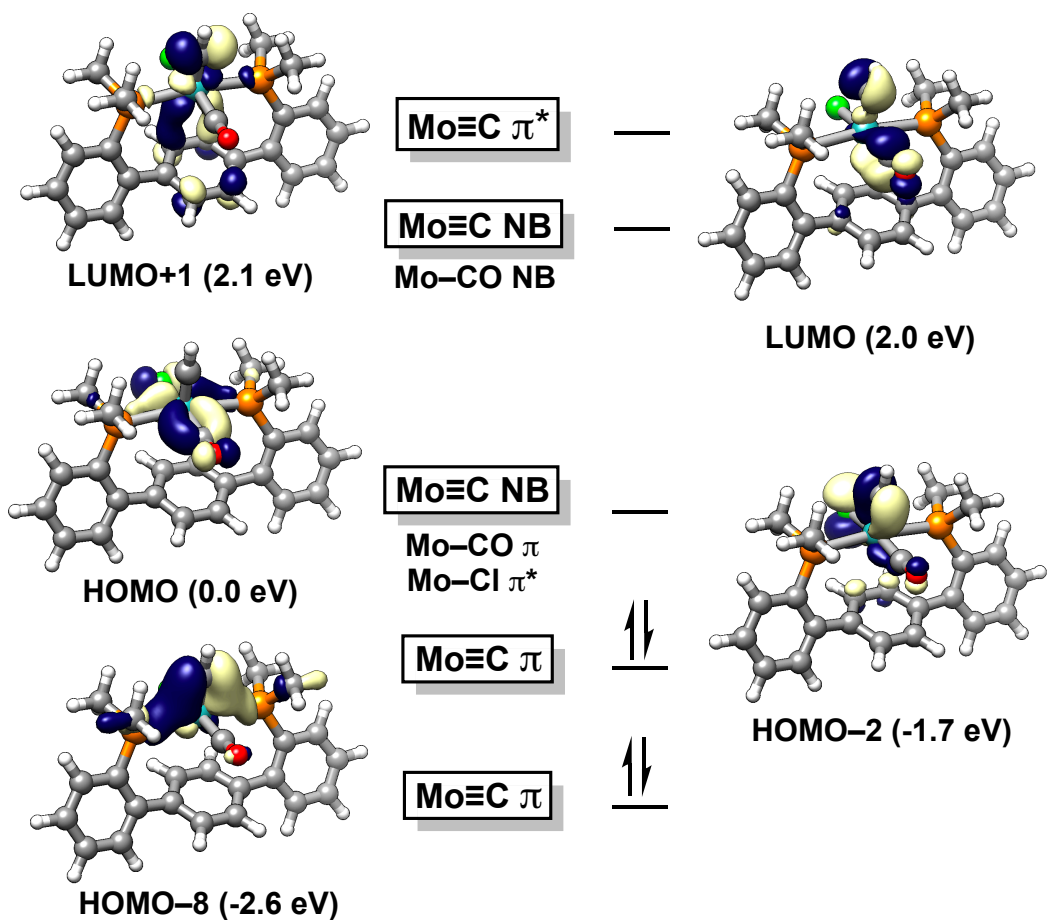

MoEC $\pi \quad 1$

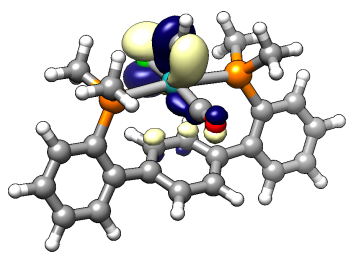

HOMO-2 (-1.7 eV)

MoEC $\pi \quad$ 1t

Figure S43 - Qualitative MO diagram for [2] $\left[\mathbf{B A r}^{\mathbf{F}}{ }_{4}\right]$ depicting only the corresponding $\beta$-molecular orbitals with isosurfaces at the $0.05 \mathrm{e}^{-} \AA^{-3}$ level. Orbital energies relative to the HOMO are given in $\mathrm{eV}$. 

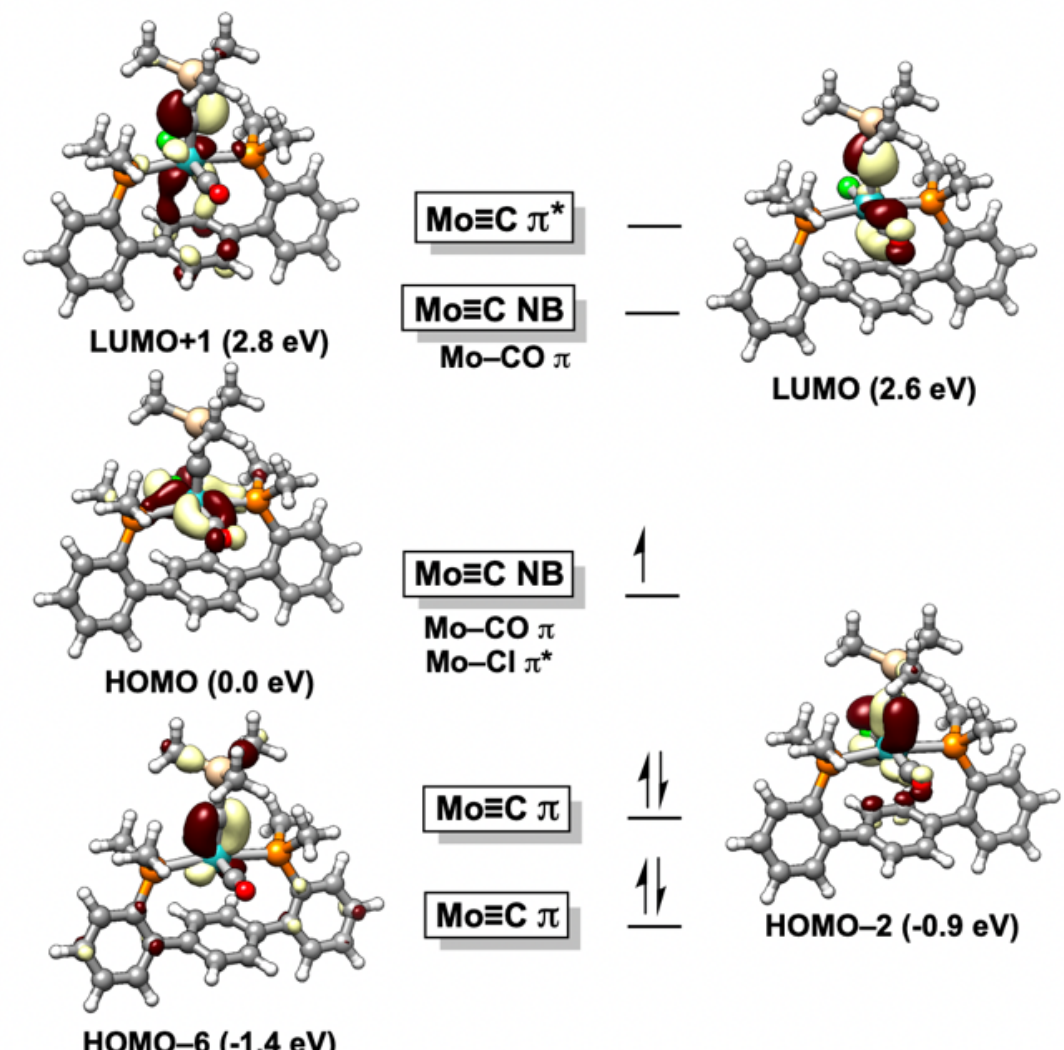

Figure S44-Qualitative MO diagram for [3][BAr $\left.{ }^{\mathrm{F}}{ }_{4}\right]$ depicting the bonding interactions of Mo with the carbide ligand. Calculated $\alpha$-molecular orbitals are depicted with isosurfaces at the $0.05 \mathrm{e}^{-} \AA^{-3}$ level; the corresponding $\beta$ molecular orbitals are depicted in Figure S42. Orbital energies relative to the HOMO are given in eV. 


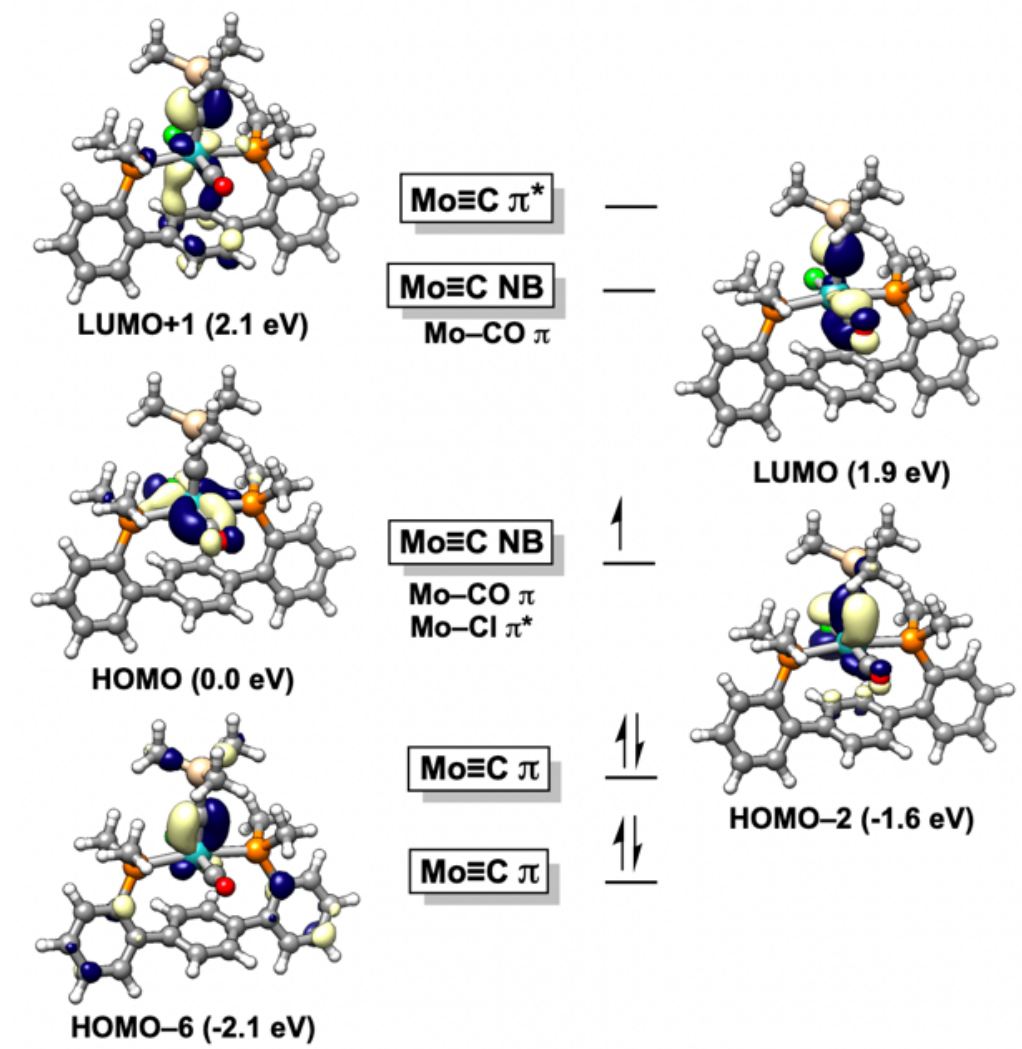

Figure S45-Qualitative MO diagram for [3] $\left[\mathbf{B A A r}^{\mathrm{F}}{ }_{4}\right]$ depicting only the corresponding $\beta$-molecular orbitals with isosurfaces at the $0.05 \mathrm{e}^{-} \AA^{-3}$ level. Orbital energies relative to the HOMO are given in $\mathrm{eV}$. 

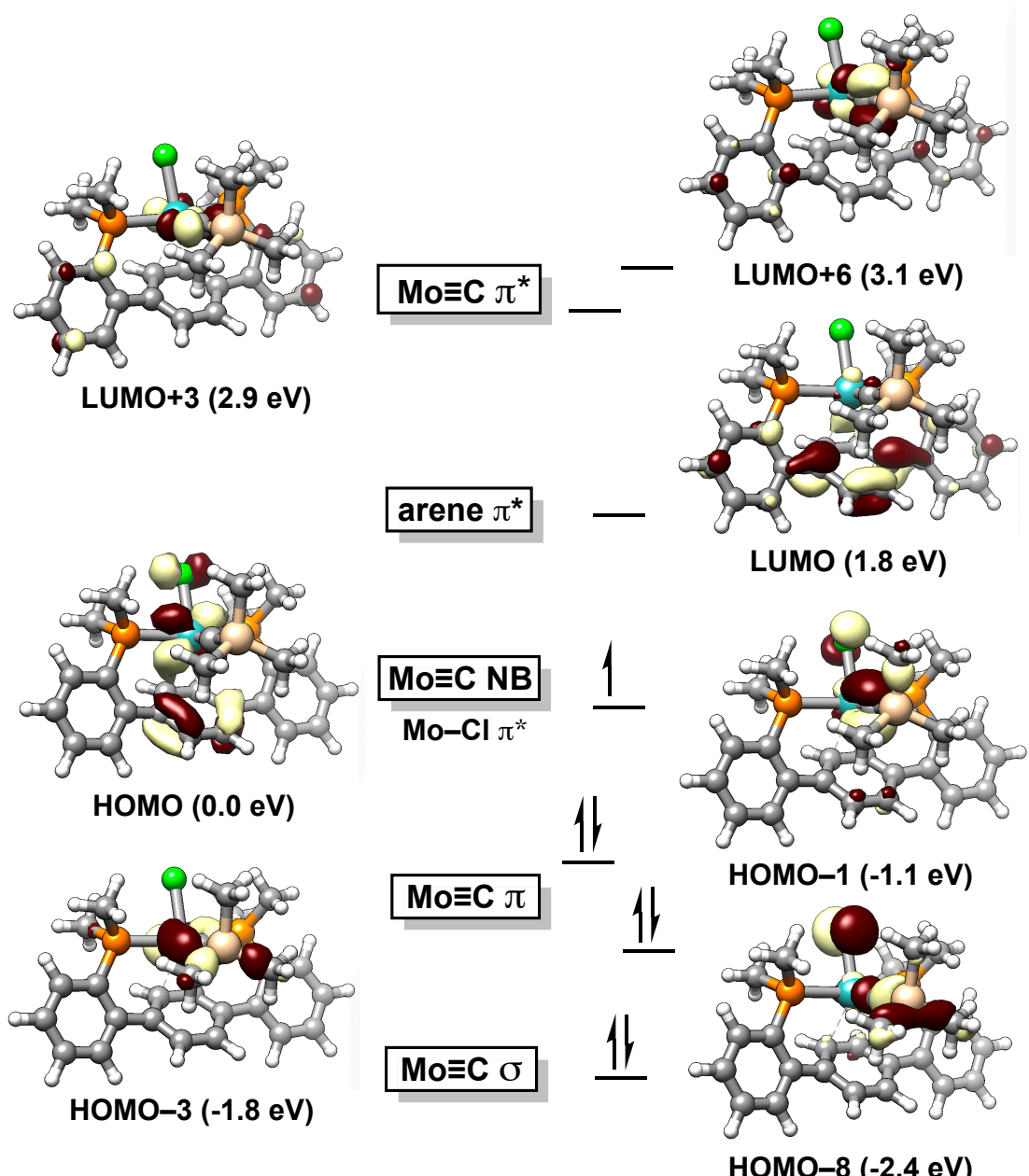

Figure S46-Qualitative MO diagram for $[4]\left[\mathbf{B A r}^{\mathrm{F}}{ }_{4}\right]$ depicting the bonding interactions of Mo with the carbide ligand. Calculated $\alpha$-molecular orbitals are depicted with isosurfaces at the $0.05 \mathrm{e}^{-} \AA^{-3}$ level; the corresponding $\beta$ molecular orbitals are depicted in Figure S44. Orbital energies relative to the HOMO are given in eV. 

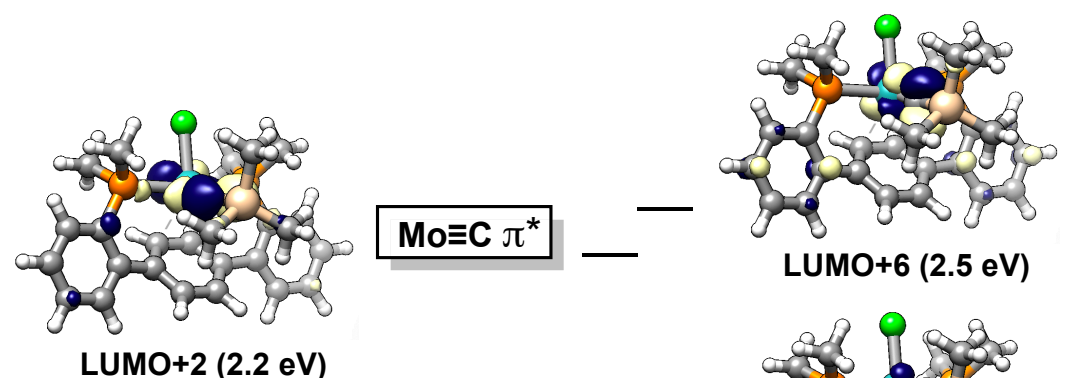

LUMO+2 (2.2 eV)
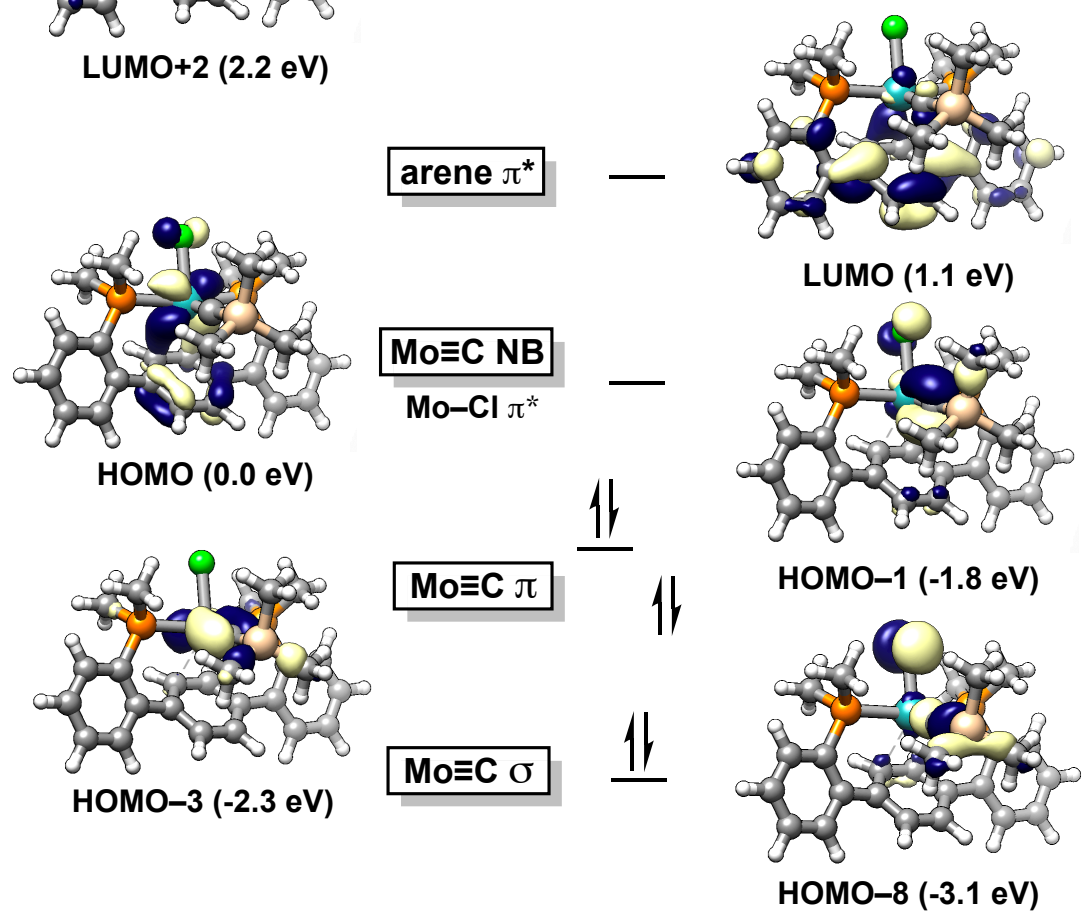

Figure S47-Qualitative MO diagram for $[4]\left[\mathbf{B A r}^{\mathbf{F}}\right.$ ] depicting only the $\beta$-molecular orbitals with isosurfaces at the $0.05 \mathrm{e}^{-} \AA^{-3}$ level. Orbital energies relative to the $\mathrm{HOMO}$ are given in $\mathrm{eV}$.

Expectation values of total spin, $<S^{2}>$

Table S3-Expectation values of total spin for open-shell carbide and carbyne complexes

\begin{tabular}{|c|c|}
\hline Complex & $\left\langle\mathbf{S}^{2}>\right.$ \\
\hline$[\mathbf{K}][1]$ & 0.7530 \\
\hline$[\mathbf{1}]\left[\mathbf{B A r}^{\mathbf{F}}{ }_{4}\right]$ & 0.7554 \\
\hline$[\mathbf{2}]\left[\mathbf{B A r}^{\mathbf{F}}{ }_{4}\right]$ & 0.7570 \\
\hline$[3]\left[\mathbf{B A r}^{\mathbf{F}}{ }_{4}\right]$ & 0.7564 \\
\hline$[4]\left[\mathbf{B A r}^{\mathbf{F}}{ }_{4}\right]$ & 0.7579 \\
\hline
\end{tabular}




\section{Cartesian Coordinates of DFT-Optimized Structures}

\section{Calculated Structure: [1][BAr ${ }^{\mathrm{F}}$ ]}

Mo 0.00001743813280

P $\quad-2.51773659219082$

P 2.51774034742371

C -3.51440704042076

C 1.41780031431000

C 3.51439856192696

C 5.69536007101099

H 6.78232843198124

C 0.69991544051734

H 1.24239501173389

C -4.91576150764980

H $\quad-5.41543726038117$

C -0.69988759914915

H -1.24234315594327

C 0.70580740893464

H 1.25105094358853

C -0.70583793130957

H $\quad-1.25110304629099$

C 5.08097672854068

H 5.68458434644806

C -2.89313352316078

C 3.69041100886086

H 3.20772269107611

C 4.91575337784793

H 5.41542500703603

C 2.89313105432118

C -1.41780280626993

C -3.69041025888180

H -3.20771918368253

C -5.08097691550460

H $\quad-5.68458300244220$

C -5.69536461331641

H -6.78233372799711

C -0.00005792007105

O -0.00001806200272

C -0.00003946006206

C -2.94805323807756

H -2.51632352482430

H -2.53743645675450

H -4.03773163419380

C -3.33941808357302

H -4.39965366416030

H -3.23759053348184

H -2.82277906934086

C 2.94811875040138

H 2.53749688191648

H 2.51640400373489

H 4.03779835194348
$-0.88841210000712$

$-1.11773516046169$

$-1.11778388118129$

0.43568674384183

1.82984107395487

0.43564988179348

1.51936718886674

1.44234771938675

2.40424825621979

2.79657369440234

0.36427865672700

$-0.60225871576593$

2.40426889044632

2.79661814359745

1.36860088194162

1.13699588045506

1.36858987858003

1.13699230975781

2.76594004714128

3.67193302342694

1.70235530092801

2.85476959825933

3.83019081728063

0.36424401215173

$-0.60229192735439$

1.70231470060657

1.82986982795000

2.85481490254981

3.83023878548268

2.76598437979937

3.67198034847765

1.51940727229863

1.44238883228194

$-2.75774932949966$

$-3.85151486553281$

$-1.66569104611243$

$-1.73014255346946$

$-2.72864302893729$

$-1.05115000368486$

$-1.78604709650496$

$-2.30855979472108$

$-2.44974918348018$

$-1.95745594193907$

$-3.27346388299809$

$-1.73032772767518$

$-1.05141417108967$

$-2.72884867815224$

$-1.78623004787924$
$-0.44210506804316$

0.02139602368151

0.02120326770065

$-0.08474395960975$

$-0.00355095502626$

$-0.08486945252532$

$-0.05882096046152$

$-0.10025317833813$

1.05758618305267

1.91909374904148

$-0.13049726456972$

$-0.20868598671649$

1.05759480191662

1.91910686986288

$-1.14464606409361$

$-2.05974446488060$

$-1.14462278987071$

$-2.05971016883158$

0.08132328618393

0.14418772743829

0.02355811887099

0.12703970714169

0.20676189112242

$-0.13064562110839$

$-0.20887921224237$

0.02349818787285

$-0.00352313860906$

0.12706394861825

0.20673769264930

0.08137404806266

0.14421056744113

$-0.05870963596998$

$-0.10012423215962$

0.34022448151079

0.71430764892766

$-1.98490681479049$

1.70311955590140

1.85353959408360

2.46156395531816

1.82852467563785

$-1.10041797700403$

$-0.85253432959600$

$-2.13440572875493$

$-1.01628621417402$

1.70286275469889

2.46137516097157

1.85318941589346

1.82825590035645 
C 3.33939005734538

H 3.23753408213458

H 4.39963270662133

H 2.82274679334446
$-2.30851911485889$

$-1.95733737006840$

$-2.44972933329475$

$-3.27342609393697$
$-1.10072802495915$

$-2.13468657736406$

$-0.85288742045635$

$-1.01665397380183$

\section{Calculated Structure: [K][1]}

\begin{tabular}{|c|c|c|c|}
\hline Mo & -0.00003629215258 & -1.04337786968776 & 167640589675 \\
\hline $\mathrm{P}$ & -2.50731189042098 & -1.13059263454822 & 0.06862805422180 \\
\hline $\mathrm{P}$ & 2.50727783662627 & -1.13061289954719 & 0.06867092274614 \\
\hline $\mathrm{C}$ & -3.51923129472049 & 0.41406027032173 & 0.04469068199613 \\
\hline $\mathrm{C}$ & 1.44628999572063 & 1.83055181435173 & -0.23822483405061 \\
\hline $\mathrm{C}$ & 3.51921175996564 & 0.41402923158546 & 0.04452472862378 \\
\hline $\mathrm{C}$ & 5.69758542998512 & 1.49908452872376 & 0.35780268869294 \\
\hline $\mathrm{H}$ & 6.77827847224749 & 1.41645648896138 & 0.48726692984018 \\
\hline $\mathrm{C}$ & 0.69533013341955 & 2.85649681729346 & 0.38649406490847 \\
\hline $\mathrm{H}$ & 1.21901262076333 & 3.60051829312579 & 0.99108611372676 \\
\hline $\mathrm{C}$ & -4.90862693423098 & 0.35290052194690 & 0.22792646418654 \\
\hline $\mathrm{H}$ & -5.39828698020328 & -0.62261274294317 & 0.28762108777062 \\
\hline $\mathrm{C}$ & -0.69531222850531 & 2.85649994242127 & 0.38652295217978 \\
\hline $\mathrm{H}$ & -1.21895686012214 & 3.60052813128511 & 0.99114231905102 \\
\hline $\mathrm{C}$ & 0.70891359642577 & 0.88984835293688 & -1.06472121439350 \\
\hline $\mathrm{H}$ & 1.22776111871755 & 0.44347325778073 & -1.91670640493804 \\
\hline $\mathrm{C}$ & -0.70898390402044 & 5433523196 & -1.06469642633388 \\
\hline $\mathrm{H}$ & -1.22786455432356 & 4391 & -1.91670 \\
\hline $\mathrm{C}$ & 5.06586312871965 & 2.75669428 & 0.327861 \\
\hline $\mathrm{H}$ & 5.65779917943492 & 3.66987466 & 0.431904 \\
\hline $\mathrm{C}$ & -2.87287749950730 & 1.6959034 & 710700 \\
\hline $\mathrm{C}$ & 3.69523549844341 & 2.84685888456077 & 0.14486797859060 \\
\hline $\mathrm{H}$ & 3.22589483237133 & 3.83118072418866 & 0.08586483660373 \\
\hline $\mathrm{C}$ & 4.90862836801544 & 0.35286262186108 & 0.22757991250589 \\
\hline $\mathrm{H}$ & 5.39828839462082 & -0.62265397281224 & 0.287225 \\
\hline $\mathrm{C}$ & 2.87286133194087 & 1.69587473010828 & -0.03074455756695 \\
\hline $\mathrm{C}$ & -1.44631588163293 & 8345 & -0.23816142050015 \\
\hline $\mathrm{C}$ & -3.69522444476189 & 2.84689010984615 & 0.14511787148867 \\
\hline $\mathrm{H}$ & -3.22588153206885 & 3.83120831831311 & 0.08607624722142 \\
\hline $\mathrm{C}$ & -5.06582955697406 & 2.75673693888783 & 0.32827147818663 \\
\hline $\mathrm{H}$ & -5.65775618616999 & 3.66991310438782 & 0.43239813397511 \\
\hline $\mathrm{C}$ & -5.69755418953053 & 1.49912828458648 & 0.358280 \\
\hline $\mathrm{H}$ & -6.77823102198799 & 1.41649992145773 & 0.48788759756163 \\
\hline $\mathrm{C}$ & 0.00004384122309 & -1.97630071448498 & 1.97589442324425 \\
\hline $\mathrm{O}$ & 0.00036022172006 & -2.53039197753668 & 3.01209732533313 \\
\hline $\mathrm{C}$ & -0.00005888640397 & -2.53253852417444 & -0.69963447001772 \\
\hline $\mathrm{C}$ & -3.38878683376696 & -2.20141188693527 & 1.29642932533666 \\
\hline $\mathrm{H}$ & -2.85922189403748 & -3.16335760990584 & 1.32341177423193 \\
\hline $\mathrm{H}$ & -3.31786515860864 & -1.74143944186270 & 2.29064858773863 \\
\hline $\mathrm{H}$ & -4.44572779148357 & -2.37725896272336 & 1.04917366692139 \\
\hline $\mathrm{C}$ & -3.04008053274043 & -1.94977190019954 & -1.50204582450402 \\
\hline $\mathrm{H}$ & -4.13660850242662 & -2.01501304353120 & -1.57133682631970 \\
\hline $\mathrm{H}$ & -2.65882700768605 & -1.37814514127263 & -2.35804973997229 \\
\hline $\mathrm{H}$ & -2.57968432392243 & -2.94693926528762 & -1.53116277223858 \\
\hline $\mathrm{C}$ & 3.38874435797023 & -2.20125024572299 & 1.29666453863252 \\
\hline
\end{tabular}


H 3.31745638515228

H 2.85946028593647

H 4.44577879014436

C 3.04004636710776

H 2.65897472139027

H 4.13656488311434

H 2.57948063123279
$-1.74127399317656$

$-3.16335075838651$

$-2.37679638733818$

$-1.95001682706093$

$-1.37836757077265$

$-2.01546368503400$

$-2.94710720883211$
2.29085433188323

1.32360649556588

1.04964236614188

$-1.50190006638385$

$-2.35796978689903$

$-1.57108229244535$

$-1.53101819286322$

\section{Calculated Structure: [2][BAr ${ }^{\mathrm{F}}$ ]}

Mo -8.77154160712932

P $\quad-9.23978202926913$

P $\quad-8.62543017195726$

$\mathrm{Cl}-7.76039102955745$

O -10.45855828866222

C -11.10372178004900

H -10.56476817020421

C -11.69277110286931

C -11.39065371332634

C -10.07226047153406

C -10.93820083176521

H -10.27269008035340

C -12.43320547388886

H -13.44408912932232

C -11.01294507260442

H -10.12786981710594

C -12.19043312258001

H -13.01332038011134

C -9.84794630326008

H $\quad-8.84351205212773$

C -10.90401440339322

C -12.69315042488569

H -13.30417012443089

C -10.88898642155617

H -10.68279875400559

C -12.02867667062845

C -12.85867864734948

H -13.59664590705436

C -12.23961990460040

H -12.29119930900335

C -13.39501635382991

H -14.36071043094771

C -9.90746619234176

C -13.30827054155412

H -14.20457124622817

C -12.07505131552938

C -7.43765042722337

H $\quad-6.65216217654787$

C -8.83739941733815

H $\quad-9.50210906968787$

H $\quad-7.79993579960240$

H $\quad-8.95137743914507$
$-4.12209465050665$

$-2.58253583763355$

$-5.75526431502938$

$-2.36048494185357$

$-6.38968199406614$

$-2.65811464095054$

$-1.71028481022134$

$-4.69934975811303$

$-5.66384850576587$

$-6.13144268912542$

$-3.51137882365119$

$-3.21546346217704$

$-6.12503888086352$

$-5.75360765571477$

$-1.02190279621022$

$-0.78286003368218$

$-7.00537515975639$

$-7.33601652064120$

$-7.02172004249887$

$-7.39966461700125$

$-1.84646860327521$

$-4.93689553051760$

$-5.83791456845920$

$-7.44973484147286$

$-8.13222502036239$

$-2.96815665395654$

$-4.08379293328805$

$-4.33066441768621$

$-0.49745949956894$

0.14691205574396

$-0.80728819250817$

$-0.40536778404939$

$-5.55297829837180$

$-1.62250919622785$

$-1.84298860658502$

$-2.13970101480188$

$-4.92447317537160$

$-5.46577057218306$

$-3.42449481102350$

$-4.28549702854601$

$-3.78015262746286$

$-2.74243498707094$
$-3.67306011230283$

$-1.62701304372685$

$-5.69613081842209$

$-4.89489793398782$

$-2.16076656333711$

$-4.27436146754339$

$-4.24841912661586$

$-5.47864877241449$

$-6.55784640944108$

$-6.78839905183596$

$-5.37064688092094$

$-6.18245468704226$

$-7.38141769939640$

$-7.20561220865228$

$-0.15188678796414$

0.44001711928892

$-8.43261595924518$

$-9.06719526352048$

$-7.85478058373312$

$-8.05260916770380$

$-1.28689373799751$

$-4.52618444199732$

$-4.60157662401938$

$-8.67679011643327$

$-9.50180751009184$

$-3.25413949013569$

$-3.42998580234101$

$-2.66491822879631$

0.25166824660225

1.12973740642934

$-0.46937376097557$

$-0.16119189311502$

$-2.72968740950378$

$-1.59492379591396$

$-2.17696298743086$

$-2.03030537239879$

$-2.84612934167093$

$-2.30654486275222$

$-0.04412964571662$

0.10034113649528

$-0.08757728404702$

0.80831517784170 
C $\quad-8.06618975038291$

H -8.81179936072785

H $\quad-7.92027137660732$

H $\quad-7.11796452121445$

C -7.30875365210001

H -7.14628963112856

H -7.58916222417221

H $\quad-6.37942239649864$

C -8.09708986913585

$\mathrm{H} \quad-8.19399704528512$

$\mathrm{H} \quad-7.06784856336079$

H $\quad-8.31446000482522$
$-7.42588161485439$

$-7.87798067200959$

$-8.08394502585025$

$-7.32660703576841$

$-5.20323830478707$

$-5.94285590411737$

$-4.23985436122178$

$-5.06347935400683$

$-1.14583857090951$

$-0.55048262551263$

$-1.51589894317408$

$-0.51875114528085$
$-5.17418164910284$

$-4.50806858469482$

$-6.04048409371322$

$-4.63039189497834$

$-6.85008650793611$

$-7.64534734757431$

$-7.29223270005687$

$-6.28325173855738$

$-1.65081762908866$

$-0.73322493749468$

$-1.74150045510436$

$-2.52360670521277$

\section{Calculated Structure: [3][BAr ${ }_{4}$ ]}

Mo 2.60851649506000

Cl 0.70004192166491

P 3.16064184861737

P 2.45726041013319

Si 1.13619982467841

O 5.39408284089792

C 5.19149228464455

C 3.93700270271284

H 3.14112762719581

C 3.72662749200565

H 2.76824283652071

C 4.76460186562831

C 6.03901897534708

H 6.86120156387011

C 6.24962774118080

H 7.23419323868933

C 5.34602014977454

C 4.45728633950935

C 4.62656152602906

H 3.95741866198404

C 5.64729538361331

H 5.74664973563758

C 6.53964931924557

H 7.34500965133357

C 6.38688531627550

H 7.06177165407848

C 4.47452536279308

C 3.42094130265873

C 3.16115343725029

H 2.35957856392894

C 3.91826485580925

H 3.68585233102216

C 4.97373129700602

H 5.57616861727217

C 5.24620514789063

H $\quad 6.05037820950960$

C 4.42094512742063
7.54470446781656

6.87206099515831

9.46413970206901

5.45389636530909

9.79074644142336

8.22085901272985

7.00758121184514

6.36739550627589

6.67639109124008

5.27891618598765

4.75969852377983

4.80189940454306

5.37095233941570

5.00166762448197

6.45890475195613

6.92734095192556

8.24198467562090

9.33597723095772

10.46040449842014

11.31728787769187

10.52010653580023

11.40097863727761

9.45262533545198

9.48972801224541

8.32989969580675

7.48039736959580

3.74841966785492

3.89041338172805

2.83170880240551

2.91403237691103

1.66141518808839

0.85363063367930

1.53610060876062

0.62763373569857

2.57307856611590

2.46876368251487

7.94299904991578
8.62243118929533

9.86635826953570

10.30744579789129

7.06178895771662

6.12353442239806

7.18814987584953

10.97767744634288

10.92563731610637

11.60396905636991

10.07561338206411

10.09890506646339

9.25102989275331

9.38680821010442

8.77188401934755

10.23868423914080

10.27925326221191

11.77562076338737

11.62729272172370

12.45631750520035

12.36486618136030

13.40357956812472

14.03816065915243

13.52656558326268

14.26053589241411

12.71740361657067

12.83237819601208

8.25525484556465

7.31908676772212

6.42934498528043

5.69390252011231

6.45044894411899

5.75617730539416

7.35656759027000

7.37795341671388

8.24517787910452

8.97508163798799

7.74125088328492 


$\begin{array}{clc}\mathrm{C} & 1.94207888801728 & 8.64429500371951 \\ \mathrm{C} & 0.16058446177766 & 8.75367158353511 \\ \mathrm{H} & -0.44473277656645 & 9.43354380749272 \\ \mathrm{H} & -0.53321452576861 & 8.06004470489353 \\ \mathrm{H} & 0.80566604100299 & 8.18407192275546 \\ \mathrm{C} & -0.03456141907235 & 10.92936941412738 \\ \mathrm{H} & -0.49257880766542 & 11.64096153941620 \\ \mathrm{H} & 0.47918770939527 & 11.51641630378118 \\ \mathrm{H} & -0.84632926287102 & 10.36573513726726 \\ \mathrm{C} & 2.49155839349060 & 10.75567400641435 \\ \mathrm{H} & 3.29370326846450 & 10.10257114678642 \\ \mathrm{H} & 2.94288540478026 & 11.52589084087538 \\ \mathrm{H} & 2.05358881028428 & 11.26856890824892 \\ \mathrm{C} & 0.70874372997324 & 4.90368162293471 \\ \mathrm{H} & 0.37602232236621 & 4.56875457238423 \\ \mathrm{H} & 0.09025641840085 & 5.76009637107204 \\ \mathrm{H} & 0.58468091636859 & 4.09288665715493 \\ \mathrm{C} & 2.89098863091977 & 5.86531083057509 \\ \mathrm{H} & 3.95540009052189 & 6.12650808215101 \\ \mathrm{H} & 2.69950655652274 & 5.01559471344235 \\ \mathrm{H} & 2.29578222164848 & 6.72793155123800 \\ \mathrm{C} & 1.63768143292781 & 9.95052418473724 \\ \mathrm{H} & 0.86109414309341 & 10.20179849238060 \\ \mathrm{H} & 1.28039120887395 & 9.10318034250238 \\ \mathrm{H} & 1.82039964062659 & 10.81504844493069 \\ \mathrm{C} & 3.65797415892043 & 11.00702112315968 \\ \mathrm{H} & 3.76915081094601 & 11.84235214615144 \\ \mathrm{H} & 4.61539283678188 & 10.84655995886152 \\ \mathrm{H} & 2.89552703694962 & 11.25519644851204\end{array}$

Calculated Structure: [4][BAr ${ }^{\mathrm{F}_{4}}$ ]

Mo 1.71744658822197

P 1.48427289346082

P 1.44694411958341

Cl 0.99558985798024

Si 5.33781676494715

C 2.21674308871754

C 2.13585812523029

C 1.04484844658445

H 0.10803597580668

C 1.87126384046111

C 2.60406287939366

H 2.81714729290112

C 2.12239099667697

C 3.08833779336224

H 3.90407004335139

C 2.18910488382187

C 1.05184810714115

H $\quad 0.12066202224683$

C 1.90944848158789

C 3.08193389372173
9.89419534258960

11.41312239764665

8.18040135223116

8.16374634952699

9.69710948361188

13.75727492419220

12.95413359336090

11.13722018624602

10.65284160262216

8.73374894721636

15.10911675305713

15.54817235636844

11.13908127498279

13.04335993452106

13.76160277276951

10.08413964083624

12.03797688353150

12.22843716220107

13.19624532421571

12.15240335057412
7.40691169077059

4.88885136555889

4.26890211231196

5.38323663887097

4.20616210814036

7.06262813729096

6.35848934470628

7.83617355364283

7.54303438248716

5.24006986164210

4.87019752989317

5.88024081981796

4.36972606135383

6.95981040175842

7.94951101754310

6.66330208247609

6.23029025784467

5.32399970208363

5.26495727064571

4.65605258276189

5.00229734403232

11.21042882371551

10.47676654045447

11.80752929097269

11.86207607760447

9.44009205978070

10.14312935864973

8.92816245085506

8.69183326598090
11.72367451772919

9.67240217100304

13.60847422174878

10.29525158771680

11.59963687673973

11.15842883465578

12.39096791006492

13.65880682739701

13.94394838950410

15.31771008628831

11.22871428242313

12.20452334805653

14.59859500372550

13.41224772045646

13.32020701213499

15.62490539988928

12.56256144184722

12.02379487900574

9.88981235462993

14.49540823782558 


\begin{tabular}{|c|c|c|c|}
\hline & 333190970959 & 19579015873568 & \\
\hline & & & \\
\hline & 79439177938318 & & \\
\hline & 2.67313088625532 & & \\
\hline & 2.9609650703 & & \\
\hline & 36115242225550 & 9797119831 & \\
\hline & 89 & & \\
\hline & & & \\
\hline & & & \\
\hline & & & \\
\hline & & & \\
\hline & & & \\
\hline & 76 & & \\
\hline & & & \\
\hline & & & \\
\hline & & & \\
\hline & & & \\
\hline & & & \\
\hline & & & \\
\hline & & & \\
\hline & & & \\
\hline & & & \\
\hline & & & \\
\hline & & & \\
\hline & & & \\
\hline & & & \\
\hline & & & 13. \\
\hline & & & \\
\hline & & & \\
\hline & & & \\
\hline & & & \\
\hline & 206 & 132 & 79 \\
\hline & & & \\
\hline & & & \\
\hline & & & \\
\hline & & & \\
\hline & & & 15 \\
\hline & 3.47 & & 13.4 \\
\hline & & & \\
\hline & & & \\
\hline & & & \\
\hline & 9614 & 19 & \\
\hline & 705 & 984 & 14.5 \\
\hline & 966761736452 & 8.40822360663682 & 13. \\
\hline
\end{tabular}




\section{CRYSTALLOGRAPHIC INFORMATION}

Supplementary crystallographic data for this paper can be obtained free of charge from the Cambridge Crystallographic Data Centre via www.ccdc.cam.ac.uk/data_request/cif(deposition numbers listed in Table S3 below).

\section{Crystallographic and refinement Details}

Crystals were mounted on a MiTeGen loop using Paratone oil, and then placed on the diffractometer under a nitrogen stream. Low-temperature diffraction data ( $\phi$-and $\omega$-scans) were collected on a Bruker AXS KAPPA APEX II diffractometer coupled to an PHOTON 100 CMOS detector with graphite monochromated Mo $K_{\alpha}$ radiation $(\lambda=0.71073 \AA)$ for the structure of [K][1] and on a Bruker AXS D8 VENTURE KAPPA diffractometer coupled to a PHOTON II CPAD detector with Mo $K_{\alpha}$ radiation $(\lambda=0.71073 \AA)$

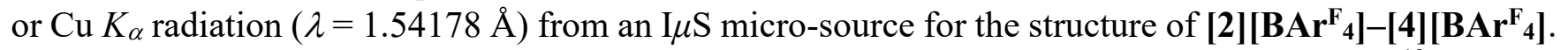
Data collection, integration, and scaling were carried out using the Bruker APEXIII software. ${ }^{12}$ Absorption corrections were applied using SADABS. ${ }^{13}$ Space groups were determined on the basis of systematic absences and intensity statistics. Structures were solved in the Olex ${ }^{2}$ software interface ${ }^{14}$ by intrinsic phasing using SHELXT (incorporated into SHELXTL) ${ }^{15}$ and refined to convergence. Unless otherwise indicated, all hydrogen atoms were included into the model at geometrically calculated positions and refined using a riding model. Graphical representations of structures were generated using the Diamond 3 visualization software. ${ }^{16}$

Details for [K][1]: Brown, single crystalline blocks of [K][1] $(0.40 \mathrm{x} 0.35 \mathrm{x} 0.15 \mathrm{~mm})$ were grown by slow mixing of pentane layered onto a 2-MeTHF solution at $-40{ }^{\circ} \mathrm{C}$. [K][1] crystallized in the monoclinic space group $C 2 / c$ with two molecules in the asymmetric unit along with two molecules of 2-MeTHF. One $\mathrm{K}^{+}$ cation was encapsulated by a crown ether that was disordered over two positions (87:13 ratio) and a molecule of 2-MeTHF that had a single atom disordered over two positions (82:18 ratio). The other $\mathrm{K}^{+}$cation was encapsulated by a non-disordered crown ether and a molecule of 2-MeTHF that was disordered over two positions (62:38 ratio). The remaining two molecules of free (unbound) 2-MeTHF were disordered over two or three positions, respectively (63:36 or 48:32:20 ratios). Disordered atoms were refined with the help of similarity restraints on the 1,2- and 1,3-distances and displacement parameters (SIMU command in $\mathrm{Olex}^{2}$ ) as well as enhanced rigid bond restraints for anisotropic displacement parameters (RIGU). Additionally, the sum of the occupation factors for the triply-disordered 2-MeTHF molecule was confined to unity using the SUMP command.

Details for [2][BAr $\left.{ }_{4}{ }_{4}\right]$ : Dichroic yellow-green, single-crystalline blocks of [2][BAr ${ }^{\mathbf{F}}$ ] $(0.16 \times 0.1 \times 0.09$ $\mathrm{mm}$ ) were grown by vapor diffusion of hexanes into solutions in THF at $-40^{\circ} \mathrm{C}$. [2][BAr $\mathbf{r}_{4}{ }_{4}$ crystallized in the monoclinic space group $\underline{P} 2_{1}$ with one molecule in the asymmetric unit. All hydrogen atoms were included into the model at geometrically calculated positions and refined using a riding model, except the methylidyne $\mathrm{H}$ atom, which was located in the electron difference density map and refined freely.

Details for [3][BAr ${ }^{\mathbf{F}_{4}}$ ]: Small brown, single-crystalline blades of [3][BA $\mathbf{r}^{\left.\mathbf{F}_{4}\right]}(0.25 \times 0.06 \times 0.02 \mathrm{~mm})$ were grown via vapor diffusion of pentane into a saturated ether solution of [3] $\left[\mathbf{B A} \mathbf{r}^{\mathbf{F}}{ }_{4}\right]$ at $-40{ }^{\circ} \mathrm{C}$. The crystals were unstable to degradation under the collection conditions, preventing collection of a full dataset. Even after refining to convergence, and despite the presence of high-angle data $\left(d_{\min } 0.79\right)$, the dataset was of insufficient quality to allow for refinement of a high-quality structure. The refined model is nevertheless 
of sufficient quality to confirm the atom connectivity of [3][BArr ${ }_{4}{ }_{4}$, though it should be considered unreliable for the inference of bond metrics.

[3][BAr ${ }^{\mathrm{F}}$ ] crystallized in the triclinic space group $\underline{P} \overline{1}$ with four molecules in the asymmetric unit. Two of the four $\left[\mathrm{BAr}_{4}\right]^{-}$counterions were refined with the help of similarity restraints on several of the anisotropic displacement parameters for the arene carbon atoms, as executed by the SIMU command in Olex $^{2}$.

Details for [4][BAr ${ }^{\mathrm{F}_{4}}$ ]: Single crystalline red blocks of [4][BAr $\left.{ }_{4}{ }_{4}\right](0.24 \times 0.15 \times 0.09 \mathrm{~mm})$ were grown via vapor diffusion of pentane into a saturated diethyl ether solution of $[4]\left[\mathbf{B A r}^{\mathrm{F}}\right]$ at $-40^{\circ} \mathrm{C}$. [4][BAr$\left.{ }^{\mathrm{F}}{ }_{4}\right]$ crystallized in the triclinic space group $P_{c}$ with two molecules in the asymmetric unit. The crystal used for [4] $\left[\mathbf{B A r}^{\mathrm{F}}{ }_{4}\right]$ was twinned. The twin components were separated and assigned using Olex ${ }^{2}$. The crystal structure for $[4]\left[\mathbf{B A r}^{\mathrm{F}}{ }_{4}\right]$ was refined with racemic twinning as applied using a TWIN law with a batch scale factor (BASF) of 0.48 .

One of the two molecules of [4][BAr $\left.\mathbf{B}_{4}\right]$ in the asymmetric unit is disordered with the $\mathrm{Mo}(\mathrm{IV})$ carbyne $[\mathrm{P} 2 \mathrm{Mo}(\equiv \mathrm{CSiMe})(\mathrm{CO})]\left[\mathrm{BAr}_{4}{ }_{4}\right]$, which has an identical structure except that a $\mathrm{CO}$ ligand replaces the $\mathrm{Cl}$ ligand in $[4]\left[\mathbf{B A r} \mathbf{r}_{4}{ }_{4}\right.$. The disordered groups were satisfactorily modelled in a 60:40 ratio and refined with the help of similarity restraints for the CO atoms, as executed by the SIMU command in Olex². Over the two molecules in the asymmetric unit (one of which exhibits no disorder), the total carbonyl ligand occupancy is $80 \%$; thus, the total ratio of $[4]\left[\mathrm{BAr}_{4}{ }_{4}\right]:\left[\mathrm{P} 2 \mathrm{Mo}\left(\equiv \mathrm{CSiMe}_{3}\right)(\mathrm{CO})\right]\left[\mathrm{BAr}^{\mathrm{F}} 4\right]$ in the crystal is $80: 20$.

Details for $[\mathbf{K}][\mathbf{6}]$ : Single crystalline brown blocks of $[\mathbf{K}][\mathbf{6}]$ were grown via vapor diffusion of pentane into the reaction mixture in THF at $-40^{\circ} \mathrm{C}$. $[\mathbf{K}][6]$ crystallized in the orthorhombic space group $\mathrm{C} 222_{1}$.

Details for $[\mathbf{K}]_{6}[\mathbf{1}]_{2}[\mathbf{5}]$ : Crystalline brown blocks of $[\mathbf{K}]_{6}[\mathbf{1}]_{2}[\mathbf{5}]$ were grown via layering of pentane into the reaction mixture in THF at $-40^{\circ} \mathrm{C}$. The space group identified was $P_{\overline{1}}$. Unfortunately, crystals grown by this method were reproducibly polycrystalline. While analysis of data subsets enabled determination of atom connectivity, the overall quality was insufficient for reliable determination of bond metrics. 
Table S4-Crystal and refinement data for open-shell carbide and carbyne complexes.

\begin{tabular}{|c|c|c|c|c|}
\hline & {$[\mathbf{K}][1]$} & {$[2]\left[\mathrm{BAr}^{\mathrm{F}}\right]$} & {$[3]\left[\mathrm{BAr}^{\left.\mathrm{F}_{4}\right]}\right.$} & {$[4]\left[\mathrm{BAr}^{\mathrm{F}}\right]$} \\
\hline CCDC Number & 2076055 & 2076057 & 2076058 & 2076060 \\
\hline Empirical formula & $\mathrm{C}_{108} \mathrm{H}_{168} \mathrm{~K}_{2} \mathrm{Mo}_{2} \mathrm{O}_{18} \mathrm{P}_{4}$ & $\mathrm{C}_{64} \mathrm{H}_{53} \mathrm{BClF}_{24} \mathrm{MoOP}_{2}$ & $\mathrm{C}_{67} \mathrm{H}_{61} \mathrm{BClF}_{24} \mathrm{MoOP}_{2} \mathrm{Si}$ & $\mathrm{C}_{66.2 .} \mathrm{H}_{61} \mathrm{BCl}_{0.8} \mathrm{O}_{0.2} \mathrm{P}_{2} \mathrm{Si}$ \\
\hline Formula weight & 2148.37 & 1498.20 & 1570.38 & 1540.90 \\
\hline $\mathbf{T}(\mathbf{K})$ & 100 & 100 & 100 & 100 \\
\hline$a, \AA$ & $33.715(7)$ & $12.3780(18)$ & $17.5768(17)$ & $18.608(4)$ \\
\hline$b, \AA$ & $13.023(3)$ & $17.656(3)$ & $21.819(4)$ & $18.995(7)$ \\
\hline$c, \AA$ & $52.537(12)$ & $14.650(2)$ & $35.488(4)$ & $19.316(5)$ \\
\hline$\alpha,{ }^{\circ}$ & 90 & 90 & $88.536(7)$ & 90 \\
\hline$\beta, \circ$ & $107.154(10)$ & $92.396(1)$ & $89.560(6)$ & $101.144(9)$ \\
\hline$\gamma, \circ$ & 90 & 90 & $89.499(11)$ & 90 \\
\hline Volume, $\AA^{3}$ & 22041(8) & 3198.9(9) & $13604(3)$ & $6699(3)$ \\
\hline $\mathbf{Z}$ & 8 & 2 & 8 & 4 \\
\hline Crystal system & monoclinic & monoclinic & triclinic & monoclinic \\
\hline Space group & $\underline{C} 2 / \mathrm{c}$ & $P 2_{1}$ & $P \overline{1}$ & $P_{c}$ \\
\hline$d_{\text {calc }}, \mathrm{g} / \mathrm{cm}^{3}$ & $\overline{1.295}$ & 1.555 & 1.533 & 1.528 \\
\hline $2 \theta$ range, $^{\circ}$ & 1.622 to 59.808 & 4.614 to 74.508 & 4.052 to 152.062 & 4.564 to to 73.654 \\
\hline$\mu, \mathbf{m m}^{-1}$ & 0.424 & 0.409 & 3.524 & 0.402 \\
\hline GooF & 1.357 & 1.067 & 1.092 & 1.045 \\
\hline$R_{1},{ }^{a} w_{R_{2}}^{b}[\mathrm{I}>2 \sigma(\mathrm{I})]$ & $0.0955,0.1862$ & $0.0382,0.0871$ & $0.1431,0.3113$ & $0.0615,0.1565$ \\
\hline Radiation Type & Mo-K $\alpha$ & Mo-K $\alpha$ & $\mathrm{Cu}-\mathrm{K}_{\alpha}$ & Mo-K $\alpha$ \\
\hline
\end{tabular}

$\underline{\text { Table S5-Crystal and refinement data for } \mathrm{C}-\mathrm{C} \text { coupled products. }}$

\begin{tabular}{|c|c|c|}
\hline & {$[\mathrm{K}][6]$} & {$[\mathrm{K}]_{6}[1]_{2}[5]$} \\
\hline CCDC Number & 2091130 & N/A \\
\hline Empirical formula & $\mathrm{C}_{36} \mathrm{H}_{48} \mathrm{~K}_{0.5} \mathrm{MoO}_{2} \mathrm{P}_{2}$ & $\mathrm{C}_{39.5} \mathrm{~K}_{1.5} \mathrm{MoO}_{2.5} \mathrm{P}_{2}$ \\
\hline Formula weight & 690.99 & 731.92 \\
\hline $\mathbf{T}(\mathbf{K})$ & 100 & 100 \\
\hline$a, \AA$ & $13.232(3)$ & $17.757(5)$ \\
\hline$b, \AA$ & $24.039(6)$ & $20.221(5)$ \\
\hline$c, \AA$ & $22.7625(14)$ & $25.354(6)$ \\
\hline$\alpha,{ }^{\circ}$ & 90 & $99.024(18)$ \\
\hline$\beta,^{\circ}$ & 90 & $103.06(2)$ \\
\hline$\gamma, \circ$ & 90 & $100.688(18)$ \\
\hline Volume, $\AA^{3}$ & $7240(3)$ & $8524(4)$ \\
\hline $\mathbf{Z}$ & 8 & 8 \\
\hline Crystal system & orthorhombic & triclinic \\
\hline Space group & $\underline{C} 222_{1}$ & P-1 \\
\hline$d_{\text {calc }}, \mathbf{g} / \mathbf{c m}^{3}$ & 1.268 & 1.141 \\
\hline $2 \theta$ range, $^{\circ}$ & 7.354 to 161.902 & 4.546 to 146.004 \\
\hline$\mu, \mathrm{mm}^{-1}$ & 4.348 & 4.770 \\
\hline GooF & 1.275 & 1.083 \\
\hline$R_{1},{ }^{a} w R_{2}^{b}{ }^{b}[\mathrm{I}>2 \sigma(\mathrm{I})]$ & $0.0388,0.1338$ & $0.1264,0.3081$ \\
\hline Radiation Type & $\mathrm{Cu}-\mathrm{K}_{\alpha}$ & $\mathrm{Cu}-\mathrm{K}_{\alpha}$ \\
\hline
\end{tabular}




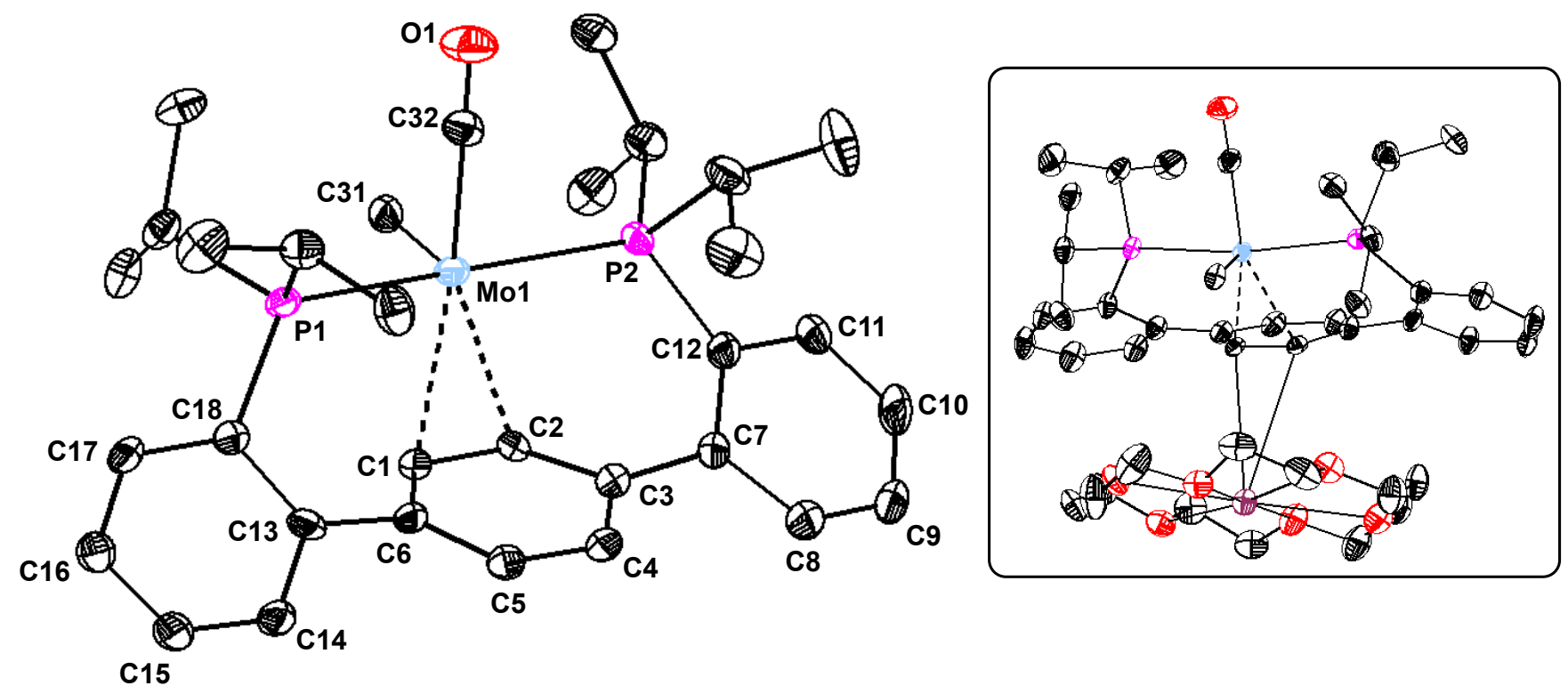

Figure S48 - Structural drawing of [K(18-crown-6)][1] with anisotropic displacement ellipsoids shown at the 50\% probability level. Hydrogen atoms, encapsulated $\mathrm{K}^{+}$counterion, and 2-MeTHF solvate molecules are omitted for clarity. Inset, right: Complete structure of [K(18-crown-6)][1] showing arene binding to encapsulated $\mathrm{K}^{+}$cation. A disordered 2-MeTHF solvates bound to the $\mathrm{K}^{+}$cation is omitted for clarity.

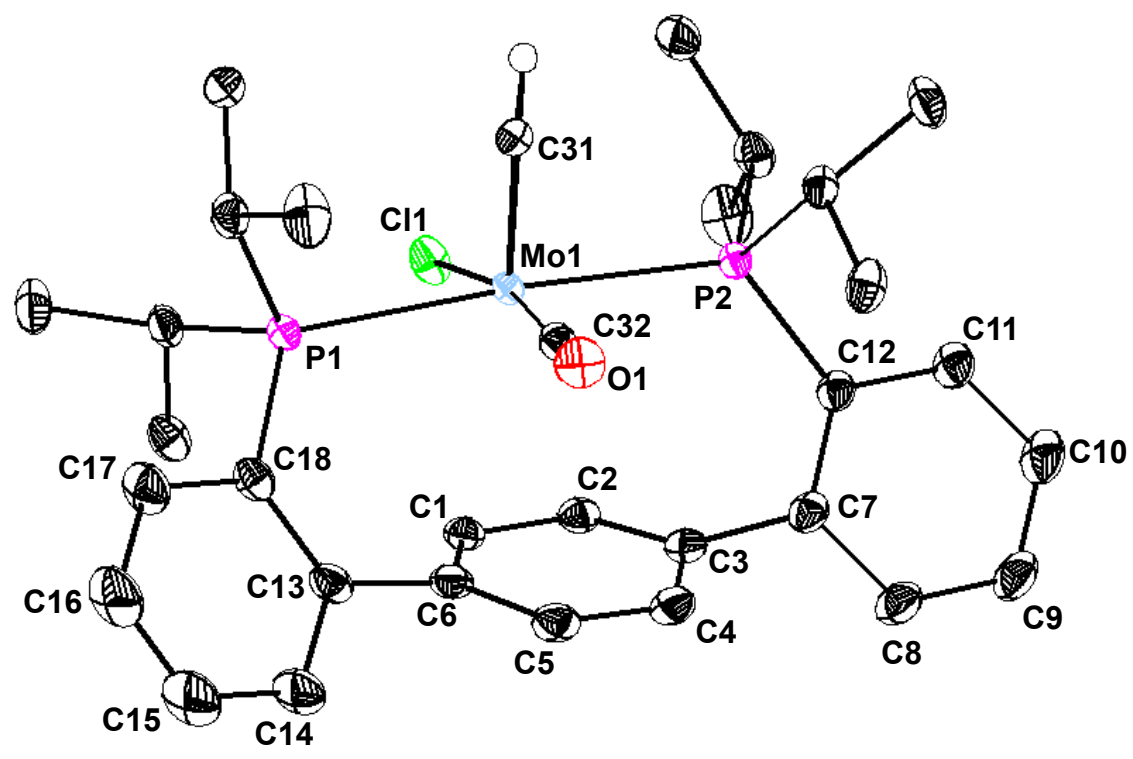

Figure S49-Structural drawing of $[2]\left[\mathbf{B A r}^{\mathrm{F}}{ }_{4}\right]$ with anisotropic displacement ellipsoids shown at the $50 \%$ probability level. Hydrogen atoms and $\left[\mathrm{BAr}^{\mathrm{F}}{ }_{4}\right]^{-}$counterion are omitted for clarity, except the methylidyne $\mathrm{H}$ atom (H31), which was located in the electron density map and refined freely. 


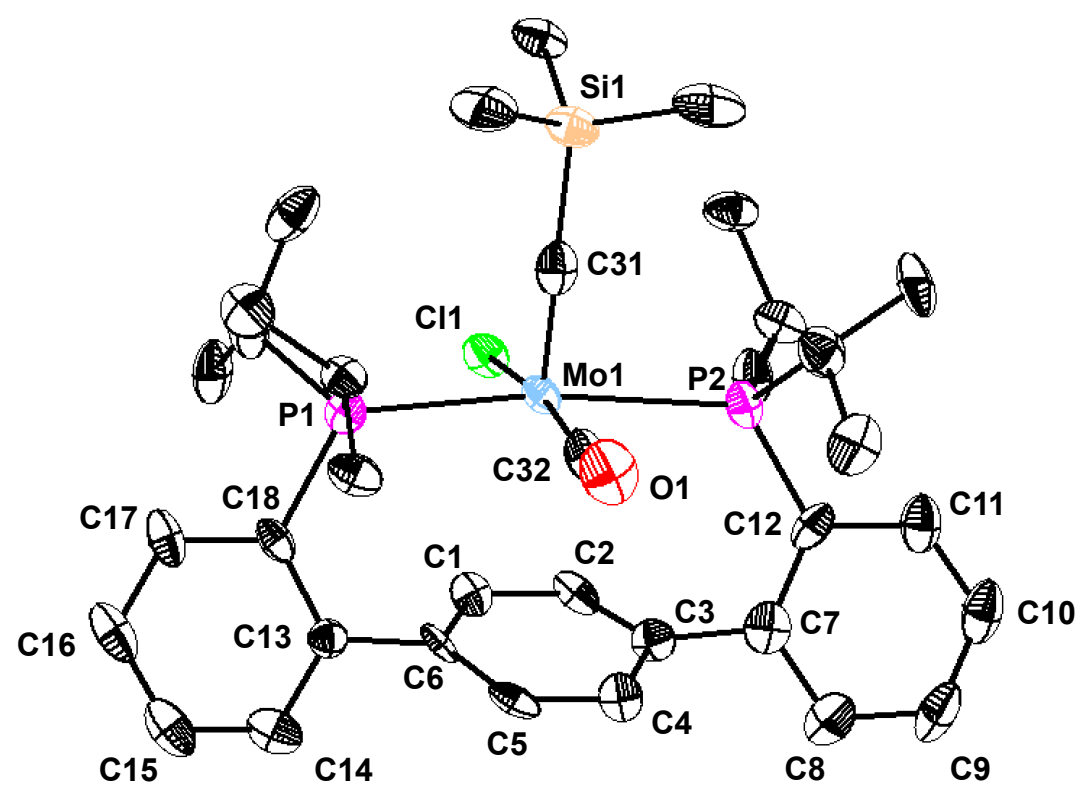

Figure S50-Structural drawing of $[3]^{+}$with anisotropic displacement ellipsoids shown at the $50 \%$ probability level. Hydrogen atoms and $\left[\mathrm{BAr}^{\mathrm{F}}{ }_{4}\right]^{-}$counterion are omitted for clarity.

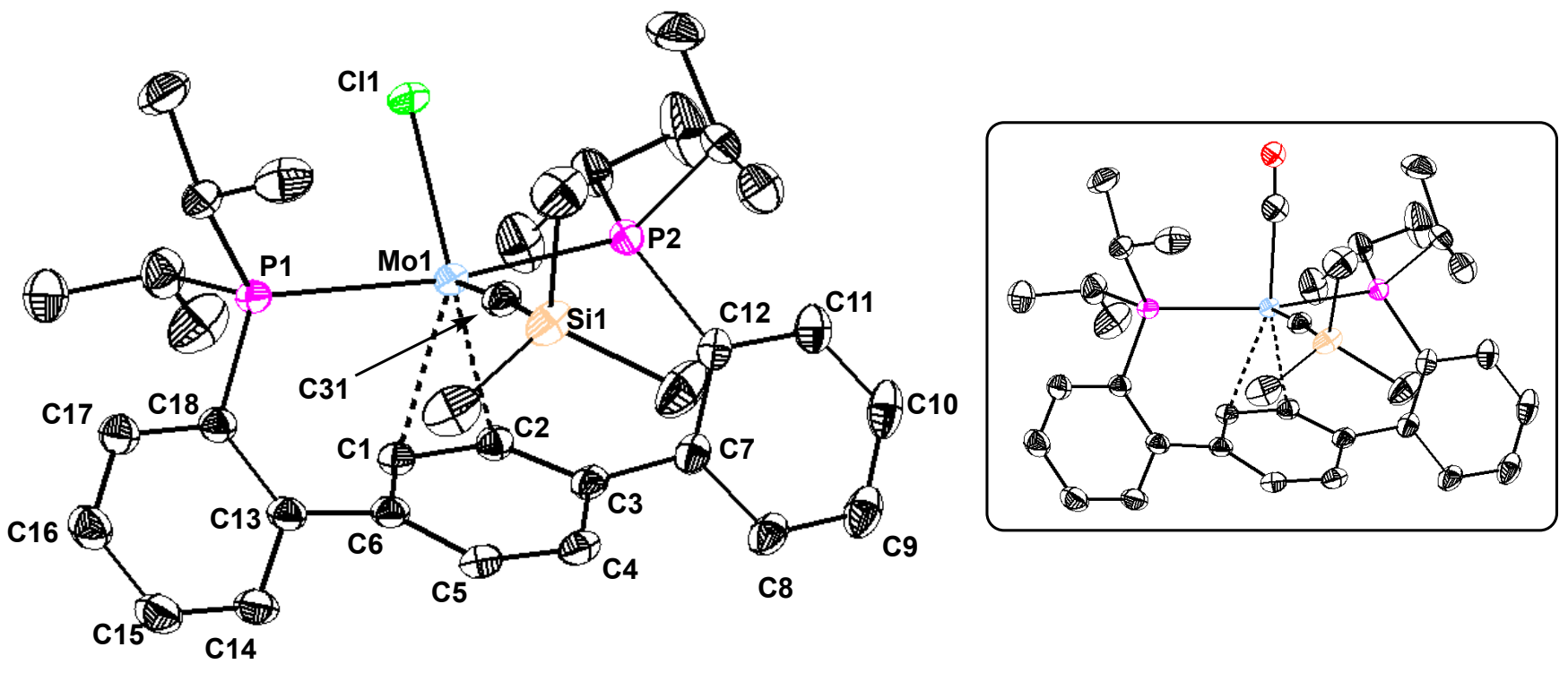

Figure S51-Structural drawing of [4][BAr $\left.{ }^{\mathrm{F}}{ }_{4}\right]$ with anisotropic displacement ellipsoids shown at the $50 \%$ probability level. The structure is disordered with $\left[\mathrm{P} 2 \mathrm{Mo}\left(\mathrm{CSiMe}_{3}\right)(\mathrm{CO})\right]^{+}(20 \%$; inset, right). Hydrogen atoms and $\left[\mathrm{BAr}_{4}^{\mathrm{F}}\right]^{-}$counterions are omitted for clarity. 

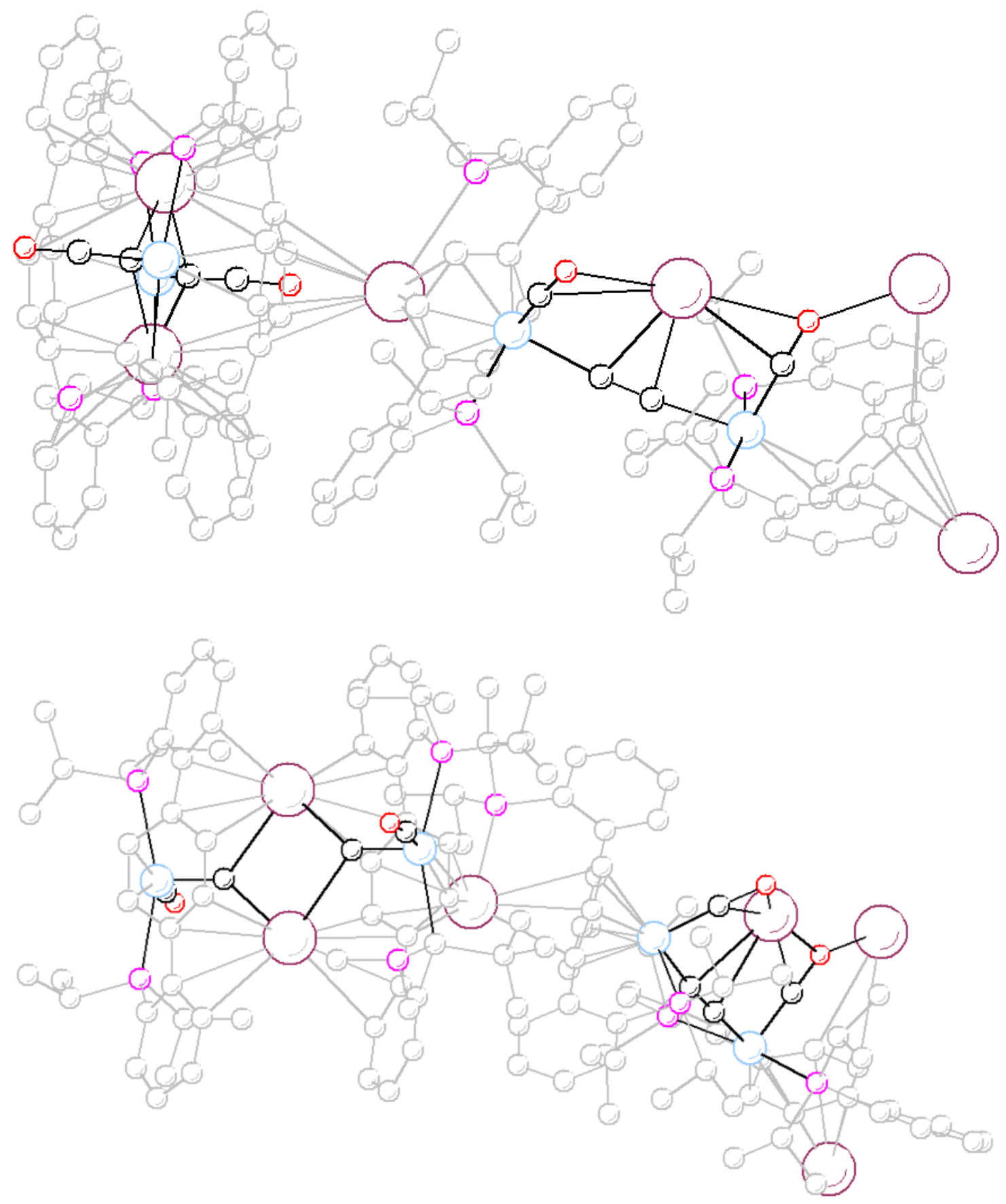

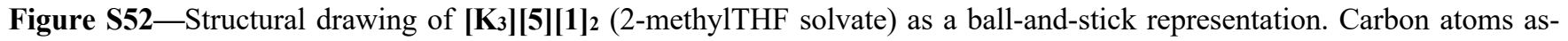
signed to carbide, $\mathrm{CO}$, and $\mu^{2}$-CC ligands in black; all other carbon atoms on the P2 ligand are shown in grey for clarity. Light blue: Mo; pink: P; red: O; purple: K. (Top) Perspective showing $\mu^{2}$-CC bridge between Mo3 and Mo4. Hydrogen atoms and 2-methyl THF solvate molecules are omitted for clarity. (Bottom) Perspective showing mutually opposing carbide ligands on $\mathrm{Mo} 1$ and $\mathrm{Mo} 2$ bridged in a $\mathrm{C}_{2} \mathrm{~K}_{2}$ diamond-shaped core. 


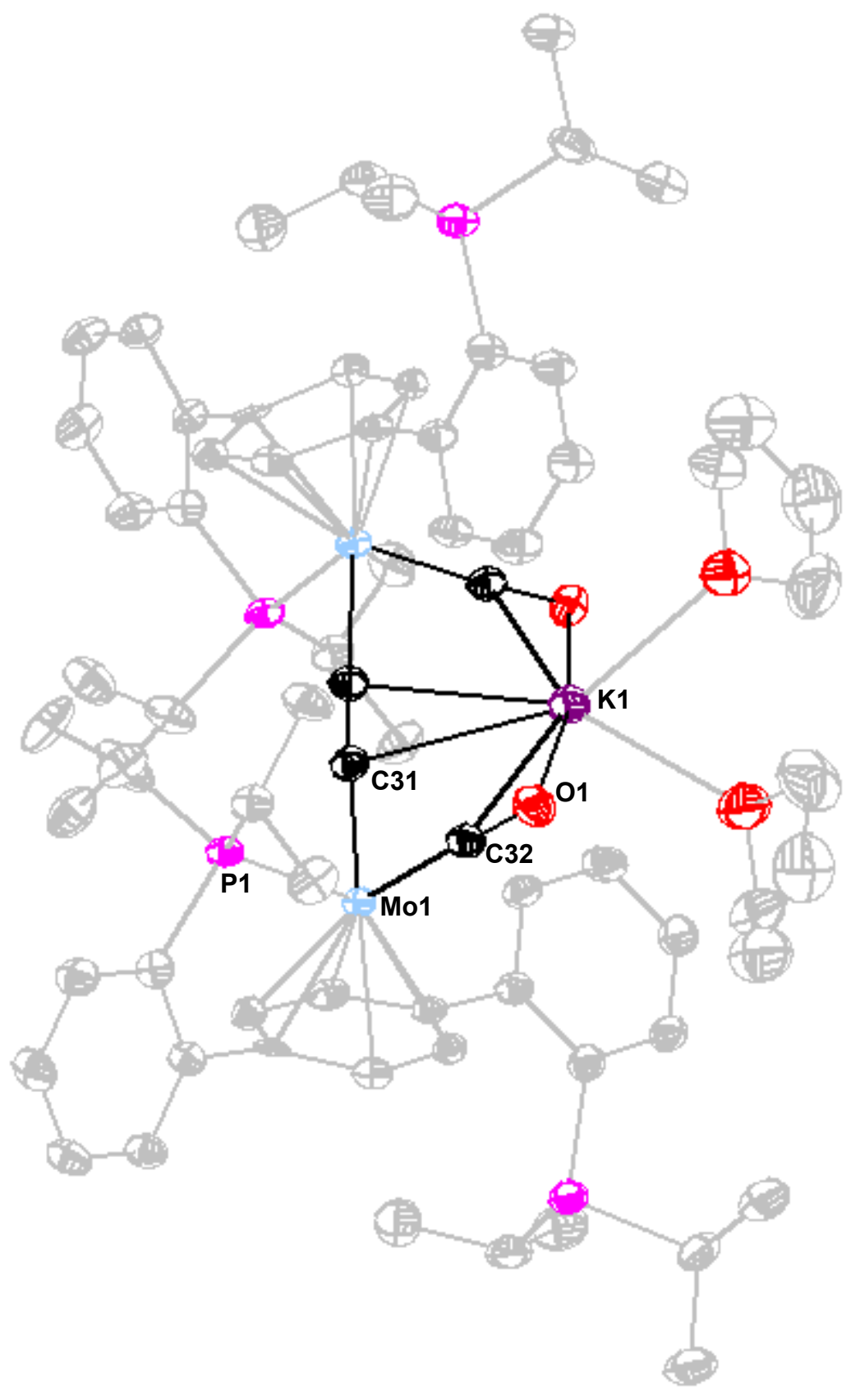

Figure S53-Structural drawing of [K][6] with 50\% probability anisotropic displacement ellipsoids. Hydrogen atoms are omitted for clarity. All carbon atoms are color in grey except the $\mathrm{C}-\mathrm{C}$ coupled and $\mathrm{CO}$ carbons, which are colored in black for clarity. 
Table S6. Key bond lengths $(\AA)$ and angles $\left({ }^{\circ}\right)$ for open-shell complexes $[2]\left[\mathrm{BAr}^{\mathrm{F}}{ }_{4}\right]-[4]\left[\mathrm{BAr}{ }_{4}^{\mathrm{F}}\right]$ and $[\mathrm{K}(18-$ crown-6)][1], compared with those of previously reported Mo(IV) silylcarbyne and methylidyne complexes 2/2' and 3/3' (Chart S2).

\begin{tabular}{|c|c|c|c|c|c|c|c|c|}
\hline Complex & Mo1-C31 & Mo-C32 & C32-O1 & Mo1-C1 & Mo1-C2 & $\mathrm{C} 1-\mathrm{C} 2$ & Mo1-Cl1 & Mo- $\mathbf{P}_{\text {avg }}$ \\
\hline$[2]\left[\mathrm{BAr}^{\mathrm{F}}{ }_{4]}\right]$ & $1.753(2)$ & $2.095(2)$ & $1.128(3)$ & - & - & - & $2.3615(7)$ & 2.605 \\
\hline$[4]\left[\mathrm{BAr}^{\mathrm{F}}{ }_{4}\right]$ & $1.734(9)$ & - & - & $2.423(2)$ & $2.445(6)$ & $1.363(9)$ & $2.355(2)$ & 2.571 \\
\hline$[K(18-c-6][1]$ & $1.739(5)$ & $1.974(6)$ & $1.157(8)$ & $2.444(6)$ & $2.449(5)$ & $1.390(7)$ & - & 2.523 \\
\hline 2 & $1.764(2)$ & $1.930(4)$ & $1.197(6)$ & - & - & & 2.526 & 2.560 \\
\hline 3 & $1.767(2)$ & $1.974(2)$ & $1.138(3)$ & - & - & & $2.5380(6)$ & 2.572 \\
\hline 2 , & $1.718(2)$ & $1.972(2)$ & $1.155(2)$ & $2.523(2)$ & $2.526(2)$ & $1.395(1)$ & $2.579(1)$ & 2.567 \\
\hline 3' & $1.796(1)$ & $1.976(1)$ & $1.158(1)$ & $2.5235(8)$ & $2.5204(7)$ & $1.396(2)$ & $2.5881(4)$ & 2.600 \\
\hline
\end{tabular}

Chart S2-Structures of complexes 2' and 3'.
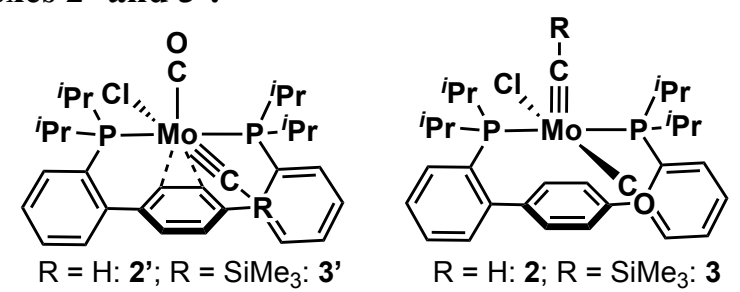

Table S7-Key bond lengths for the arene moiety in [K][1] relative to comparator complexes: Mo(IV) methylidyne and silylcarbyne complexes 2' and 3' (Chart S2).

\begin{tabular}{|c|c|c|c|c|c|c|c|}
\hline & Mo1-C1 & Mo1-C2 & $\mathrm{C} 1-\mathrm{C} 2$ & $\mathrm{C} 2-\mathrm{C} 3$ & $\mathrm{C3}-\mathrm{C} 4$ & $\mathrm{C4}-\mathrm{C} 5$ & C5-C6 \\
\hline$[\mathrm{K}][1]$ & $2.444(5)$ & $2.449(5)$ & $1.390(7)$ & $1.445(8)$ & $1.409(7)$ & $1.374(7)$ & $1.408(8)$ \\
\hline 2 & $2.510(2)$ & $2.531(2)$ & $1.396(2)$ & $1.419(2)$ & $1.382(2)$ & $1.407(2)$ & $1.383(2)$ \\
\hline 3', & $2.5235(8)$ & $2.5204(7)$ & $1.395(1)$ & $1.424(1)$ & $1.383(1)$ & $1.407(2)$ & $1.382(1)$ \\
\hline$[4]\left[\mathrm{BAr}^{\mathrm{F}}{ }_{4}\right]$ & $2.428(2)$ & $2.439(2)$ & $1.405(3)$ & $1.416(3)$ & $1.396(4)$ & $1.401(4)$ & $1.395(3)$ \\
\hline \multirow[t]{2}{*}{ DFT } & 2.521 & 2.521 & 1.424 & 1.458 & 1.437 & 1.404 & \\
\hline & C6-C1 & C3-C7 & C7-C8 & C8-C9 & C9-C10 & C10-C11 & C11-C12 \\
\hline$[\mathrm{K}][1]$ & $1.446(7)$ & $1.433(7)$ & $1.421(9)$ & $1.359(9)$ & 1.41(1) & $1.39(1)$ & $1.403(7)$ \\
\hline 2 & $1.426(2)$ & $1.480(2)$ & $1.409(2)$ & $1.402(2)$ & $1.392(2)$ & $1.388(2)$ & $1.390(2)$ \\
\hline 3' & $1.421(1)$ & $1.477(2)$ & $1.404(1)$ & $1.385(2)$ & $1.385(2)$ & $1.391(1)$ & $1.403(2)$ \\
\hline \multirow[t]{2}{*}[4]{$\left[\mathbf{B A r}^{\mathrm{F}}{ }_{4}\right]$} & $1.408(3)$ & $1.477(3)$ & $1.400(3)$ & $1.384(4)$ & $1.381(5)$ & $1.380(4)$ & $1.407(4)$ \\
\hline & C12-C7 & C6-C13 & C13-C14 & C14-C15 & C15-C16 & C16-C17 & C17-C18 \\
\hline$[\mathrm{K}][1]$ & $1.432(8)$ & $1.459(7)$ & $1.416(8)$ & $1.369(9)$ & $1.39(1)$ & $1.388(9)$ & $1.397(8)$ \\
\hline 2 & $1.409(2)$ & $1.479(2)$ & $1.403(2)$ & $1.390(2)$ & $1.386(2)$ & $1.390(2)$ & $1.402(2)$ \\
\hline 3' & $1.417(1)$ & $1.475(2)$ & $1.405(1)$ & $1.386(2)$ & $1.391(1)$ & $1.388(2)$ & $1.404(2)$ \\
\hline$[4]\left[\mathrm{BAr}^{\mathrm{F}}{ }_{4]}\right]$ & $1.404(3)$ & $1.470(3)$ & $1.400(3)$ & $1.390(4)$ & $1.380(4)$ & $1.386(4)$ & $1.409(4)$ \\
\hline
\end{tabular}




\section{REFERENCES}

1. Pangborn, A. B.; Giardello, M. A.; Grubbs, R. H.; Rosen, R. K.; Timmers, F. J. Safe and convenient procedure for solvent purification. Organometallics 1996, 15 (5), 1518-1520.

2. Buss, J. A.; Bailey, G. A.; Oppenheim, J.; VanderVelde, D. G.; Goddard, W. A.; Agapie, T. CO Coupling Chemistry of a Terminal Mo Carbide: Sequential Addition of Proton, Hydride, and CO Releases Ethenone. J. Am. Chem. Soc. 2019, 141 (39), 15664-15674.

3. Buss, J. A.; Agapie, T. Four-electron deoxygenative reductive coupling of carbon monoxide at a single metal site. Nature 2016, 529 (7584), 72-75.

4. Heinekey, D. M.; Radzewich, C. E. Synthesis and Reactivity of the Cationic Methylene Complex [Cp2ReCH2]+. Organometallics 1998, 17 (1), 51-58.

5. $\quad$ Fulmer, G. R.; Miller, A. J. M.; Sherden, N. H.; Gottlieb, H. E.; Nudelman, A.; Stoltz, B. M.; Bercaw, J. E.; Goldberg, K. I. NMR Chemical Shifts of Trace Impurities: Common Laboratory Solvents, Organics, and Gases in Deuterated Solvents Relevant to the Organometallic Chemist. Organometallics 2010, 29 (9), 2176-2179.

6. Stoll, S.; Schweiger, A. EasySpin, a comprehensive software package for spectral simulation and analysis in EPR. Journal of Magnetic Resonance 2006, 178 (1), 42-55.

7. Gaussian 09, Revision C.01, Frisch, M. J.; Trucks, G. W.; Schlegel, H. B.; Scuseria, G. E.; Robb, M. A.; Cheeseman, J. R.; Scalmani, G.; Barone, V.; Mennucci, B.; Petersson, G. A.; Nakatsuji, H.; Caricato, M.; Li, X.; Hratchian, H. P.; Izmaylov, A. F.; Bloino, J.; Zheng, G.; Sonnenberg, J. L.; Hada, M.; Ehara, M.; Toyota, K.; Fukuda, R.; Hasegawa, J.; Ishida, M.; Nakajima, T.; Honda, Y.; Kitao, O.; Nakai, H.; Vreven, T.; Montgomery, Jr., J. A.; Peralta, J. E.; Ogliaro, F.; Bearpark, M.; Heyd, J. J.; Brothers, E.; Kudin, K. N.; Staroverov, V. N.; Kobayashi, R.; Normand, J.; Raghavachari, K.; Rendell, A.; Burant, J. C.; Iyengar, S. S.; Tomasi, J.; Cossi, M.; Rega, N.; Millam, J. M.; Klene, M.; Knox, J. E.; Cross, J. B.; Bakken, V.; Adamo, C.; Jaramillo, J.; Gomperts, R.; Stratmann, R. E.; Yazyev, O.; Austin, A. J.; Cammi, R.; Pomelli, C.; Ochterski, J. W.; Martin, R. L.; Morokuma, K.; Zakrzewski, V. G.; Voth, G. A.; Salvador, P.; Dannenberg, J. J.; Dapprich, S.; Daniels, A. D.; Farkas, Ö.; Foresman, J. B.; Ortiz, J. V.; Cioslowski, J.; Fox, D. J. Gaussian, Inc., Wallingford CT, 2009.

8. Neese, F. The ORCA program system. WIREs Computational Molecular Science 2012, 2 (1), 73-78.

9. (a) Perdew, J. P.; Ruzsinszky, A.; Csonka, G. I.; Constantin, L. A.; Sun, J. Workhorse Semilocal Density Functional for Condensed Matter Physics and Quantum Chemistry. Phys. Rev. Lett. 2009, 103 (2), 026403. (b) Perdew, J. P.; Ruzsinszky, A.; Csonka, G. I.; Constantin, L. A.; Sun, J. Erratum: Workhorse Semilocal Density Functional for Condensed Matter Physics and Quantum Chemistry [Phys. Rev. Lett. 103, 026403 (2009)]. Phys. Rev. Lett. 2011, 106 (17), 179902.

10. Hanwell, M. D.; Curtis, D. E.; Lonie, D. C.; Vandermeersch, T.; Zurek, E.; Hutchison, G. R. Avogadro: an advanced semantic chemical editor, visualization, and analysis platform. J. Cheminform. 2012, 4 (1), 17.

11. Pettersen, E. F.; Goddard, T. D.; Huang, C. C.; Couch, G. S.; Greenblatt, D. M.; Meng, E. C.; Ferrin, T. E. UCSF Chimera-A visualization system for exploratory research and analysis. J. Comput. Chem. 2004, 25 (13), 1605-1612.

12. APEX3, Version 1 User Manual, M86-EXX229, Bruker Analytical X-ray Systems, Madison, WI, May 2016.

13. Sheldrick, G.M. "SADABS (version 2008/1): Program for Absorption Correction for Data from Area Detector Frames", University of Göttingen, 2008.

14. Dolomanov, O. V.; Bourhis, L. J.; Gildea, R. J.; Howard, J. A. K.; Puschmann, H. OLEX2: a complete structure solution, refinement and analysis program. J. Appl. Cryst. 2009, 42 (2), 339-341.

15. Sheldrick, G. Crystal structure refinement with SHELXL. Acta Cryst. C 2015, 71 (1), 3-8.

16. Brandenburg, K. (1999). DIAMOND. Crystal Impact GbR, Bonn, Germany. 